\title{
RESUCITANDO LA CRÓNICA $X$. RECONSTRUCCIÓN FI- LOLÓGICA DE UN FRAGMENTO INICIAL DE LA CRÓNICA MEXICÁYOTL DE HERNANDO DE ALVARADO TEZOZÓMOC
}

\author{
REVIVING THE CRÓNICA $X$. PHILOLOGICAL RECONS- \\ TRUCTION OF AN INITIAL FRAGMENT OF THE CRÓNICA \\ MEXICAYÓTIL BY HERNANDO DE ALVARADO TEZOZÓMOC
}

\author{
Gabriel Kenrick Kruell
}

Resumen: Este artículo respresenta un homenaje a Robert H. Barlow, quien en 1943 fundó la revista Tlalocan junto con George T. Smisor. El joven Barlow propuso en 1945 una interesante hipótesis acerca de un documento histórico mexica tenochca hoy en día perdido, el cual bautizó Crónica $X$, y que debió de haber sido la fuente principal de dos historias en español del siglo XVI, la Crónica mexicana de Hernando de Alvarado Tezozómoc y la Historia de las Indias de Nueva España de Diego Durán. Estudios recientes han sugerido que la Crónica $X$ podría indentificarse con otra historia en náhuatl del historiador tenochca Tezozómoc, la conocida Crónica mexicáyotl. Anteriormente, los investigadores no habían reconocido la Crónica mexicáyotl como la fuente que se creía extraviada, porque el único manuscrito que conocemos de esta historia es una copia del historiador chalca Domingo de San Antón Muñón Chimalpáin, el cual no sólo no transcribió intergralmente el texto original de la Crónica mexicáyotl, sino que introdujo muchas interpolaciones. Así que lo que aquí se propone es un trabajo filológico sobre el texto de la Crónica mexicáyotl con el objetivo de reconstruir un fragmento de la que Barlow llamó Crónica $X$.

Palabras clave: Crónica X, Crónica mexicáyotl, Hernando de Alvarado Tezozómoc, Robert H. Barlow, filología náhuatl.

Summary: This article is a tribute to Robert H. Barlow, who, together with George T. Smisor, founded the journal Tlalocan in 1943. Two years later, in 1945, Barlow devised a hypothesis about a lost Mexica Tenochca historical document that he called the Crónica $X$, which is most likely the Nahuatl source of two sixteenth-century historical documents written in Spanish: the Crónica Mexicana by Hernando de Alvarado Tezozomoc and the Historia de las Indias de Nueva España by Diego Durán. Recent studies have suggested that the Crónica $X$ can be identified as the well-known Crónica Mexicáyotl which is attributed to the Tenocha historian Tezozomoc. Scholars did not previously recognize the Crónica Mexicáyotl as the source, which was originally thought to be lost because the only manuscript that contains this historical source is a copy made by the Chalca historian 
Domingo de San Antón Muñón Chimalpáin, who failed to transcribe the original Crónica Mexicayotl in its entirety and added several interpolations as wel. For this reasons, this article presents a philological study of the Crónica Mexicayotl and aims to reconstruct a fragment of Barlow's Crónica X.

Keywords: Crónica X, Crónica Mexicáyotl, Hernando de Alvarado Tezozomoc, Robert H. Barlow, Nahuatl philology.

\section{Introducción}

Después de haber leído el título que encabeza este artículo, el lector podría preguntarse ¿es posible reconstruir la Crónica X?, un documento histórico en náhuatl que, por lo que sabemos, no se encuentra en ninguna biblioteca del mundo y sólo existe como hipótesis imaginada hace casi 70 años por Robert H. Barlow (Barlow, 1945, reeditado en 1990). ${ }^{1}$ Una posible respuesta a esta duda más que legítima se basa en las más recientes investigaciones historiográficas acerca de la Crónica mexicáyotl (Riese, 1998; Cortés, 2003; Peperstraete, 2007; Castañeda de la Paz, 2008a; 2008b) y en una hipótesis novedosa: un fragmento del texto original náhuatl de la Crónica $X$ habría sobrevivido hasta nuestros días, tratándose precisamente de la primera parte de la Crónica mexicáyotl, obra escrita en el siglo XVI por el historiador tenochca Hernando de Alvarado Tezozómoc (Kruell, 2013).

1 Antes de Barlow, al final del siglo XIX y principio del XX, ya se había formulado una primera hipótesis acerca de un autor anónimo tenochca que hubiera escrito una historia en náhuatl en el siglo XVI y del cual se conocía sólo una traducción al castellano, el famoso Códice Ramírez: véase Ramírez (1867: I, xii; 1878: 9-15), Orozco y Berra (1878: 159-162) y Chavero (1878: 162-167). Sin embargo, Edmundo O’Gorman (1940: xi-xxiii) desmontó la validez de esta primera hipótesis, demostrando que el Códice Ramírez era en realidad una copia de la Relación del origen de los indios de Juan de Tovar, el cual a su vez había compendiado la Historia de las Indias de Diego Durán para darla a conocer a José de Acosta, quien utilizó la Relación de Tovar en algunos pasajes de su Historia natural y moral de las Indias. Después del artículo de Barlow (1945), la hipótesis de la Crónica X fue criticada, replanteada y desarrollada por diferentes autores, pero siguió vigente hasta nuestros días: véase Bernal (1947), Kubler y Gibson (1951), Lafaye (1972: 23-26), Colston (1973a: 45; 1973b; 1974; 1977), Couch (1987: 27-34), Camelo y Romero Galván (1995: 31-39), Tena (1997), Vázquez Chamorro (1997: 58), Graham (1998: 11-20), Riese (1998: 213214; 2004: 16-17), Fuente del Pilar (2001), Romero Galván (2003a: 96-105; 2003b: 185195), Peperstraete (2007; 2010), Castańeda de la Paz (2008a: 193-195; 2008b: 158-164), Castañeda de la Paz y Oudijk (2009) y Kruell (2011; 2013). 
Además de este fragmento inicial de la Crónica mexicáyotl, tenemos dos traducciones y adaptaciones al castellano del texto integral de la Crónica $X$, elaboradas una por el mismo Tezozómoc y otra por el fraile español Diego Durán, cuyos títulos respectivos son Crónica mexicana e Historia de las Indias de Nueva España. Contando con estas tres obras históricas, la reconstitución filológica del texto original de la Crónica $X$ no sólo es posible, sino necesaria para los historiadores del México antiguo. ${ }^{2}$

La primera mención de la presencia en la Crónica mexicáyotl de un texto en náhuatl muy similar a aquél que debía ser el original en náhuatl de la Crónica X pertenece al investigador alemán Berthold Riese (Riese, 1998: 213-214). Algunos ańos después, la investigadora norteamericana Rocío Cortés propuso un primer cotejo extensivo entre la Crónica mexicana, la Historia de las Indias, el Códice Ramírez y la Crónica mexicáyotl con el objetivo de recostruir algunos pasajes perdidos de la Crónica mexicana (Cortés, 2003: 153-162). ${ }^{3}$ Por otra parte, la historiadora Sylvie Peperstraete en su tesis de doctorado por la Universidad de Bruselas, luego publicada como libro en 2007, se dio a la tarea de reconstruir e interpretar con esmero filológico e historiográfico la Crónica $X$, pero se basó sólo en el cotejo de las dos obras en castellano, la Crónica mexicana de Tezozómoc y la Historia de las Indias de Durán. Acerca de la relación entre la Crónica $X$ y la Crónica mexicáyotl dedicó pocas pero relevantes palabras (Peperstraete,

2 En mi reconstrucción de la Crónica X, sigo el método preconizado por Barlow (1945: 77) y desarrollado por Peperstraete (2007: 58-59). Así, no tomo en cuenta la Relación del origen de los indios y el Códice Ramírez de Juan de Tovar, ni la Historia natural y moral de las Indias de José de Acosta, porque, como explica O’Gorman (1940: xi-xiii), Tovar copió a Durán y a su vez Acosta a Tovar. Sin embargo, hay autores que tienen ideas diferentes acerca del método de reconstrucción de la Crónica $X$ : en el estudio que realizaron Oudijk y Castańeda de la Paz (2009: 255-266) sobre un documento presentado por los tlatelolcas en 1709 ante la Real Audiencia de México, documento que demuestra un parecido notable con los textos de Durán, Tovar y Acosta, los autores no toman en cuenta la Crónica mexicana de Tezozómoc y consideran que tanto Tovar como los tlatelolcas tuvieron entre sus manos la Crónica X, el primero para la realización del Códice Ramírez y los segundos para la redacción del documento presentado a la Real Audiencia.

3 Cortés (2003: 163, nota 4) no se pronuncia sobre la validez de la hipótesis de Barlow, afirmando muy pragmáticamente que hasta que no encuentre el manuscrito de la Crónica $X$ será imposible corroborarla. Más allá de este escepticismo, Cortés es la primera en proponer un cotejo que permitiera ver las correspondencias entre la Crónica mexicáyotl, la Crónica mexicana y la Historia de las Indias. 
2007: 50-51 y 110). ${ }^{4}$ En 2008, salió a la luz en esta misma revista un artículo de la historiadora María Castañeda de la Paz, en el cual se hace mención del uso de la Crónica $X$ por parte de Tezozómoc en varios pasajes de su Crónica mexicáyotl (Castañeda de la Paz, 2008a: 193-195 y cuadro 6). Personalmente, he dedicado mi investigación de maestría (Kruell, 2011) a intentar esclarecer las relaciones que vinculan la Crónica mexicáyotl y la Crónica $X$, proponiendo una plena identificación entre las dos. Mi hipótesis se aleja de los estudios anteriores de Riese (1998), Peperstraete (2007) y Castañeda de la Paz (2008a; 2008b), en la medida en la cual creo que una parte importante de los textos que se encuentran en la Crónica mexicáyotl, en particular un pasaje atribuible a Alonso Franco y las genealogías que ocupan la segunda parte, son inserciones de Chimalpáin y no de Tezozómoc. ${ }^{5}$ En esto concuerdo con Paul Kirchhoff (1951), quien propuso que Chimalpáin sería el autor de la segunda parte de la Crónica mexicáyotl. Así, puedo afirmar que el meollo de mi hipótesis acerca de la Crónica $X$ y de la Crónica mexicáyotl es que estas dos historias debían ser una misma.

El objetivo del presente artículo, por lo tanto, es ofrecer al lector una parte del texto original de la Crónica $X$ o Crónica mexicáyotl, que considero perteneciente a Tezozómoc, depurando las notas, las glosas y las informaciones complementarias insertadas en él por Chimalpáin. Hay que saber, en efecto, que no conocemos el manuscrito original de la Crónica mexicáyotl escrito por Tezozómoc en el siglo XVI, sino una copia realizada por Chimalpáin a comienzos del siglo XVII. Se trata del manuscrito descubierto en 1982 por el bibliotecario Wayne Ruwet en el fondo de la Biblioteca de la Sociedad Bíblica con sede en la Universidad de Cambridge, Inglaterra (Ruwet, 1994: 38-39). ${ }^{6}$ Este manuscrito ha sido editado en 1997 por Arthur J. O. Anderson y Susan Schroeder con el título de Codex

${ }^{4}$ En un artículo posterior (Peperstraete, 2010) la autora profundiza más sobre la Crónica mexicáyotl, pero ofrece sólo un pequeño ensayo del cotejo sistemático y extendido que se puede hacer entre la Crónica mexicáyotl, la Crónica mexicana y la Historia de las Indias.

5 La mayoría de los historiadores (Riese 1998; Johansson K., 2007: 261-264; Peperstraete 2010) están de acuerdo que el texto de Alonso Franco corresponde a grandes rasgos con aquel del Códice Aubin, pero María Castañeda de la Paz (2008: 194) piensa que el relato de Alonso Franco y del Códice Aubin representan dos historias diferentes.

${ }^{6}$ Manuscrito 374, vol. III, $202 \mathrm{f}$. 
Chimalpahin (Chimalpahin Quauhtlehuanitzin, 1997). ${ }^{7}$ En la copia de la Crónica mexicáyotl, que ocupa los folios 18-40 del manuscrito y representa sólo una de las varias obras misceláneas que Chimalpáin recopiló, son evidentes las interpolaciones del historiador chalca, quien menciona su nombre, ofrece versiones de la historia mexica diferentes a la de Tezozómoc (como el referido fragmento de historia de Alonso Franco) y habla de acontecimientos de su ciudad natal, Chalco Amaquemecan. Esta situación hace patente la necesidad de distinguir, en el manuscrito redactado por Chimalpáin, las partes atribuibles a Tezozómoc de aquéllas interpoladas por el copista chalca. Este trabajo sería muy complicado y arriesgado si no contáramos con dos términos de comparación, que son la Crónica mexicana del mismo Tezozómoc y la Historia de las Indias de Durán.

Además de insertar sus notas en el transcurso de su transcripción del texto náhuatl de Tezozómoc que tenía bajo sus ojos, es muy probable que Chimalpáin decidiera no copiar completamente el manuscrito original de la Crónica mexicáyotl de Tezozómoc, hoy desgraciadamente perdido. Así, dejó la historia trunca en el episodio de la entronización del primer tlahtoani de Tenochtitlan, Acamápich, completándola con una escueta información genealógica de los gobernantes del altépetl tenochca hasta la época colonial. Eso es una verdadera lástima para nosotros, porque nos privó de la mayor parte de un texto histórico en náhuatl que, por lo que deja entrever lo poco que tenemos, debió tener una riqueza narrativa y retórica inigualable. Sin embargo, no hay que lamentar demasiado la pérdida y más bien es urgente aprovechar el fragmento que nos dejó Chimalpáin (22 folios) y trabajarlo con un enfoque filológico.

Igualmente fragmentario se halla el texto de la Crónica mexicana y esto representa un obstáculo para su cotejo con la Crónica mexicáyotl. Efectivamente, el manuscrito más antiguo que se conoce de la Crónica mexicana, conservado en el fondo H. P. Kraus de la Biblioteca del Congreso de Washington, ${ }^{8}$ presenta dos importantes lagunas en el folio

7 En el estudio introductorio, Susan Schroeder (1997: 10) opina que la Crónica mexicáyotl debe ser atribuida a Chimalpáin y que Tezozómoc sirvió sólo como una de tantas fuentes. En un artículo posterior (Schroeder 2011: 233-235), la misma autora radicaliza su posición y atribuye por completo la Crónica mexicáyotl a Chimalpáin, afirmando que Tezozómoc no entró siquiera como fuente en su composición.

8 Manuscrito $117,158 \mathrm{f}$. 
$3 \mathrm{v}$, una debida probablemente a una laguna en el manuscrito original del cual se copiaba y otra al extravío de los folios 4 y el 5 (Cortés, 2003: 150). Sin embargo, allá donde falta la Crónica mexicana será imprescindible la comparación con la Historia de las Indias.

Vamos entonces a describir los detalles metodológicos de mi reconstrucción del fragmento inicial de la Crónica mexicáyotl. Presentaré la paleografía del texto náhuatl en las páginas izquierdas y a la derecha mi traducción al español. Para el texto náhuatl utilizaremos la paleografía proporcionada por Susan Schroeder y Arthur J. O. Anderson en su Codex Chimalpahin, vol. I (Chimalpahin Quauhtlehuanitzin, 1997).9 El texto náhuatl estará organizado en párrafos que siguen la división del manuscrito propuesta por Anderson y Schroeder y que corresponde perfectamente a la edición en español de Adrián León (Tezozómoc, 1998). ${ }^{10}$ En mi reconstrucción, empezaré por el párrafo 8 de la Crónica mexicáyotl, no porque los primeros siete no pertenezcan a esta obra, sino porque contienen un proemio de Tezozómoc extremadamente interesante, pero que no tiene paralelo ni en la Crónica mexicana, ni en la Historia de las Indias. Es muy probable que este prólogo, escrito por Tezozómoc en 1609, ya al final de su vida, no apareciera en versiones anteriores de la Crónica mexicáyotl, escritas durante el siglo XVI, las cuales sirvieron de fuente principal para la Historia de las Indias, terminada por Durán en 1581, y para la Crónica mexicana, tal vez redactada en 1598. Por estas razones, el párrafo 8 de la Crónica mexicáyotl ocupará la posición número 1 de mi reconstrucción, mientras que el último párrafo, el 118, la posición 69. Al principio de cada párrafo, entonces, aparecerá su posición en mi recostrucción, del 1 al 69, y luego entre corchetes la posición que este párrafo ocupa originalmente en el manuscrito de Chimalpáin. Por

9 Esta paleografía por lo general es bastante cuidadosa y apegada al manuscrito original, sin embargo la corregiré en algunos puntos con base en el cotejo con un copia microfilmada del Manuscrito 374, vol. III y señalaré mis correcciones en notas a pie de página.

10 Un cotejo con el Manuscrito 374, vol. III deja ver que en realidad la organización del texto escrito por Chimalpáin no corresponde a la división en secciones propuesta por Anderson y Schroeder, los cuales siguen la edición de León, sin hacerlo explícito y sin numerar las secciones como lo hizo León. Este detalle podría parecer irrelevante, sin embargo me parece que siembra una duda sobre la metodología paleográfica de Anderson y Schroeder, quienes en ningún momento explican su forma de proceder en la realización de la paleografía del Manuscrito 374, vol. III. 
ejemplo: el primer párrafo será señalado como "\$1[8]" y el último como “\$69[118]". ${ }^{11}$

Habrá que preguntarse: ¿ de los 118 párrafos que conforman la primera parte de la Crónica mexicáyotl, por qué sólo seleccioné 69? ¿Qué pasó con los 49 faltantes? Ya expliqué las razones de la eliminación de los primeros siete. Por las mismas razones, omití otros cuatro párrafos, del 9 al 13, porque representan una introducción que explica el papel del cristianismo en la historia mexica, la cual no tiene correspondencia ni en la Crónica mexicana ni en la Historia de las Indias. ${ }^{12}$ La expulsión más importante es aquélla que afecta a veintiún párrafos del manuscrito de Chimalpáin, del 14 al 34. Creo que todos ellos son una gran interpolación de Chimalpáin: los párrafos 14 y 15 vierten sobre la cronología de la migración mexica y su correspondencia con el calendario cristiano y se encuentran iguales en otras obras del autor chalca, como sus Relaciones y el Memorial de Colhuacan, mientras que los párrafos 16-34 refieren una tradición histórica mexica diferente de aquélla de Tezozómoc, cuyo informante fue Alonso Franco. Existen varias razones por las que he excluído los diecisiete párrafos restantes $(58-60,62,69,70,72-75,96,99,100,106-109)$ : primero, porque no tienen ninguna correspondencia con la Crónica mexicana y la Historia de las Indias y luego, porque tratan de temas ajenos a la Crónica mexicáyotl de Tezozómoc, pero predilectos para Chimalpáin: discusiones cronológicas, observaciones genealógicas, listas de personajes y notas sobre Chalco Amaquemecan.

Sólo en un caso he modificado el orden de los párrafos como aparece en el manuscrito de Chimalpáin: se trata de los párrafos 97-98, que en mi reconstrucción ocupan las posiciones 59 y 60 y aparecen dislocados entre

11 Esto ayudará a hallar fácilmente estos párrafos en la edición de la Crónica mexicáyotl de Adrián León, publicada por primera vez en la UNAM en 1949 y cuyas reediciones en México son mucho más difundidas que la edición de Susan Schroeder de 1997. El problema de la edición de León es que su paleografía no se basa directamente en el manuscrito de Chimalpáin, sino en una copia de tercera mano realizada en parte por José Antonio Pichardo y en parte por Antonio de León y Gama en el siglo XVIII (Riese, 1998: 21-22), hoy resguardada en el Fondo Mexicano de la Biblioteca Nacional de París, bajo en número de catálogo 311.

12 A menos que queramos ver en las tachaduras del folio $1 \mathrm{r}$ de la Crónica mexicana algunas palabras que tienen que ver con la voluntad de Dios y la perversión de los demonios (Tezozómoc, 1997: 67, nota 1). 
los párrafos 105 y 110. En ellos se mencionan los nombres de los trece mexicas chichimecas que fundaron el altépetl de Tenochtitlan y de los cuatro cargadores de los dioses que los acompañaron. Mi reorganización del texto ha sido por razones de coherencia narrativa: si hubiera dejado estas listas de nombres en el lugar que ocupan en el manuscrito de Chimalpáin, habría cortado de manera innatural la narración de los consejos que tuvieron los mexicas después de fundar Tenochtitlan en los párrafos 95 y $101 .^{13}$

Hay que decir que, además de los 49 párrafos eliminados, suprimí también palabras u oraciones al interior de los 69 párrafos seleccionados. En mi reconstrucción, señalo la supresión de estos fragmentos de texto mediante tres puntos encerrados entre corchetes [...]. Varias veces es el mismo Chimalpáin quien nos indica a través de paréntesis que se trata de inserciones suyas, como sucede en los párrafos 35, 51, 57, 64, 81, 85,103 y $111 .{ }^{14}$ Otras veces he eliminado partes del texto porque no tenían correspondencia con la Crónica mexicana y la Historia de las Indias y tampoco tenían coherencia con el relato de Tezozómoc. En algunos casos he tenido que reintegrar entre corchetes los nombres originales de los personajes históricos de la Crónica mexicáyotl: en estos casos creo que Chimalpáin los sustituyó con otros que seguramente había leído en fuentes que él reputaba más confiables que la de Tezozómoc. Así sucedió con los nombres de Cuauhtliquetzqui, sustituido por Cuauhcóatl en los párrafos 57, 90 y 103, y de Achitómetl, reemplazado por Coxcoxtli en lo párrafos 64, 65 y $67 .{ }^{15}$ Otras reconstrucciones que pude deducir por el cotejo

13 Una razón muy importante para ubicar estas dos listas entre los párrafos 105 y 110 es que en el párrafo 106 Chimalpáin repite por segunda vez la lista de los trece fundadores de Tenochtitan.

14 Un caso paradigmático en el que Chimalpáin inserta entre paréntesis información complementaria ya había sido señalado por Castañeda de la Paz (2008a: 194), sin embargo, esta investigadora supone que la inserción fue originalmente de Tezozómoc y no de Chimalpáin.

15 Castañeda de la Paz (2008b: 194-195 y cuadro 6) nota la confusión en la Crónica mexicáyotl entre los personajes de Cuahtliquetzqui y Cuauhcóatl por un lado, y de Achitómetl y Coxcoxtli por otro, y elabora la hipótesis de que Tezozómoc combinó varias fuentes, por una parte la Crónica $X$ y por otra, una fuente perteneciente a aquello que ella llama "Grupo de la Tira de la peregrinación". Personalmente, prefiero pensar que originalmente la versión de Tezozómoc de la Crónica mexicáyotl contenía sólo los nombres 
con la Crónica mexicana son los inicios de los tres primeros capítulos de la Crónica mexicáyotl: Chimalpáin sólo reporta el principio del capítulo I (\$13), pero restituí entre corchetes los principios de los capítulos II (\$40) y III (\$49).

Por último, ofrezco un aparato crítico a pie de página que representa un sistema de cotejo rápido entre el texto de la Crónica mexicáyotl y los textos de la Crónica mexicana y de la Historia de las Indias. Tanto en el texto en náhuatl como en mi traducción al español, evidencio en cursiva aquellas palabras que tienen una correspondencia literal con palabras de las dos obras en castellano de Tezozómoc y Durán. A pie de página del texto náhuatl, copio todas las palabras nahuas evidenciadas en el texto, y a pie de página de la traducción pongo las palabras en español de la Crónica mexicana o de la Historia de las Indias que tienen correspondencia con la Crónica mexicáyotl. Así, el lector podrá darse cuenta sinópticamente de las interesantísimas equivalencias que existen entre estas tres obras y que demuestran que una versión de la Crónica mexicáyotl, anterior a aquélla copiada por Chimalpáin, dio origen a la Crónica mexicana y a la Historia de las Indias.

En el aparato crítico, privilegio la comparación de la Crónica mexicáyotl con la Crónica mexicana, porque esta obra histórica parece una traducción al castellano mucho más literal que la Historia de las Indias. Sin embargo, por las lagunas mencionadas en la Crónica mexicana, el cotejo entre la Crónica mexicáyotl y la Historia de las Indias será imprescindible en esos pasajes. Además, se reportarán a pie de página los lugares de las tres obras históricas en los cuales se hallan las palabras en náhuatl y español que son equivalentes. A tal efecto, se usarán las abreviaturas CC para el Codex Chimalpahin, vol. I (Chimalpahin Quauhtlehuanitzin, 1997), CM para la Crónica mexicana (Tezozómoc, 1997) y HI para la Historia de las Indias, vol. I (Durán, 1995). No sólo indicaré las páginas de las tres ediciones modernas utilizadas para este ejercicio filológico, sino también los folios de los manuscritos respectivos. ${ }^{16}$

de Cuauhtliquetzqui y Achitómetl y sólo después Chimalpáin añadió y los sustituyó con los nombres de Cuauhcóatl y Coxcoxtli.

16 De los tres manuscritos (Manuscrito 374, vol. III; Manuscrito 117; Manuscrito Durán), sólo el Manuscrito Durán es accesible gratuitamente al público en el sitio de internet de la Biblioteca Nacional de Espańa. 
En un apéndice al final de este artículo pondré un análisis en tres líneas de todo el texto de la Crónica $X$. En la primera línea aparecerá el texto náhuatl segmentado morfológicamente, en la segunda, las respectivas glosas morfológicas y en la tercera, mi traducción literal, que en los casos problemáticos será comentada a pie de página y cotejada con las traducciones al español de Adrián León (Tezozómoc, 1998) y Rafael Tena (Chimalpáhin, 2012), la traducción al inglés de Arthur J. O. Anderson y Susan Schroeder (Chimalpahin Quauhtlehuanitzin, 1997) y la traducción al alemán de Berthold Riese (2004). Aprovecho para agradecer a la Dra. Karen Dakin y a la Dra. Mercedes Montes de Oca por sus valiosísimas observaciones que llamaron mi atención sobre aspectos interesantes de la lengua náhuatl y me ayudaron a proporcionar una traducción al español más apegada al texto original de la Crónica mexicáyotl. También agradezco las importantes observaciones de los editores y dictaminadores de la revista, quienes me permitieron enriquecer considerablemente este trabajo.

Para terminar, quisiera expresar mi deuda intelectual con Robert H. Barlow, quien hace 70 años fundó esta revista y abrió el camino al fascinante tema historiográfico y filológico que estoy tratando. Apasionado por la poesía de vanguardia y por las novelas policíacas, impuso el misterioso nombre de Crónica $X$ a la fuente que aquí intento reconstruir y desde entonces nadie se ha atrevido a cambiarlo. No pude conocerlo en persona, pero su legado no termina de sorprendernos. Ojalá el lector pueda disfrutar del resurgimiento de este fragmento de la Crónica $X$, el cual es sólo un pequeño homenaje al que fue un exitoso investigador $y$, sobretodo, un gran hombre. 
Crónica Mexicáyotl Crónica Mexicana 


\section{CRÓNICA MEXICÁYOTL}

[f. 20r]

tlatolpeuhcayotl

$[\ldots]$

\$1[8] Yzcatqui Nican ompehua yn chronica Mexicayotl. yn oncan quitauhcateneuhtoc yn intemoca yn intlacatiliz. yn huel yehuatl yn intzintiliz ipehualiz yhuan yn inhuallaliz yn imecoliz. in yehuantin. y nican ipan in nueua españa motenehua omotecaco yhuan oquimacehuaco y mochi yn ixquich yc huey. yehuatl. auh yhuan ynic otzintic ynic opeuh ynic onelhuayohuac in huey altepetl yn Mexico tenochtitlan. ca yn intoca. Mexitin chichimeca aztlan tlaca chicomoztoca. auh yn iquac yn ipā cahuitl amo huel molnamiqui yn iquin quehma

\$2[13] Capitulo achto oncan mitohua yn inhuallaliz yn imecoliz in yehuantin Mexica in nicā ypan yancuic nueua españa. yhuan yn ixquich tlacatl yn oquihualhuicaque calpoleque. yhuan yn quenin quihualhuicac ytlan hualla in yehuatl yn çan tlapic teutl huitzilopochtli. yn ihueltiuh huitzilopochtli ytoca Malinalxocht

$\$ 3[35]$ Auh ca cenca nohuian Nenque yn mexica yn chichimecatlalpan yn cana qualcan huecahuaya cenpohualxiuhtia. yn motlallia yn tlahuelmati. yn cana caxtolli xihuitl yn motlallia. yn cana matlacxiuhtia [f. 24v] yn cana macuilxiuthtia yn motlallia. y cana nauhxihuitl yexihuitl. yn motlallia. yn cana onxiuhtia. yn cana cexiuhtia yn motlallia yn amo tlahuelmati. yn cana cempohualilhuitl ompohualilhuitl yn motlallia [...]

\$1 CC, p. 64; 66 (f. 20r): Nican ompehua yn chronica Mexicayotl / -temoca / -huallaliz / nueua españa / altepetl yn Mexico tenochtitlan / chicomoztoc- / aztlan tlaca / Mexitin / chichimeca.

$\$ 2$ CC, p. 66 (f. 20v-21r): Capitulo achto / -huallaliz / teutl huitzilopochtli.

$\$ 3$ CC, p. 76 (f. 24r-v): cenca nohuian / Nenque / chichimecatlalpan / cana / cenpohualxiuh- / tla-mati / motlallia / matlacxiuh- / ye- / on- / cexiuh- / cempohualilhuitl. 


\title{
CRÓNICA MEXICANA
}

\author{
[f. 20r] Inicio del relato \\ [...]
}

\$1[8] He aquí que aquí comienza la crónica mexicana. Allí está declarada gloriosamente su descendencia, su nacimiento, aquello mismo, su origen, su principio y su venida, su llegada de ellos aquí, en la que se llama Nueva España. Vinieron a juntarse y vinieron a merecerla toda entera, por eso ella es grande, y también por eso se fundó, por eso comenzó, por eso se arraigó la gran ciudad de México Tenochtitlan. Sus nombres son mexitin, chichimecas, gente de Aztlán, chicomoztocas. Cuándo, en qué tiempo no se puede recordar, cuándo, en qué momento.

$\$ 2[13]$ Capitulo primero, en el que se habla de su venida, de su llegada de ellos, los mexicas, aquí a la nueva Nueva España, y de todas las personas que habían traído los dueños de los barrios, y de cómo los trajo consigo, vino él, el falso dios Huitzilopochtli y su hermana de Huitzilopochtli, llamada Malinálxoch.

$\$ 3[35]$ Por muchas partes anduvieron los mexicas en la tierra de los chichimecas. En algunas partes, en un lugar bueno permanecían, transcurren veinte años, en los que se asientan, en los que les parece bien, en algunas partes se establecen quince años, en algunas partes transcurren diez años, [f. 24v] en algunas partes transcurren cinco años, en los que se asientan, en algunas partes cuatro años, tres años, en los que se asientan, en algunas partes transcurren dos años, en algunas partes transcurren un año en el que se asientan, en el que no les parece bien, en algunas partes se asientan veinte días, cuarenta días [...]. Por todas partes

\$1CM, p. 67-68 (f. 1r): Aquí comiença la Corónica Mexicana / deçendencia / benida / Nueba España / çiudad de Mexico Tenuchtitlan / mexitin / chichimeca / aztlantlaca / chicomoztoc.

$\$ 2 C M$, p. 67 (f. 1r): Capítulo primero / benida / dios Huitzilopochtli.

$\$ 3 C M$, p. 68-69 (f. 1r-v): muchas tierras / abían andado / [en] las... tierras... chichimecas / les paresçía / en partes / beinte... años / hazían asiento / diez / tres / dos / un año / beinte días. 
Auh ca nohuian quihualtocatiaque yn tlalli. auh yn quihualquatiaque. ${ }^{1}$ yn intech monequia. nacatl yn tonacayotl. yhuā yn etl. huauhtli. chian yhuan chilli. xitomatl.

$\$ 4[36]$ auh y cana cenca huecahuaya, Moteocaltiaya. oncan quiquetzque yn ical yn inteouh yn huitzilopochtli. auh ca oc no cequintin. yn quinhualhuicac yn inteohuan ynic mitohua yn chicome calpolli yn Mexica in huallaque Auh ynic ce calpolli yopica. ynic ome calpolli tlacochcalca. ynic yey calpolli. huitznahuac. ynic nahui calpolli cibuatecpaneca. ynic macuilli calpolli chalmeca. ynic chicuacen calpolli tlacatecpaneca. ynic chicome calpolli yzquiteca.

\$5[37] Auh ye omito ca cēca nohuian hualnentiaq`. yn chichimecatlalpan yn cana quihualcaubtiaque toctli miahuati. yn cana quihualcaubtehuaque. xilloti helloti. coçahuia. auh yn cana oc quipixca. quihualquatehua yn tonacayotl. auh ca cenca. miyec tlamantli. yn quichiuhque yn otlipā ynic huallaque. nohuian nenque in culhuacan yn hueca chulhuacan. Yhuan yn tona yehuacan anoço tonallan ca cenca moch ic nenque. auh ca yncotoncahuan yn michhuaque. $\bar{y}$ mexica. Yhuan yn Malinalca. auh ca mochintin huallaque. auh ynic quincauhque. yn michhuaque atlan mahuiltiaya yn oquichtin. yhuan yn cibua. yn oncan bazquallo. ytocayocan. auh quinhualcuilitehuaque yn yntilma yn inmaxtli. yn cihua yn incue yn inhuipil. quincuillique. Auh yn oquichtin aocmo maxtleque. ça tzintlapantinemia. anoço ça tzintlapātinemi maxauhtinemi. auh yn cihua ça yncicuil y comana. auh yn oquichtin. yc huipilleque omochiuhque. o yhui $\bar{y}$. yn quincauhque michhuaque.

$\$ 3$ CC, p. 76 tonacayotl / etl / chilli. xitomatl.

$\$ 4$ CC, p. 76 (f. 24v): cana / Moteocaltiaya / inteouh yn huitzilopochtli / chicome calpolli / ynic ce calpolli / yopica / tlacochcalca / ynic yey calpolli. huitznahuac / ynic yey calpolli. huitznahuac / chalmeca / chalmeca / ynic chicome calpolli / yzquiteca.

$\$ 5$ CC, p. 76 (f. 24v): cana / qui-cauh-que / cana / qui-cauh-que / xilloti helloti / nohuian / culhuacan / michhuaque / Malinalca / atlan mahuiltiaya yn oquichtin. yhuan yn cihua. yn oncan bazquallo / yn yntilma yn inmaxtli. yn cihua yn incue yn inhuipil. quincuillique / yn oquichtin aocmo maxtleque / auh yn cihua / cicuil / yn oquichtin. / huipillique omochiuhque.

1 En la palografía de Anderson y Schroeder se encuentra "quihualquitiaque" (CC, p. 76), pero la lectura correcta es "quihualquatiaque", siguendo el Manuscrito 374, vol. III (f. 24v). 
vinieron sembrando la tierra, vinieron comiendo lo que a ellos les hacía falta, carne era la comida y frijol, amaranto, chía, chile y jitomate.

$\$ 4[36]$ En algunas partes en las que permanecían mucho tiempo, hacian sus templos. Ahí levantaron la casa de su dios Huitzilopochtli y también de algunos otros de sus dioses que trajeron, por eso se mencionan los siete barrios de los mexicas que vinieron. El primer barrio era de los yopicas, el segundo de los tlacochcalcas, el tercer barrio de Huitznábuac, el cuarto barrio de los cihuatecpanecas, el quinto barrio de los chalmecas, el sexto barrio de los tlacatecpanecas y el séptimo barrio de los izquitecas.

$\$ 5[37$ Ya se dijo que por muchas partes vinieron a vagar en la tierra de los chichimecas, en algunas partes vinieron dejando el maíz echando mazorca, en alguna otra parte partieron dejándolo en mazorcas tiernas, en mazorcas maduras, haciéndose amarillas. En alguna parte aún lo cosechan, vienen a partir comiendo el sustento. Muchísimas cosas hicieron en el camino por el que vinieron. Por muchas partes anduvieron, por Colhuacan, por el lejano Colhuacan. En el lugar donde se levanta el calor, o Tonallan, mucho por todo anduvieron. Los michhuaques eran parientes de los mexicas y también los malinalcas. Todos juntos vinieron. Por eso dejaron a los michhuaques, en el agua jugaban los hombres y las mujeres, allá en el lugar nombrado Pátzcuaro. Partieron tomándoles sus tilmas y sus taparrabos, les tomaron las faldas y los huipiles a las mujeres. Los hombres ya no tuvieron taparrabo, sólo andaban con el trasero descubierto o sólo andan con el trasero descubierto, con la entrepierna descubierta, y las mujeres sólo se ponen el cicuilli. Los hombres por eso se pusieron huipiles. Así fue como dejaron a los michhuaques.

$\$ 3$ CM, p. 68-69 (f. 1r-v): comida / frisol / chile, xitomate.

$\$ 4$ CM, p. 69 (f. 1v): en las partes / hazían hazer el cu o templo / dios de ellos, Huitzilopochtli / siete barrios / el uno de los barrios / Yopica / Tlacochçalca / el tercero barrio Huitzanahuac / Çihuatecpaneca / Chalmeca / Tlacatecpaneca / el seteno barrio / Yzquiteca.

$\$ 5 \mathrm{CM}$, p. 69-70 (f. 1v): en las partes / dexaban / en partes / dexaban / en maçorca el maíz... en flor / muchas partes / Culiacan / Mechuacan / Malinalco / hombres y mugeres començaron a rretoçar en el agua de gran contento, adonde es... Pascuaro / les tomaron... sus mantas y atapador de sus bergüenças (maxtli) y a las mugeres sus huipiles y naguas / los barones quedaron sin ataparse / y las mugeres / çicuilli / los barones / usaron el traxe... güeipil. 
\$6[38] Auh in yehuatl yn itoca yn Malinalxoch yn ihueltiuh yn huitzilopochtli. ynic quicauh yn otlipan mochitin yn itahuan [f. 25r] yn itahuan ca quicochcauhque ypampa amo tlacatl cēca tlahuelilocayotl yn quimotequiuhtia teyolloquani tecotzanani teyxcuepani. teotlaxiliani. tecochmamani tecohuaqualtiani. Tecoloqualtiani. ca mochi quinotza yn petlaçolcohuatl. yn tocatl. yhuan tlahuipochin mocuepa ca cenca huey tlahuelliloc. auh ca yehuatl ynic amo cōnec yn huitzillopochtli. ynic amo quihualhuicac yn iVeltiuh. yn itoca mallinalxoch. yn mochintin yn itahuā yn çan quincochcauhque.

\$7[39] auh niman oquihto yn tlamacazqui, yn huitzilopochtli. auh quimilhuia yn itahuā yn motenehua yn teomamaque. ye cuel yehuātin yn itoca quaubtlequetzqui ynic ome ytoca Axollohua tlamacazqui ynic yei ytoca quauhcohuatl. ynic nahui ytoca ococaltzin. auh oquimilhui notahuane ca amo notequiuh yn quimotequiuhtia yn malinalxoch. yn ompa ynic oniquiçaco ynic onihuallibualoc ca mitl. ca chimalli. yn onimacoc. ca yaoyotl y notequiuh. auh ca nelchiquiuh ca notzonteco ynic niquittaz. y nohuian yn altepetl. auh ca nitechiaz ca nitenamiquiz. yn nauhcampa ca niteatlitiz. ca nitetlamacaz. ca nican niquinnechicoz. y nepapan tlaca. Auh ca amo çā nen. ca niquinpehuaz. ynic niquittaz. yn chalchiuhcalli. yn teocuitlacalli. yn quetzalcalli. yn quetzalitzcalli. yn tapachcalli. yn tlapaltehuillocalli. y nepapan yhuitl. yn xiuhtototl. yn tlauhquechol.

\$6 CC, p. 76; 78 (f. 24v-25r): yn itoca yn Malinalxoch yn ihueltiuh yn huitzilopochtli / quicauh / otlipan / itahuan / quicochcauhque / ypampa / tlahuelilocayotl / quimotequiuhtia / teyolloquani tecotzanani teyxcuepani / -cohua- / -colo- / quinotza / petlaçolcohuatl / tocatl / tlahuipochin mocuepa / huitzillopochtli / amo quihualhuicac / iVeltiuh / mallinalxoch / quincochcauhque.

\$7 CC, p. 78 (f. 25r-v): oquihto yn tlamacazqui, yn huitzilopochtli / quimilhuia / mamaque / itoca quauhtlequetzqui / ynic ome / ytoca / Axollohua / tlamacazqui / ynic yei / quauhcohuatl / ynic nahui / ococaltzin / oquimilhui / ca amo notequiuh / quimotequiuhtia yn malinalxoch / -quiça- / onihuallihualoc / mitl / chimalli / onimacoc / ca yaoyotl / notequiuh / nelchiquiuh / -tzonteco / niquittaz / nohuian / altepetl / nitechiaz / nitenamiquiz / niteatlitiz / nitetlamacaz / niquinnechicoz / nepapan tlaca / ca amo çā nen / niquinpehuaz / chalchiuhcalli / teocuitlacalli / quetzalcalli / quetzalitzcalli / tehuillocalli / nepapan yhuitl. 
\$6[38] A ella, a la llamada Malinálxoch, hermana mayor de Huitzilopochtli, por eso la dejó en el camino, todos sus padres [f. 25r] la dejaron dormida, porque no es humana, se ocupa de grandes maldades, es comedora de corazones humanos, cogedora de pantorrillas, torcedora de caras, desviadora del camino de la gente, cargadora de gente dormida, ofrecedora de comida hecha de serpientes, ofrecedora de comida hecha de alacranes. Invoca todos los ciempiés, las arañas y se vuelve bruja, es una grandísima perversa. Así es ella, por eso no la quiso Huitzilopochtli, por eso no vino a traer a su hermana mayor, la llamada Malinálxoch, a todos sus padres tan sólo los dejaron dormidos.

\$7[39] Luego dijo el tlamacazqui Huitzilopochtli, les dice a sus padres, a los que se llaman cargadores de los dioses, en seguida a ellos, al llamado Cuauhtliquetzqui, al segundo llamado Axolohua tlamacazqui, al tercero llamado Cuauhcóatl y al cuarto llamado Ococaltzin. Les dijo: "Padres míos, no es mi oficio el que ejerce Malinálxoch. De allá por eso vine a salir, por eso fui enviado, es flecha, es escudo lo que se me dio, es guerra mi oficio. Mi pecho, mi cabeza entonces los veré por todas partes y pueblos, esperaré a la gente, encontraré a la gente de los cuatro rumbos, daré de beber a la gente, daré de comer a la gente. Aquí juntaré la gente de todos lados. Y eso no es en vano. Los conquistaré, por eso veré la casa de chalchihuite, la casa de oro, la casa de pluma de quetzal, la casa de esmeralda, la casa de coral, la casa de cristal colorado, la multitud de plumas, el cotinga azul, el espátula rosada, el

$\$ 6$ CM, p. 70 (f. 1v-2r): llamada Malinalxoch... hermana del dios Huitzilopochtli / la dexaron / en un camino / padres... dellos / dexándola adormida/ por / mala dissistión / usando con ellos de sus artes / teyolocuani tecotzana[ni] teixcuepani / bíuora... sierpe / alacrán / llamaua / çientopiés / arańas / bruxa... se tra[n] formaua / Huitzilopochtli / permitió no traerla / su hermana / Malinalxoch / la dexaron adormida.

\$7 CM, p. 70-71 (f. 2r): dixo tlamacazqui Huitzilopochtli / dixo / solían traer cargada / que se llamauan Cuauhtlonquetzque / segundo / llamado / Axolohua / tlamacazqui / terçero / Cuauhcoatl / cuarto / Ococaltzin / díxoles / no es mi cargo / tales oficios y cargos tenía... Malinalxoch / salida / fue yo manda[d]o / flechas / rrodelas / se me dio / es guerra / mi ofiçio / mi pecho / cabeça / tengo de uer / [en] todas partes / pueblos / tengo de... aguardar gentes / e de... dar de beuer / e de sustentar y dar de comer / tengo de juntallos / todas suertes de naçiones / esto no graciosamente / e de conquistar / casa de preçiada esmeralda / casa... de oro / casa... adornada de plumería / casa de esmeralda preçiada / casa... transparente como un cristal / diuersas colores de preçiada plumería. 
yn tzinitzca. yn ye yxquich yn tlaçoihuitl auh yn tlapapalcacahuatl. yn tlapapalychcatl ca mochi niquittaz. ca nel notequiuh ca yc onihuallihualoc. auh ynin notahuane ximitacatican ma tihuian ca nechca yn titlamatihui. auh niman hohuallaque yn oncan yn ytocayocan yn ocopipillah. nimā huallehuaque. oncan motlallico yn itocayocan Acahualtzinco. oncan huecahuaque oncan yn xiuhmol [f. 25v] pilli chiuhcnahui [...] acatl yn inxiuhtlapohual yn huehuetque. ye omito yhuan oncan quizque oncan motlallique yn ocopipilla yhuan yn itocayocan Acahualtzinco. auh niman yc acico yn oncan cohuatepec yn ihuicpa yn tullam

$\$ 8[40]$ [Capitulo ynic ome oncan mitohua] in yehuatl yn ihueltiuh yn huitzilopochtli yn itoca Malinalxoch yn iquac quicochcauhque yn oquicxicauhque yn ohualliçac niman ye choca yn mallinalxoch. quimilhuia yn ittahuan nottahuan campan tiazque ca nel otechnahualcauh y noquichtiuh yn huitzillopochtli. campan ohuia yn tlahueliloc auh ma tictemocan yn tlalli. yn canin tiezque ca ye nohuian onohuac Auh niman oquittaque yn tepetl ytoca texcaltepetl. yn icpac omotlallique auh quintlatlaubtique in yehuantin oncan chaneque yn texcaltepeca. Niman oquimilhuique ca ye qualli. oncan onximotlallican ycpac yn texcaltepetl. auh in yehuatl yn Malinalxoch. ye otztli ye huey yn iti. Auh yn otlacat yn iconeuh yn Malinalxoch. oquichtli ytoca copil. yn ita ytoca chimalquauhtli tlatohuani mallinalco.

$\$ 9$ [41] Auh yn oc centlamantin in yn oncan omotlallique yn cohuatepec quin oncan huel omonextique yn mexica chichimeca. auh in yehuantin yn

\$7 CC, p. 78 (f. 25r-v): tlaçoihuitl / tlapapalcacahuatl / tlapapalychcatl / mochi niquittaz / ca nel notequiuh / onihuallihualoc / notahuane ximitacatican / nechca / auh niman hohuallaque yn oncan yn ytocayocan yn ocopipillah / yn itocayocan Acahualtzinco. oncan huecahuaque / yn xiuhmolpilli chiuhcnahui acatl / huehuetque / quizque / ocopipilla yhuan / Acahualtzinco / cohuatepec yn ihuicpa yn tullam.

\$8 CC, p. 78 (f. 25v): [Capitulo ynic ome oncan mitohua] / yn ihueltiuh yn huitzilopochtli / Malinalxoch yn iquac quicochcauhque / choca / quimilhuia yn ittahuan nottahuan campan tiazque ca nel otechnahualcauh y noquichtiuh yn huitzillopochtli. campan ohuia / tlahueliloc / thalli / ye nohuian onohuac Auh niman oquittaque yn tepetl ytoca texcaltepetl. yn ipcac omotlallique / quintlatlauhtique / oncan chaneque / texcaltepeca / yn Malinalxoch. ye otztli / otlacat yn iconeuh / ytoca copil.

$\$ 9$ CC, p. 80 (f. 25v): cohuatepec / oncan / omonextique yn mexica chichimeca. 
trogon mexicano, todas las plumas preciosas, el cacao multicolor, el algodón multicolor, todo lo veré, en verdad es mi tarea, porque por eso fui enviado. ¡Por esto, padres míos, provéanse de provisiones, vayamos alli donde vamos a hacer prisioneros!" Luego vinieron allí en el lugar que se llama Ocopipilla. Luego vinieron a partir, vinieron a asentarse allí en el lugar llamado Acahualtzinco. Alli permanecieron, alli ataron [f. 25v] los años en nueve [...] caña de la cuenta anual de los ancianos. Ya se dijo que allí salieron, que allí se establecieron en Ocopipilla y Acahualtzinco. Después de eso vinieron a llegar allí en Coatépec, cerca de Tollan.

$\$ 8$ [40] [Capitulo segundo, en el cual se trata de] ella, la hermana de Huitzilopochtli, llamada Malinálxoch, cuando la dejaron dormida, la dejaron atrás. Despertó Malinálxoch y luego se pone a llorar, dice a sus padres: "Padres mios, ¿adónde iremos?, porque realmente nos dejó con engaño mi hermano Huitzilopochtli. ¿Adónde se fue el malvado? ¡Busquemos la tierra adónde estaremos!, ya que por todos lados está ocupada." Luego vieron el cerro llamado Tlaxcaltépetl, sobre el cual se establecieron. Les rogaron a ellos, a los habitantes de ahi, a los texcaltepecas. Entonces les dijeron: “¡Está bien, vayan a establecerse allí arriba, en el Texcatépetl!” Ella, Malinálxoch, ya está preñada, ya está grande su vientre, y nació el hijo de Malinálxoch, un varón llamado Cópil, su padre es el llamado Chimalcuauhtli, gobernante de Malinalco.

\$9[41] Los del otro grupo se establecieron allí en Coatépec, después de que alli se mostraron bien los mexicas chichimecas. Ellos, los moradores de

\$7 CM, p. 70-71 (f. 2r): preçiada plumería / cacao de muchas colores / colores de algodón / todo lo tengo de beer / pues... es... mi ofiçio / me es mandado / padres míos, rrecogé cantidad de matalotaxe / allí es donde / Y así, con esto... llegaron en el lugar que llaman Ocopipilla / en el lugar que llaman Acahualçingo, y allí asiestieron mucho tiempo / yn xiuhmolpilli... (chicnahui acatl) / antiguos / salidos / Ocopipilla y / Acahualçingo / Coatepec, términos de Tonalan.

\$8 CM, p. 71-72 (f. 2r): Capítulo segundo. Trata de / la hermana de Huitzilopoch / Malinalxoch, quando... la dexaron dormida / començó a llorar / dixo a sus padres... "Padres míos, ¿a dónde yremos, pues que con engaño manifiesto me dexó mi hermano Hitzilopochtli? ¿Por dónde se fue? / maluados / tierra / ya toda está ocupada... Y así, vieron el çerro de la gran peña llamada Texcaltepetl y allí fueron a hazer asiento / rrogáronle / bezinos de aquel lugar / texcaltepecas / la Malinalxoch estaua ya preñada / parió un hijo / le llamaron Cohuil.

$\$ 9$ CM, p. 72 (f. 2r-v): Coatepec / allí / se mostraron los mexicanos chichimecos / moradores. 
oncan chaneque yn otomi. çan quinmotetzanhuia quitohuaya aquique yn campa ohuallaque $\bar{y}$ nican omotlallico. campa ynchan $c a$ amo tlaca ca cenca tlahueliloque

$\$ 10[42]$ auh in yehuantin yn Mexica. niman ye quiquetza yn iteocal. yn ichan yn huitzilopochtli._nimä ye quimana oncà. yn quauhxicalli. yhuan in yopico. yhuā tlacochcalco. huitznahuac. tlacatecpan. tzonmolco. atempā. tezcacohuac. tlamatzinco. mollocotitla. nonohualco. cihuatecpan. yzquitlan. milnahuac. cohuatl xoxouhcan. aticpac. ca huel oncan quincenquixti [f. 26r] quincenquixti. quintecpan. quinpouh yn ixquichtin tlatlacatecollo. in yehuatl. yn huitzilopochtli. ca yehica ynteyacancauh ymachcauh yn diablosme.

$\$ 11[43]$ auh in yehuatl yn huitzilopochtli. niman ye quiteca yn itlach nimā ye quimana. yn itzonpan. auh niman ye yc queltzaqua. yn atlauhtli yn tlamimilolli. oncan omotecac yn atl. otentimoma. ytencopa omochiuh yn huitzilopochtli. auh niman oquimilhui yn ittahuan yehuantin Mexica. notahuane ca ye omoma yn atl xicaquican xictocacan huexotl, yhuan yn ahuehuetl yn acatl. yn tolli. atlacueçonalxochitl. yhuan ye quixinachohua yn mimichtin. yn cueyame yn axollome. yn acociltin. aneneztin. ahuihuitlame yn axaxayacatl. yn quatecomatl. yoyolli. Auh yhuan yn izcahuitli. yhuan yn totome. yn canaubtli yn yacacintli yn quechilton. yn acatzanatl acollalauhque. Tozcacoztique Auh yn huitzilopochtli. nimā oquihto. Ynin yzcahuitli. ca huel nonacayo. neço notlapallo. Auh niman oncan oqueuh

$\$ 9$ CC, p. 80 (f. 25v): chaneque / otomi / quitohuaya aquique yn campa ohuallaque / ca / tlaca / tlahueliloque.

$\$ 10$ CC, p. 80 (f. 25v-26r): auh / yn Mexica / iteocal / ichan yn huitzilopochtli. nimā ye quimana / quauhxicalli / yopico / tlacochcalco. huitznahuac. tlacatecpan. tzonmolco. atempā. tezcacohuac. tlamatzinco. mollocotitla. nonohualco. cihuatecpan. yzquitlan. milnahuac. cohuatl xoxouhcan. aticpac / -tecpan / ixquichtin tlatlacatecollo / ca yehica / ymachcauh.

$\$ 11$ CC, p. 80 (f. 26r): huitzilopochtli. niman ye quiteca yn itlach / itzonpan / atl / ytencopa / yn huitzilopochtli. auh niman oquimilhui yn / Mexica / ye omoma yn atl xicaquican xictocacan huexotl, yhuan yn ahuehuetl yn acatl. yn tolli. atlacueçonalxochitl / -xinachohua / mimichtin / cueyame / axollome / acociltin / axaxayacatl / izcahuitli / canauhtli / acatzanatl / huitzilopochtli / oquihto / yzcahuitli / -nacayo / -eço / -tlapallo. Auh niman / oqueuh / -cuic cuicoya no hualmitotia / cuicatl. ytoca tlaxote-yotl. yhuan tecuilhuicuicatl / huitzilopochtli / oquihto / yzcahuitli / -nacayo / -eço / -tlapallo. Auh niman / oqueuh. 
ahí, los otomies, los tomaban como mal augurio, decian: “Quiénes son éstos? ¿De qué parte vinieron éstos? ¿Vinieron a establecerse aquí? ¿Dónde están sus casas? Porque no son gente, son muy malos."

$\$ 10[42]$ Ellos, los mexicas, en seguida levantan su templo, la casa de Huitzilopochtli, luego ponen allí la jicara del águila y las parcialidades de Yopico, Tlacochcalco, Huitznáhuac, Tlacatecpan, Tzonmolco, Atempan, Tezcacóac, Tlamatzinco, Molocotitlan, Nonoalco, Cihuatecpan, Izquitlan, Milnáhuac, Cóatl Xoxouhcan y Atícpac. Allí pudo reunirlos, [f. 26r] ordenarlos, contarlos a todos los demonios, él, Huitzilopochtli, por ser el guía, el principal de los diablos.

$\$ 11[43]$ A él, a Huitzilopochtli, en seguida le ponen su juego de pelota, luego le colocan su tzompantli, a continuación obstruyen el barranco, el altozano, allí se estancó el agua, se llenó hasta la orilla, se hizo por mandado de Huitzilopochtli. Luego dijo a sus padres, a ellos, a los mexicas: "Padres míos, ya está lleno de agua. iPlanten, siembren sauces y ahuehuetes, cañas y tules, flores de lirio acuático!" Y ya los multiplican, los pescados, las ranas, los ajolotes, los camarones, las larvas de libélulas, los gusanos lacustres, las larvas de moscos acuáticos axaxayácatl y cuatecómatl, los animalitos. Y el gusano de la laguna izcahuitli, y los pájaros, los patos, las gallinetas yacacintli y cuachilton, los tordos de hombro bermejo, de pecho amarillo. Huitzilopochtli después dijo: "Este gusano de la laguna izcahuitli en verdad es mi cuerpo, mi sangre, mi color." Luego ahí comenzó su canto, se cantaba y

$\$ 9$ CM, p. 72 (f. 2r-v): otomís / dezían: “¿Qué gentes son estas? ¿De dónde vinieron? / Porque / gentes / malos.

$\$ 10$ CM, p. 72 (f. 2v): Y / los mexicanos / su templo / casa... de Huitzilopochtli... luego pusieron / gran xícara / Yopico / Tlacochcalco, Huitznahuac, Tlacatecpan, Tzommolco, Atenpan, Tezcacoac, Tlamatzinco, Mollocotlilan, Nonohualco, Çihuatecpan, Yzquitlan, Milnahuac, Coaxoxouhcan, Aticpac / orden / todos demonios / por ser / mayoral de.

\$11 CM, p. 72-73 (f. 2v): Y así, le pusieron... su juego de pelota... del Huitzilopochtli / y tzompan / agua / por mandado / del dios Huitzilopochtli. Y luego... dixo... a los / mexicanos / ya... está lleno de agua... sembrá y plantá árboles de sauces y aciprés de la tierra (ahuehuetl) y carrizo, cańaverales, tulares, atlacueçonan xochitl / se multiplicaron / pescado / rranas / axolote / camarón / axaxayacatl / yzcahuitle / patos / tordos / Huitzilopochtli / dixo / yzcahuitle / -cuerpo / sangre / colorado... y luego / començó / cantar. 
yn icuic cuicoya no hualmitotia. yn cuicatl. ytoca tlaxotecayotl. yhuan tecuilhuicuicatl. yn oncan quitlalli.

$\$ 12[44]$ Auh nimà oquihtoque yn itahuan centzonhuitznahuatl. quilhuia in yehuatl huitzilopochtli. tlamacazque ca ye nican yez. yn motequiuh ynic tihualla. yn titechiaz. yn titenamiquiz. yn nauhcampan yn tictotopehuaz. yn altepetl. ynic ticaciz melchiquiuh. motzonteco yca. yhuan moyollo meço. motlapallo. ynic tiquittaz. yn titechtenehuilli y nepahpan chalchihuitl. yn tlaçotetl. yn teocuicatl. yn quetzalli. $\overline{\mathrm{y}}$ nepahpan tlaçoyhuitl. yn tlapapalcacahuatl yn tlapapalychcatl. yhuan $\bar{y}$ nepahpan xochitl. yhuā y nepahpan xochiqualli. yn nepahpan netlamachtilli ca nel oticnelhuayoti. otictzonteconti. y maltepeuh $\bar{y}$ nican cohuatepec. ma ye nican mocentlallicā yn motahuā y momacehualhuan yn azteca yn Mexitin quitlatlauhtia. in yehuatin yn centzonhuitznahuatl.

$\$ 13[45]$ [f. 26v] Auh niman oquallan yn huitzilopochtli. niman oquimilhui tleyn anquitohua cuix amehuan anquimatin cuix amotequiuh cuix änechpanahuia ca nehuatl nicmati yn tlein nicchihuaz. Auh niman ye mochichihua yn huitzilopochtli. yn oncan yn ichan. yn iteocalticpac. yn onmochichiuh ynic onmoyaochichiuh çan iconecuitl ynic onmoxaxauh yn quimixteyayahualti yhuan ychimal yn concuic ynic quinnamic yn itlahuan ynic micalque. oncan yn inan huitzilopochtli ytoca coyolxauhcibuatl yn onmoyaochichiuh niman ye huitz. yn quinpoloquiuh yn quinmictiquiuh yn itlahuan yn centzonhuitznahuatl oncan yn teotlachco. yn quinqua yn itlahuan Auh in yehuatl yn inan yn quimonantica) yn itoca coyolxauhcihuatl catca $\mathrm{ni}^{\mathrm{ma}}$ achtopa ytech opeuh yn quimicti. yn oncan teotlachco.

\$11 CC, p. 80 (f. 26r) -cuic cuicoya no hualmitotia / cuicatl. ytoca tlaxote-yotl. yhuan.

\$12 CC, p. 80; 82 (f. 26r): Auh nimā oquihto- / centzonhuitznahuatl / nican / -tequiuh / -techiaz / nauhcampan / -caci- / -elchiquiuh / -tzonteco / -eço / chalchihuitl. yn tlaçotetl. yn teocuicatl. yn quetzalli / tlaçoyhuitl / cacahuatl yn tlapapalychcatl. yhuan nepahpan xochitl. yhuā y nepahpan xochiqualli. yn nepahpan netlamachtilli ca nel o-cnelhuayoti. o-ctzonteconti / -altepeuh nican cohuatepec / -tahuā / macehualhuan yn azteca yn Mexitin quitlatlauhtia. in yehuatin yn centzonhuitznahuatl.

$\$ 13$ CC, p. 82 (f. 26v): oquallan / huitzilopochtli / oquimilhui tleyn anquitohua / cuix amotequiuh cuix ānechpanahuia / nehuatl nicmati / huitzilopochtli / iteocalticpac / huitzilopochtli ytoca coyolxauhcihuatl / teotlachco. 
también venían a bailar, el canto llamado tlaxotecáyotl y el canto de la fiesta de los señores (tecuilhuicuicat), allí lo compuso.

\$12[44] Luego dijeron sus padres, Centzonhuitznábuatl, le dicen a él, a Huitzilopochtli, "Dador de vida: ya aqui será tu cargo por lo que viniste, esperarás a la gente, enfrentarás a la gente de las cuatro partes del mundo, empujarás por todas partes el poblado, por eso alcanzarás con tu pecho, con tu cabeza y con tu corazón, tu sangre, tu color, por eso verás lo que nos revelaste, la multitud de esmeraldas, las piedras preciosas, el oro, las plumas de quetzal, la multitud de plumas preciosas, el cacao multicolor, el algodón multicolor y la multitud de flores y la multitud de frutas, la multitud de cosas placenteras, porque en verdad arraigaste, hiciste cabeza tu pueblo, aqui en Coatépec. Que se junten ya aquí tus padres, tus vasallos, los aztecas, los mexitin." Le ruegan a ellos, a Centzonhuitznáhuatl.

$\$ 13[45]$ [f. 26v] Entonces se enojó Huitzilopochtli, luego les dijo: "¿Qué es lo que ustedes dicen? ¿Ustedes acaso lo saben? ¿Es vuestro cargo? ¿Ustedes son más que yo? ¡En realidad sólo yo sé lo que he de hacer!” En seguida se prepara Huitzilopochtli, allá en su casa, sobre su templo, fue a prepararse, fue a prepararse, ataviarse para la guerra, sólo con su estiércol de niño, con eso fue a pintarse la cara, con eso pintó sus ojos con círculos y agarró su escudo, con eso se enfrentó a sus tíos, por eso pelearon. Allí la madre de Huitzilopochtli, llamada Coyolxauhcíhuatl, fue a prepararse para la guerra y luego ya viene. Él vino a derrotar, vino a matar a los tíos de Centzonhuitznáhuatl, allí en el juego de pelota sagrado, donde comió a sus tíos. Ella, su madre, la que se había hecho su madre, la llamada Coyolxauhcíhuatl, que luego fue primero, empezó

\$11 CM, p. 72-73 (f. 2v): Cuicoyan nohuan mitotia / canto... que le llamó -tlaxoteyotl y tecuilhuicuicatl.

\$12 CM, p. 73-74 (f. 2v-3r): 12. E le- dix- / Çentzonhuitzna-atl / aquí / cargo / a- de esperar / de quatro partes... del mundo / alcanç- / pecho / cabeça / sangre / esmeraldas, piedras de gran balor, oro... plumería / preçiada-... pluma / cacao... lanas de diuersas tintes, diuersas flores... diferentes maneras de frutas... muchas cosas de mucho placer... pues a- plantado y edificado... cabeça / pueblo... en este lugar de Coatepec / padres / basallos, los aztecas... los mexitin... le dieron muchas gracias... ellos... Çentzonhuitznahua-.

$\$ 13$ CM, p. 74 (f. 3r): se enoxó / Huitzilopochtli / les dixo: “¿Qué dezís vosotros?” / “¿Es a u[est]ro cargo... ? ¿Queréis... ser más que yo? / Yo lo sé / Huitzilopochtli / a su templo / Huitzilopochtli... una muger llamada Coyulxauh / teotlachco / come-. 
quiquechcoton. oncan quiqua yehuatl yn iyollo in coyolxauhcihuatl quiqua yn huitzilopochtli.

$\$ 14[46]$ Auh ca coyolxauh = ca yhueltiuh catca yn centzonhuitznahuatl auh yn iquac yn oquinqua yohualnepantla. auh yn otlathuic tlahuizcalpan. niman oquimittaque yn itahuan yn imacehualhuā yn mexica. ça mochi helcoyontoque yn coyolxauh. yhuan yn centzonhuitznahua. yn oncan teotlachco. aocmo tley yn iyollo. mochi oquiqua. yn huitzilopochtli. ca cenca huey tzitzimitl, huey colleletli omochiuh yn huitzilopochtli.

\$15[47] Auh yn Mexica. cenca omomaubtique auh in yehuantin yn centzonhuitznahuatl ynic momatia yn oncan cohuatepec. oncan yez. yn altepetl. ye oncan mexico yez. auh ca amo quinec in yehuatl huitzilopochtli. $\mathrm{ni}^{\mathrm{ma}}$ quicuitlacoyoni yn atl quixitini. ynic queltzacca yn atlauhtli. yn onca ${ }^{\mathrm{n}}$ catca yn onca ${ }^{\mathrm{n}}$ mania in atl. niman mochi huac yn ahuehuetl yn huexotl. yn acatl. yn tolli. yn atlacueçonalxochitl [f. 27r] xochitl. auh mochi micque yn anemia yn michin yn cueyatl. axollotl. axaxayacatl. yn quatecomatl. yoyolli. yhuan acocillin. anenetzin. yhuan opoliuhque omochi yahque. yn cacanauhtin. yacacintin. quachiltin. yn teotzaname. yn aztatl. yn acoltlatlauhque. tozcacoztique. in ye yxquich totome.

\$16[48] auh niman ye hualpeuh yn huitzilopochtli. yn quinhualhuicac yn itahuan yn imacehualhuan yn mexica. auh yn oncā cohuatepec. oncan quilpique yn inxiubtlapohual ce tecpatl [...]

$\$ 17$ [49] [Capitulo ynic yei ypan mitohua] ce tecpatl [...] yn tonalli ypan tlacat. yn huitzilopochtli. [...]

$\$ 18[50]$ Auh niman ye huitze acico. yn tollan amo huecauhque yn oncan nimā hualmiquanique yn atlitlallacyan. hualmiquanique tequixquiac oncan quichiuhque yn inchinan quitocaque yn chinamitl

$\$ 13$ CC, p. 82 quiquechcoton / iyollo / coyolxauh-.

$\$ 14$ CC, p. 82 (f. 26v): auh yn otlathuic tlahuizcalpan / oquimittaque / mexica / mochi helcoyontoque / yn centzonhuitznahua / aocmo tley yn iyollo / oquiqua. yn huitzilopochtli / huey tzitzimitl / omochiuh yn huitzilopochtli.

$\$ 15$ CC, p. 82 (f. 26v-27r): yn Mexica / omomauhtique / oncan cohuatepec / quicuitlacoyoni / quixitini / in atl / huac / mochi / yn michin / yah / totome.

$\$ 16$ CC, p. 82 (f. 27r): auh / yn mexica / oncā / -lpi- / -xiuh-.

$\$ 17$ CC, p. 82 (f. 27r): [Capitulo ynic yei ypan mitohua] ce tecpatl / ypan tlacat. yn huitzilopochtli.

\$18 CC, p. 84 (f. 27r): huitz- / acico. yn tollan / hualmiquanique yn atlitlallacyan. hualmiquanique tequixquiac oncan quichiuhque yn inchinan / chinamitl. 
con ella, la mató allí en el juego de pelota sagrado, la degolló, allí él comió el corazón de Coyolxauhcíhuatl, la comió Huitzilopochtli.

$\$ 14[46]$ Coyolxauh era la hermana mayor de Centzonhuitznáhuatl. Cuando los comió era medianoche. Amaneció a primeras horas de mañana y entonces los vieron sus padres, sus vasallos, los mexicas, todos estaban con los pechos agujerados, Coyolxauh y los centzonhuitznahuas allí en el juego de pelota divino ninguno tenía su corazón. Todos los comió Huitzilopochtli, así que se volvió un muy gran brujo, un gran demonio Huitzilopochtli.

$\$ 15[47]$ Los mexicas se espantaron mucho. Ellos, Centzonhuitznáhuatl, pensaban que allí en Coatépec, allí sería el poblado, que ya allí sería México. Pero no quiere Huitzilopochtli, entonces perfora el agua, destruye aquello que está obstruyendo el barranco, donde estaba, donde se extendía el agua. Entonces todo se secó, el ahuehuete, el sauce, la caña, el tule, la flor [f. 27r] del lirio acuático. Murieron todos los animales que vivían en el agua, los peces, las ranas, los ajolotes, las larvas de moscos acuáticos axaxáyacatl y cuatecómatl, los animalitos y los camarones lacustres, las larvas de libélulas desaparecieron, todos se fueron, los patos, las gallinetas yacacintin y cuachiltin, los mirlos, las garzas, los pájaros de hombro bermejo, de pecho amarillo, todas las aves.

$\$ 16[48]$ Luego vino a partir Huitzilopochtli, vino a traer a sus padres, a sus vasallos, a los mexicas. Allí en Coatépec, allí ataron su cuenta de los años en uno pedernal $[\ldots]$.

$\$ 17$ [49] [Capitulo tercero en el que se trata de] uno pedernal, [...] el día en el que nació Huitzilopochtli. [...]

$\$ 18[50]$ En seguida vienen, vinieron a llegar a Tollan, pero no permanecieron allí mucho tiempo. Luego vinieron a trasladarse a Atlitlalacyan, vinieron a trasladarse a Tequíxquiac, alli hicieron sus sementeras, sembraron la chinámitl.

\$13 CM, p. 74 (f. 3r): la mató / tlachco... degolló / el corazón / Coyolxauh. $\$ 14$ CM, p. 74 (f. 3r): Y... amanesçido... muy de mañana / se bieron / mexicanos / todos los cuerpos aguxerados / los Çentzon-a-as / no tenía nenguno dellos coraçón / los comió Huitzilopochtli / gran brujo / se tornó... el Huitzilopochtli. $\$ 15$ CM, p. 74 (f. 3r): los mexicanos / se atemorizaron / en este lugar de Coatepec / aguxeró / quebró / -el agua / se secó / todos / los peces / se pasó / abes.

$\$ 16$ CM, p. 74 (f. 3r): Y / yn mexica / allí / -lpi- / xiuh-.

$\$ 17$ CM, p. 74 (f. 3r): Capítulo terçero que trata... de... çe tecpatl / que fue del nasçimiento de Huitzilopochli.

$\$ 18$ CM, p. 74-75 (f. 3r): beni- / llegaron... a-... Tula / salieron y llegaron a-... Atlitlalaquian... binieron a Tequixquiac y allí labraron camellones / chinamitl. 
\$19[51] Auh niman huallehuaque motlallico oncan acico in atēco [...] nimā on oncan quimanque yn intzonpan oncan oquihtoque ynic axcan ytocayocan tzompanco [...] niman onmotlallico. yn mexica yn quachilco. auh niman acico yn xaltocan oncan yc ye mochinantia oncan quitocaque yn tlaolli y huauhtli. yn etl. yn ayotli. yn chilchotl. yn xitomatl. nimā ye yc huitze yn epcohuac. ca no oncā mochinantique.

$\$ 20[52]$ Auh niman motlallico yn ecatepec. yhuan ytocayocan acalhuacan. niman huallaque yn oncan tolpetlac. ye no ceppa hualle [f. 27v] huaque oncan motlallico ytocayocan huixachtitla. Auh niman huallaque motlallico ytocayocà tecpayocan oncan ye no ceppa yn xiubmolpilli ome acatl niman huallaque motlallico yn oncā atepetlac. Auh niman huallehuaque oncan motlallico ytocayocan cohuatl yayauhcan. nimā huallaque yn oncan ytocayocan tetepanco huallehuaque oncan motlallico yn itocayocä aculnahuac. niman huallaque motlallico yn oncan popotlan. auh niman buallaque yn oncan chapoltepec yn icuitlapilco. ytocayocan techcantitlan quin yehuantin yuh quitocayotique yn mexica. Aub yn oncan chapoltepec oncan ye no yn xiuhquilpique yn xiuhtlapohualli ome acatl

\$21[53] auh nimā oncan ye quinnahuatia yn Mexica in yehuatl yn huitzilopochtli. ye quimilhuia in yehuantin teomamaque yn itoca quauhtlequetzqui. ynic ome ytoca axollohua tlamacazqui. yhuan yniquey ytoca ococaltzin. auh in yehuantin in yn teomamaque oquimilhui yn huitzilopochtli. notahuane. yn tleyn mochihuaz. oc xicchiyecan ca anquittazque. tla oc xicchiyecan ca nehuatl nicmati. ximochicahuacan

$\$ 19$ CC, p. 84 (f. 27r): acico in atēco / oncan quimanque yn -tzonpan / axcan / tzompanco / quachilco. auh / xaltocan oncan / mochinantia / quitocaque yn tlaolli y huauhtli. yn etl. yn ayotli. yn chilchotl. yn xitomatl / epcohuac. ca no / mochinantique.

$\$ 20$ CC, p. 84 (f. 27r-v): ecatepec. yhuan / acalhuacan / oncan tolpetlac / oncan / huixachtitla / ytocayocā tecpayocan oncan ye no / yn xiuh- / ome / atepetlac / ytocayocan cohuatl yayauhcan / huallaque yn oncan ytocayocan tetepanco / oncan / itocayocā aculnahuac / oncan popotlan. auh / huallaque / chapoltepec yn icuitlapilco. ytocayocan techcantitlan / yuh quitocayotique yn mexica. Auh yn oncan / xiuh- / ome.

\$21 CC, p. 84 (f. 27v): auh / oncan / quinnahuati- yn Mexica / huitzilopochtli / teomamaque / quauhtlequetzqui / axollohua tlamacazqui. yhuan / ococaltzin / in yn teomamaque oquimilhui / notahuane. yn tleyn mochihuaz / xicchiyecan ca / anquittazque / ca nehuatl nicmati. ximochicahuacan. 
\$19[51] Luego partieron hacia acá, vinieron a establecerse ahí, vinieron a llegar a Atenco. [...] Luego alli colocaron su tzompantli, allí lo nombraron, por eso ahora el lugar se llama Tzompanco. [...] Luego vinieron a establecerse los mexicas en Cuachilco. Luego vinieron a llegar a Xaltocan, allí entonces se hacen sementeras, allí sembraron maiz, amaranto, frijol, calabaza, chilchotl y jitomate. Entonces con esto vienen a Epcóac y allí también se hicieron sementeras.

$\$ 20[52]$ Luego vinieron a establecerse en Ecatépec y en el lugar llamado Acalhuacan. Después vinieron allí a Tolpétlac y otra vez partieron hacia acá, vinieron [f. 27v] a establecerse allí en el lugar llamado Huixachtitlan. Entonces vinieron hacia acá, vinieron a establecerse en el lugar llamado Tecpayocan, allí otra vez se ató el año dos caña. Luego vinieron hacia acá, vinieron a establecerse allí en Atepétlac. En seguida partieron de allí, vinieron a establecerse en el lugar llamado Coatlyayauhcan. Luego vinieron allí en el lugar llamado Tetepanco. Partieron de allí, vinieron a establecerse, en el lugar llamado Acolnábuac. Luego vinieron, vinieron a establecerse allí en Popotlan. Luego vinieron allí, a las espaldas de Chapoltépec, en el lugar llamado Techcatitlan, después ellos, los mexicas, asi lo nombraron. Alli en Chapoltépec también ataron el año, la cuenta anual en dos (ome) caña.

\$21[53] Entonces allí habla a los mexicas él, Huitzilopochtli, ya les dice a ellos, a los cargadores del dios, al llamado Cuaubtliquetzqui, al segundo llamado Axolohua, tlamacazqui, y al tercero llamado Ococaltzin, a ellos, a estos cargadores del dios, les dijo Huitzilopochtli: "'Padres mios, lo que se tiene que hacer todavía espérenlo y lo verán! ¡Todavía espérenlo ya que yo lo sé! ¡Fortalézcanse, atrévanse,

$\$ 19$ CM, p. 75 (f. 3r): vinieron y llegaron en Atengo / allí pusieron el tzompan / agora / Çumpango / Cuachilco, y / Xaltocan... allí / hizieron camellones / sembraron maíz y huauhtli, frisol, calabaça, chilchotl, xitomate / Eycohuac... asimismo / hizieron sus sementeras.

\$20 CM, p. 75 (f. 3r-v): Ecatepec, y / Acalhuacan / allí... Tulpetlac / allí / Huixachtitlan / al lugar [que] llaman... Tecpayuca... allí / año / ome / Atepetlac / al lugar de Coatlayauhcan / vinieron a la parte que llaman Tetepanco / de allí / al lugar de Acolnahuac / allí... Popotlan... Y / biniéronse / a las haldas del çerro de Chapultepec, en el lugarejo que diçen... Techcatitlan / así le pusieron nombre los mexicanos... y allí / año / ome.

\$21 CM, p. $75-76$ (f. 3v): Y / allí / les habló... a los mexicanos / Huitzilopochtli / teomamaque / Cuauhtloquetzqui / Axoloa, tlamacazqui y / Aococaltzin / a estos cargadores de este ydolo... les dixo / "Padres míos... lo que a e uenir a ser / aguardá y lo beréis / que yo sé... / Esforçáos. 
ximotlapallocan. ximochichicahuacan. ximocencahuacan macamo nican yn tiezque. oc nechca yn titlamatihui yn oncan titlapiezque. Auh inin ma oc tiquinchiyecan yn techpolloquihui. ontlamantin in ye huitze.

\$22[54] Auh in yehuatl yn itoca Mallinalxoch. yn ihueltiuh yn huitzilopochtli. oquilhui yn iconeuh in yehuatl yn itoca Copil. quilhui nonantzine. ca cenca nicmati oncan moquichtiuh niman oquilhui ca quemaca ca onca yn motla. ytoca huiztilpochtli. ynic nechcauh çan nechcochcauh [f. 28r] Çan nechcochcauh, nechnahualcauh yn otlipan auh nimā yc nican titotlallique yn texcaltepeticpac. niman oquihto. yn copil ca ye qualli nonantzine ca ye nehuatl nicmati ca nictemotiuh yn canin otlahuelmatito. yn canin omotlallito. ca nicpopollotiuh ca nicquatiuh Auh ca niquinpopollotiuh ca niquinpehualtiuh yn oquinhuicac yn itahuan yn imacehualhuan auh ca cenca nicmati yn ixquich ynemac yn itech pouhqui yn quittaz. yn quimahuiçoz. y nepahpah netlamachtilli. auh ca nehuatl niyez ca nehuatl nonemach ez. yn ixquich y nepahpan chalchihuitl. yn teocuitlatl. yn quetzalli. y nepahpā yhuitl yn tlapahpalcacahuatl. yn tlapahpalychcatl. y nepapan xochitl. y nepahpan xochiqualli. auh ynin nonātzine. maca xitlaocoya. ye niyauh nictemotiuh yn tlahuelliloc notlah. cenca xinechmochilli

$\$ 23[55]$ auh ca nimā ye yc huitz. omocencauh omochichiuh yehuatl yn itoca copil. ca cenca huey tlahueliloc. Auh ca cenca huey nahualle amo mach iuhqui yn inan yn itoca Mallinalxoch. ca cenca huey tlahueliloc. yn copil. niman ye huitz. ipan ce calli xihuitl [...] oncan mocuepaco. yn itocayocan çoquitzinco. ye no ceppa huitz. oncan mocuepaco yn itocayocan atlapalco. ye no ceppa huitz. oncan mocuepaco yn itocayocan ytztapaltemoc. Auh ca yehuatl yn copil. yc mocuep ypan moquixti ytztapaltetl. yc motocayotia. yn axcan ca tiquitohua yn mochi tlacatl. ytztapaltetitla Auh ca in yehuatl yn copil. ca ynecuepca mochiuh yn ytztapaltetl. in yehuatl yn copil auh ye no ceppa mocuepa yn ichan yn texcaltepeticpac ytoca. Auh yn axcan yn mallinalco. ca yehuatl quitocayotica ypampa ca yehuatl ycaca ytoca yn Mallinalxoch. ynic monotza altepetl Malinalco. quin yehuatl oncan yc

\$21 CC, p. 84 (f. 27v): ximochichichuacan / macamo nican yn tiezque. oc nechca / ti-hui / titlapiezque / ontlamantin in ye huitze.

\$22 CC, p. 84-86 (f. 27v-28r): yn itoca Mallinalxoch. yn ihueltiuh yn huitzilopochtli / -nantzin- / nictemotiuh / -cpopollo- / -tlah.

$\$ 23$ CC, p. 86 (f. 28r): yn itoca copil / tlahueliloc / mallinalco. 
prepárense, dispónganse, que no es aqui donde tenemos que estar! Todavía más adelante vamos a hacer cautivos, allí guardaremos las cosas. ¡Por esto todavía esperemos los que nos vienen a destruir, dos grupos de ellos ya vienen!”

$\$ 22[54]$ A ella, a la llamada Malinálxoch, hermana mayor de Huitzilopochtli, le dijo su hijo, él, el llamado Cópil, le dijo: "Madre mía, sé muy bien dónde está tu hermano." Entonces le dijo: "Sí, es cierto que ahí está tu tío, llamado Huitzilopochtli, quien me dejó, sólo me dejó dormida, [f. 28r] me dejó con engaño en el camino. Entonces nos establecimos aquí, arriba del Texcaltépetl." Luego le dijo Cópil: "Está bien, madre mía, yo ya lo sé, lo voy a buscar en donde fue a sentirse a su gusto, en donde fue a establecerse, voy a destruirlo por completo, voy a comérmelo. Voy a destruir por completo, voy a conquistar a los que trajo, a sus padres, a sus vasallos. Conozco muy bien todos sus bienes, sus pertenencias que él verá, que él admirará, la multitud de riquezas. Seré yo, yo tendré conocimiento de todo, la multitud de chalchihuites, de oro, de plumas de quetzal, la multitud de plumas, de cacao multicolor, de algodón multicolor, la multitud de flores, la multitud de frutas. Por esto, madre mía, ¡no te aflijas!, ya me voy, voy a buscar al malvado de mi tio, ¡espérame mucho!"

$\$ 23[55]$ Entonces viene él, el llamado Cópil, se ha preparado, se ha ataviado, porque es un muy gran malvado. Es un muy gran brujo, aunque no parece serlo tanto como su madre llamada Malinálxoch, es un muy gran malvado Cópil. Luego ya viene en el año uno casa, [...] vino a transformarse en el lugar llamado Zoquitzinco. Otra vez viene, se trasforma allí en el lugar llamado Atlapalco. Otra vez viene, se transforma allí en el lugar llamado Itztapaltémoc. Con eso él, Cópil, se transformó, se convirtió en una loza de piedra, por eso se le da el nombre al lugar, ahora todo mundo le decimos Itztapaltetitlan. Esa es la transformación de él, de Cópil, se volvió una loza de piedra. Otra vez él, Cópil, regresó a su casa llamada Texcaltepetícpac, que ahora es Malinalco, ya que ella le está dando este nombre, porque ella, la nombrada Malinálxoch está morando allí, por

\$21 CM, p. 75-76 (f. 3v): començáos aparejar / que no emos de estar más aquí, que otro poco adelante / yremos / emod de aguardar / dos géneros de gentes uendrán... presto.

\$22 HI, p. 80-81 (f. 11v): la qual se llamaba Malinalxoch... hermana del dios Vitzilopochtli / madre / lo ir a buscar / lo destruir / tío.

\$23 HI, p. 81 (f. 11v): Copil (que así se llamaba) / malvadas / Malinalco / Malinalxuch. 
tlatoca [f. 28v] Macatacito yn itoca Malinalxoch. ynic acico. auh in yehuatl yn copil. ye no ceppa huitz. quihuicatz ychpoch ytoca azcatl xochtzin. oncan mocuepaco yn itocayocan tecpantzinco.

\$24[56] Auh in yehuatl yn huitzilopochtli. niman huell oquimah huell oquitac in ca yehuatl yn imach in ye huey yn itoca copil. niman oquimilhui yn itahuan notahuane ximochichihuacan. ximocencahuacan ca ye huitz. yn tlahueliloc y nomach. ye niyauh nicpopolotiuh nicmictiz auh niman oquinamic yn oncan ytocayocan tepetzinco auh yn oquittac oquilhui ac tehuatl campa tihuitz. quihualilhui ca nehuatl oc ceppa conilhui campa mochan. quihualilhui ca ompa yn texcaltepeticpac. niman oquihto. yn huitzilopochtli. ca ye qualli cuix amo tehuatl. yn omichiuh y nohueltiuh in Malinalxoch. / niman oquihto yn copil. ca quemaca. ca nehuatl. auh ca nimitzaciz. ca nimitzpopolotiuh tle ypampa yn ticcochcauh yn ticnahualcauh $y$ nonantzin auh ca nimitztlatlatiz conilhui yn huitzilopochtli. ca ye qualli tla xihuallauh Niman ye yc monahualtotoca. nimā ocacique yn copil. yn oncan tepetzinco. auh yn iquac yn omic ca nimā quiquechcoton niman ye queltequi. yn oqueltec conanilli yn iyollo. auh ycpac quitlalli yn tepetzintli yn itzonteco. yn axcan ye ytocayocan Acopilco. auh ytzonteco yn copil oncā mic

$\$ 25[57]$ Auh in yehuatl yn huitzilopochtli. yn oconmicti niman ye yc hualmotlallotia yca. yn iyollo yn copil. auh in yehuatl yn teomama yn itoca quaubtlequetzqui quinamictiuh yn huitzilopochtli. yn oquinamic. oquilhui Oticmihiyohuilti tlamacazque. oquihualilhui tla xihuallauh quauhtlequetzque. Yzca yn iyollo. yn tlahueliloc. yn copil. ca onicmictito. auh xicmotlalochti yn tollitic yn acayhtic yc tiquittaz oncan [f. 29r] oncan mani tepetlatl. oncan mocehui yn quetzalcohuatl yn iquac yah. auh yn icpal tiquitaz ${ }^{2}$ centetl tlauhyo cētetl tliltic. oncan timoquetzaz. yn toconmayahuiz. yn yehuatl. yn iyollo. yn copil. auh

\$24 CC, p. 86 (f. 28r-v): huitzilopochtli / oquimah / copil / tlahueliloc / nicmictiz / ytocayocan tepetzinco / omichiuh / ocacique / conanilli yn iyollo / tepetzintli / Acopilco / copil / mic.

\$25 CC, p. 86; 88 (f. 28v-29r): oconmicti / yn itoca quauhtlequetzqui / xicmotlalochti / conmayahuiz.

2 “ic [tiquitaz...]pal” en Anderson y Schroeder (CC, p. 88), pero me parece que esa trascripción no permite reconocer la palabra "icpal” (asiento) y prefiero "icpal tiquitaz". 
eso el pueblo se llama Malinalco. Despúes él vino a llegar allí para que alcanzara a darle [f. 28v] el gobierno la dicha Malináxoch, por eso vino a llegar. Él, Cópil, otra vez viene, trae a su hija llamada Azcatlxochtzin, vino a regresarse allí en el lugar llamado Tecpantzinco.

\$24[56] Él, Huitzilopochtli, entonces supo bien, vio bien que aquél, su sobrino llamado Cópil, ya era grande. Luego dijo a sus padres: "Padres míos, iprepárense, arréglense! que ya viene el malvado de mi sobrino. Yo ya me voy, voy a destruirlo por completo, lo mataré." En seguida lo encontró allí en el lugar llamado Tepetzinco. Lo vio y le dijo: "¿Quién eres tú? ¿De dónde vienes?” Le contestó: "Soy yo.” Otra vez fue a preguntarle: “¿Dónde está tu casa?” Le contestó: "Está allá sobre el Texcaltépetl." Luego Huitzilopochtli dijo: "Está bien, jacaso no eres tú a quien parió mi hermana Malinálxoch?” Entonces Cópil dijo: "Es cierto, soy yo. Te alcanzaré, voy a destruirte por completo porque dejaste dormida a mi madre, la dejaste con engaño. Acabaré contigo." Dijo Huitzilopochtli: "Está bien, ¡ven!" Entonces se persiguen como nahuales y tomaron a Cópil allí en Tepetzinco. Cuando murió luego lo degolló y entonces le abre el pecho y habiéndole abierto el pecho fue a sacarle el corazón. Arriba del cerrito puso su cabeza, ahora ya se le dice al lugar Acopilco. La cabeza de Cópil murió allí.

\$25[57] Él, Huitzilopochtli, fue a matarlo, en seguida viene corriendo con el corazón de Cópil. Él, el cargador del dios llamado Cuaubtliquetzqui, fue a encontrar a Huitzilopochtli, lo encontró y le dijo: "Te has cansado, dador de vida." Le contestó: “¡Ven, Cuauhtliquetzqui, toma el corazón del infame de Cópil, a quien fui a matar! jLlévatelo de prisa al interior de los juncos y de las cañas! Ahí verás [f. 29r] que se halla un petate de piedra, en el que descansó Quetzalcóatl cuando se fue. Verás su asiento, uno es rojo y uno es negro. Allí te pararás e irás a arrojar aquello, el corazón de Cópil."

\$24 HI, p. 81-82 (f. 11v-12r): Vitzilopochtli / sabiendo / Copil / malvado / le matasen / que llaman Tetepetzinco / parir / lo tomaran / le sacaron el coraçon / cerrillo/ Acopilco / Copil / fué muerto.

\$25 HI, p. 81-82 (f. 12r): fue muerto / que se llamaba Cuauhtloquetzqui / lo llevase- / lo arrojase. 
niman ye yc huitz yn quauhtlequetzqui yn quimayahuiz yollotli. yn onacico yn oncan oquitlatenehuili. niman oquittac. yn tepetlatl. oncan moquetz yn conmayauh yollotli. nimā ompa huetztito. yn tollotic yn acayhtic. niman ye yc oncan mocuepa yn oconmayahuito. in yollotli in yehuatl yn [...] quauhtlequetzqui. [...] auh yn axcan tictocayotia tlalcocomocco. yn oncan moquetz. yn [quauhtlequetzqui] ynic quimayahuico yollotli.

\$26[61] Auh ynic ontlamantli. yn oncan mochiuh yn chapoltepecuitlapilco oncan quinyaoyahualloque $=$ yn mexica. yn ixquich yn tepaneca. azcapotzalca yhuan yn tepaneque culhuaque. yn xochimilca. $\bar{y}$ cuitlahuaca. yhuan yn chalca. ompa mocenquixtique. mocentlallique yn altepetl ipan tlaca yn ixquichtin. yn ompa yn chalco. ychan yn itoca huehue cacamatl teuhctli yntlatocauh catca yn chalca amaquemeque. [...]

\$27[63] Auh yn chapoltepec. Oncan cacique yn huehue huitzilihuitl. in yehuatl yn achtopa yn tlahtohuani catca huitzilihuitl. ompa quihuicaque yn culhuacan ompa quimictique yn culhuaque

$\$ 28[64]$ Auh niman ye yc onmiquania yn Mexica yn oncan acuezcomac oncan quixinque oncan quicuiq yn atlatl. ynic axcan ytocayocan Atlacuihuayan niman ye yc huitze. onmotlallico. yn maçatlan yhuan yn tepetocan mochi yc motecaque in Mexica. auh ca nimā oncan huallaque yn culhuacan. auh yehuatl [...] yn achi [f. 30v] Tometl tlahtohuani yn oncan culhuacan [...]. niman oquimilhui yn Mexica yn huitzilopochtli. notahuane xictlatlauhtican yn [achitometl]. canin tiezque niman oquitlatlauhtique yn [achitometl]. quilhuique tlacatle tlahtohuanie. ca timitztotlatlauhtilia = campa nel tiazque ca onell oticmatque. yn Matzin yn Motepetzin. ma xitechmotlaocolili. achitzin yn motlaltzin. yn oncan ypan tonyezque. nimā oquinnanquilli oquihto. yn [achitometl]. ca ye qualli

\$25 CC, p. 86; 88 (f. 28v-29r): yollotli / huetztito. yn tollotic / axcan -ctocayotia tlalcocomocco. yn oncan.

$\$ 26$ CC, p. 90 (f. 29v): chapoltepec- / yahualloque / azcapotzalca / culhuaque / xochimilca / chalca / mocentlallique / tlaca yn ixquichtin / itoca / cacamatl teuhctli / tchalca.

\$27 CC, p. 90 (f. 30r): cacique / huitzilihuitl / quihuicaque yn culhuacan / quimictique.

\$28 CC, p. 90; 92 (f. 30r-v): -miquani- yn Mexica / atlatl / Atlacuihuayan / maçatlan / culhuacan / yn achiTometl tlahtohuani yn oncan culhuacan / oquimilhui / yn huitzilopochtli / notahuane xictlatlauhtican / canin tiezque / quilhui- / -tlatlauhti- / campa / tiazque. 
En seguida Cuauhtliquetzqui viene para arrojar el corazón y vino a llegar allí, al lugar que le había indicado. Entonces vio el petate de piedra, se paró allí y fue a lanzar el corazón. Así que fue a caer lejos, en medio del tular y del cañaveral. En seguida regresó de allí, habiendo arrojado el corazón él, [...] Cuauhtliquetzqui [...]. Ahora llamamos Tlalcocomocco el lugar en el cual se paró [Cuauhtliquetzqui] para venir a arrojar el corazón.

\$26[61] Lo segundo que aconteció allí, a las espaldas de Chapoltépec, fue que allí los enemigos cercaron a los mexicas, todos los tepanecas azcapotzalcas y los colhuacas, los xochimilcas, los cuitlahuacas y los chalcas se reunieron allá, se congregaron en el pueblo todas las gentes de allá, de Chalco, de la casa del señor llamado Huehue Cacámatl, quien era gobernante de los chalcas amaquemeques. [...]

\$27[63] En Chapoltépec capturaron a Huehue Huitzilíhuitl: él fue el primer gobernante Huitzilíhuitl. Lo llevaron allá a Colhuacan y allá los colhuaques lo mataron.

$\$ 28[64]$ Entonces los mexicas iban a refugiarse allí en Acuezcómac, allí tallaron, allí tomaron el lanzadardos, por eso ahora se le denomina al lugar Atlacuibuayan. En seguida vienen, vinieron a asentarse en Mazatlán y en Tepetocan todos se establecieron. Después vinieron allí en Colhuacan. [...] Achi- [f. 30v] -tómetl es el gobernante de Colhuacan [...]. Luego Huitzilopochtli dijo a los mexicas: “Padres mios, pidanle a [Achitómetl] un lugar en donde estaremos!" Luego le rogaron a [Achitómetl], le dijeron: "Señor gobernante, te suplicamos un lugar en el que realmente podamos $i r$, porque en verdad hemos sabido que éste es tu pueblo. Sé un poquito misericordioso con nosotros, vamos a estar sobre tu tierra." Entonces [Achitómetl] les contestó, dijo: "Está bien."

\$25 HI, p. 81-82 (f. 12r): coraçon / fue a caer....en el tular... en el medio / en el lugar que agora llaman Tlalcocomolco.

$\$ 26$ CC, p. 90 (f. 29v): chapoltepec- / yahualloque / azcapotzalca / culhuaque / xochimilca / chalca / mocentlallique / tlaca yn ixquichtin / itoca / cacamatl teuhctli / chalca.

\$27 CC, p. 90 (f. 30r): cacique / huitzilihuitl / quihuicaque yn culhuacan / quimictique.

\$28 CC, p. 90; 92 (f. 30r-v): -miquani- yn Mexica / atlatl / Atlacuihuayan / maçatlan / culhuacan / yn achiTometl tlahtohuani yn oncan culhuacan / oquimilhui / yn huitzilopochtli / notahuane xictlatlauhtican / canin tiezque / quilhui- / -tlatlauhti- / campa / tiazque. 
$\$ 29[65]$ Auh niman oquinnahuati yn itlahtocahuan yn [achitometl]. yn culhuaque quimilhuia. campan yezque oquilhuique yn itlahtocahuan tlacatle tlahtohuanie. ma ompa huian ma ye ompa yeti. yn tepetitlan. $\bar{y}$ nican tiçapan. nimā ompa quincahuato. oquintlallito. yn ompa tiçaapā. auh niman oquinonotzque yn tlahtohuani yn [achitometl] = quilhuia tlacatle tlahtohuanie. ca otiquincahuato. yn tiçaapā yn Mexica. niman oquihto. yn [achitometl] = ca ye qualli. ca amo tlaca. ca cenca tlahuelliloque açompa tlamizque cohuaquallozque. ca cenca ȳchan yn cocohua.

$\$ 30[66]$ Auh in yehuantin yn Mexica. cenca opahpacque yn oquimittaque yn cocohua. çan moch yehuantin yn quinmopahuaxillia. yn quinmotlehuachillia. yn quiqua yehuantin mexica.

\$31[67] Auh niman ye quitohua yn [achitometl]. oquilnamic ye quimilhuia culhuaquehe. yn anquincahuato tla xiquimittati. cuix omicque niman oquilhuiq ${ }^{-}$ca ye qualli tlacatle tlatohuanie ma tiquimittatin [f. 31r] Ma tiquimittatin. auh yn oquimonittaque. tlapopotztoque. poctli mani. tlatlatia. yn ipan onacique. nimā quimilhuique. ohuanquihiyohuique. mexicaye. çā tamechittaco. tamechtlapalloco. quen ancate. nimā oquinhualnanquillique. oquimilhuique oantechmocnellilique. ca tipacticate quimonilhuique ca ye qualli. ye tihui. huallaque yn tecpan niman ye quinonotza. yn [achitometl]. ye quilhuia tlacatle tlahtohuanie. ca otiquimonittato. ca oquintlatlamiq. yn cocohua yn oquinquaque cayocaque yn cocohua ca otlanque. nimā oquihto. yn [achitometl]. o tla xiquimitacan ca tlahuelliloque. ma quichiuhtiecan = maca xiquinnotzacan.

$\$ 32[68]$ Auh in mexica. in ye huecahua ye quinmocihuamontia yn imichpochhuā yn culhuaque in yehuantin Mexica auh yn culhuaque ye quinmomontia yn Mexica yn intelpochhuā ye nellihui yn inpilhuan //

\$29 CC, p. 92 (f. 30v): achitometl. yn culhuaque / campan / tepe- / tiçapan / -tlalli- / tlahtohuani- / yn Mexica / oquihto / tlami- / cenca / cocohua.

$\$ 30$ CC, p. 92 (f. 30v): opahpacque / -itta- / cocohua / quinmopahuaxillia / quinmotlehuachillia / -qua.

\$31 CC, p. 92 (f. 30v-31r): achitometl / quimilhuia / xiquimittati / -tlapallo- / oantechmocnellilique / tipacticate / quinonotza / oquintlatlamiq- / oquinquaque / tlahuelliloque. ma quichiuhtiecan.

$\$ 32$ CC, p. 92 (f. 31r): quinmocihuamontia yn imichpochhuā / quinmomontia / yn intelpochhuā. 
\$29[65] Luego [Achitómetl] habló a sus gobernantes, a los colhuaques, les dice: “En qué lugar estarán?” Le contestaron sus gobernantes: "Señor gobernante, que se vayan allá, que ya vayan a estar allá al cerro que está aquí en Tizaapan." Entonces los fueron a dejar allá, los fueron a asentar allá en Tizaapan. Después informaron al gobernante [Achitómetl], le dicen: "Señor gobernante, hemos ido a dejar a los mexicas en Tizaapan." Luego [Achitómetl] dijo: "Está bien, porque no son humanos, son unos grandes malvados, quizás se acabarán, serán comidos por las serpientes, ya que es la morada de muchas culebras."

$\$ 30[66]$ Ellos, los mexicas, se alegraron mucho al ver las culebras. Se las asan todas, se las cuecen y las comen ellos, los mexicas.

\$31[67] Entonces habla [Achitómetl], se recordó y ya les dice: "Colhuaques, ustedes fueron a dejarlos, vayan a verlos, tal vez han muerto." Luego le contestaron: "Está bien, señor gobernante, vayamos a verlos." [f. 31r] Aquéllos que fueron a verlos fueron invadidos por el humo, el humo se expande, arde mucho sobre los que fueron a llegar. Luego les dijeron: "Han sufrido trabajo, mexicas. Sólo venimos a verlos, venimos a saludarlos, ¿cómo están?” Entonces vinieron a responderles, les dijeron: "Ustedes nos han hecho bien ya que nosotros estamos contentos." Fueron a contestarles: "Está bien, ya nos vamos." Vinieron al palacio y entonces le relatan a [Achitómetl], ya le dicen: "Señor gobernante, fuimos a verlos y acabaron con las serpientes, se las comieron, ya no hay serpientes, se han extinto." Entonces [Achitómetl] dijo: "Vean que gente tan mala son, déjenlos, ¡no les dirijan la palabra!"

$\$ 32[68]$ Los mexicas permanecen mucho tiempo, ellos mismos casan a sus hijos con las hijas de los colhuaques. Los colhuaques, por su parte, casan a sus hijas con los hijos de los mexicas, ya están mezclados sus hijos.

\$29 HI, p. 83 (f. 12v): Achitometl... Culhuacan / qué lugar / cerro / Tiçapan / aposentar / Seńor / los Mexicanos / le dixo / acabar / muchas / culebras.

$\$ 30$ HI, p. 83-84 (f. 12v: se regustaron / viendo / culebras / dellas asadas / dellas cocidas / comiendo.

\$31 HI, p. 84 (f. 12v-13r): Achitometl / díjoles / Id y ved / saludar / el bien que se les auia hecho / el contento que tenían / relatándole / las... acabaron / las consumieron / gente mala... dejaldos.

\$32 HI, p. 84 (f. 13r): casándose los hijos y hijas / casándose / hijos y hijas. 
\$33[71] Auh niman ohualpanoque. yn oncan culhuacan yn mexica oquinhualhuicaque yn incihuahuan yn imichpochhuan yn culhuaque ye quinpilhuatia yn oncan yhtic altepetl. yn culhuacan

$\$ 34[76]$ Auh in yehuatl niman oquimilhui yn itahuan yn huitzilopochtli. quimilhui notahuane oc ce tlacatl $\bar{y}$ neciz. ytoca yaocihuatl. ca nocitzin. auh ca tiquixnextizq ${ }^{-}$[f. 32r] Auh ca tiquixnextizque. auh tla xiccaquican notavane. ca amo nican yn tiezque ca nechca yn titlamatihui yn oncan titlapiezque. auh ca amo çan nen yn tiazque. yn tiquintlalcahuizque yn culhuaque. ca ticacocuizque yn tomiuh yn tochimal. auh yn axcan ximochicahuacā. ximocencahuacan ca ohuanquicacque yn oncan ixneciz yn yaocihuatl. $\overline{\mathrm{y}}$ nocitzī auh ca namechnahuatia. tla xihuian xiquitlaniti yn ipiltzin. yn ichpoch yn achitometl. huel yehuatl yn itlaçopiltzin anquitlanilizque ca nehuatl nicmati namechmacaz.

$\$ 35[77]$ auh niman oyahque $\bar{y}$ mexica. oquitlanito. yn ichpoch yn achitometl. o. quitlatlauhtique. yn Mexica quilhuia nopiltzitzine tlacatle tlahtohuanie. ca timitztotlatlauhtilia yn timocolhuan yn timomacehualhuan yhuā yn ixquichtin yn Mexica. ca ticmomacahuiliz ca titechmomaquiliz. yn mocozqui yn moquetzal yn mochpochtzin yn toxhuiuhtzin yn cihuapilli ca ompa motlapiellitiez. yn oncan yn tepetitlan tiçaapan. auh niman oquihto yn achitometl ca ye qualli Mexicahye. ma xichuicacan nimà oquinmacac yn mexica oquibuicaque yn ichpoch. yn achitomel. caxitique ocontlallito yn oncan tiçaapan niman ye quitohua yn huitzilopochtli. quilhuia yn intoca teomamaque. axollohua tlamacazqui. yhuan yn quauhtlequetzqui [...]. quimilhuia notahuane namechnahuatia yn ichpoch yn achitometl xicmictican xicxipehuacan yn iquac yn oanquixipeuhque. ce tlacatl xoconaquicā. yn tlamacazqui.

$\$ 36[78]$ auh niman ye quimictia. yn quixipehua yn cihuapilli. yn oconxipeuhque yn iyehuayo nimā ye conaquia. yn ce tlacatl tlamacazqui.

$\$ 33$ CC, p. 94 (f. 31r): Auh niman ohualpanoque. yn oncan culhuacan yn mexica. $\$ 34$ CC, p. 94 (f. 31v-32r): oquimilhui yn itahuan yn huitzilopochtli / ytoca yaocihuatl / noci- / ca amo nican yn tiezque ca nechca / ca ticacocuizque yn tomiuh yn tochimal / ximochicahuacā. ximocencahuacan / yaocihuatl / tla xihuian xiquitlaniti yn ipil- / achitometl / -amechmacaz.

$\$ 35$ CC, p. 95 (f. 32r): oyahque $\bar{y}$ mexica. oquitlani-. yn ichpoch / nimā oquinmacac yn mexica oquihuicaque / quitohua yn huitzilopochtli / tlamacazqui / xicmictican xicxipehuacan / xoconaquicā.

$\$ 36$ CC, p. 96 (f. 32r-v): quimictia / quixipehua / conaquia. 
$\$ 33[71]$ Entonces los mexicas empezaron a entrar a Colhuacan, los trajeron sus mujeres, las hijas de los colhuaques, ya engendran a sus hijos adentro del pueblo de Colhuacan.

$\$ 34[76]$ Luego Huitzilopochtli dijo a sus padres, les dijo: "Padres míos, hay otra persona quien aparecerá, la cual se llama mujer de la guerra, es mi preciada abuela. Nosotros la presentaremos. [f. 32r] ¡Escuchen, padres míos! No estaremos aqui, porque más adelante vamos a hacer cautivos, allí guardaremos las cosas. No iremos en vano. Nos apartaremos de los colhuaques, porque elevaremos nuestra flecha, nuestro escudo. Ahora, ifortalézcanse, prepárense!, ya que han escuchado que allí Yaocíhuatl, mi preciada abuela, se mostrará. Yo les mando que vayan, vayan a pedir a la joven hija querida de Achitómetl, ustedes pedirán su muy noble hija, porque yo sé que se la daré."

$\$ 35[77]$ Luego los mexicas se fueron, fueron a pedir a la hija de Achitómetl, los mexicas se la rogaron, dicen: "Hijito mío, señor gobernante, te suplicamos nosotros que somos tus abuelos, que somos tus vasallos y todos los mexicas, que concedas, que nos otorgues tu collar, tu pluma de quetzal, tu preciada hija, tu nieta querida, la noble mujer quien será custodiada allá en Tepetitlan Tizaapan.” Entonces Achitómetl contestó: "Está bien, mexicas, llévensela." Luego se la dio a los mexicas, se llevaron a la hija de Achitómetl. La acompañaron y la fueron a establecer en Tizaapan. Entonces Huitzilopochtli habla, dice a los cargadores de los dioses, al sacerdote Axolohua y Cuauhtliquetzqui [...], les dice: "Padres míos, les mando que maten a la hija de Achitometl y que la desuellen y cuando ustedes la hayan desollado jvistan con ella a un sacerdote!"

$\$ 36$ [78] Entonces la matan, desuellan a la mujer noble y, una vez desollada, visten con su cuero a un sacerdote. Des- [f. 32v] -pués,

$\$ 33$ HI, p. 84 (f. 13r): entonces empezaron los mexicanos á entrar en Culhuacan. \$34 HI, p. 84-85 (f. 13r): dijo á sus... ayos Vitzilopochtli / la qual se ha de llamar la muger de la discordia / mi aguela / Porque no es este el lugar donde emos de haçer nuestra habitaçion / que empeçemos a leuantar nuestras... flechas, rodelas / ampeçaos á aparejar y aperciuir / muger de la discordia / que vayais... le pidais su hija / Achitometl / os la dará.

\$35 HI, p. 85 (f. 13r): los mexicanos... fueron... pídenle á su hija / dióla luego a los mexicanos... la lleuaron / habló Vitzilopochtli / sacerdote- / matá... desollallaeis / vestidselo.

$\$ 36$ HI, p. 85 (f. 13r-v): mátanla / desuéllanla / visten. 
auh ni [f. 32v] Man oquihto yn huitzilopochtli. notahuane tla xicnotzati yn achitometl. niman oyahque yn mexica oquinotzato. quilhuia. totecuiyoye noxhuiuhtzine. tlacatle tlahtohuanie timitztotlalcahualtizque. timitztotlapololtizque. yn timomacehualhuan. ca mitzmotlatlauhtilia. yn mocolhuan yn Mexica. ca quihtohua ma quimotilliqui. ma quimotlapalhuiqui yn iteotzin. ca tocontonochillia.

\$37[79] auh niman oquihto. yn achitometl ca ye qualli ma tihuian niman oquimilhui yn itlahtocahuan yn achitometl. ma tihuian yn tiçaapan, techcohuanotza yn Mexica oquinanquillique. oquilhuique. ca ye qualli tlahtohuanie ma ximohuica. auh niman ye quihuica holli copalli. amatl. xochitl. in yetl. yhuan yn itoca tlacatlaqualli. ye quitlamanilizque yn teotl yn iuh quilhuique achitometl ynic quinotzato, auh ca ye amo nelli in yehuatl. auh ca ye yehuatl yn oquixipeuhque.

$\$ 38[80]$ auh yn oacic yn oncan tiçaapan in yehuatl yn achitometl. quilhuia yn Mexica ynic ye quihualnamiqui. oticmihiyohuilti. noxhuiuhtzine tlacatle tlahtohuanie. cocoliztli timitztocuitilizque yn timocolhuan. yn timomacehualhuan ma xicmottilli. ma xicmotlapalhui yn moteotzin. niman oquihto. ca ye qualli nocolhuane. nimā ye conana yn holli. yn copalli. yn xochitl. yn iyetl yn tlacatlaqualli. ye quitlamamaca yxpan quitequillia yn çan tlapic yteouh. in yehuatl yn oquixipeuhque. auh in yehuatl yn achitometl. niman ye yc yxpan quinquechcotona in çoçoltin yn iteouh. auh ca ayemo huel quittaya [f. 33r] Quittaya in aqui yn yxpan quiquechcotona yn çoçoltin niman ye yc quitlenamaquilia quixabuilia. yn tlemaytl, yn onmaquiticac. yn ehuatl, yn ce tlacatl. tlamacazqui. auh yn iquac huell oquittac yn ca yehuatl. yn ichpoch. yn achitometl. cenca omomauhti. niman ye yc tzatzi quintzatzillia. yn itlahtocahuan yhuan yn imacehualhuan quimilhuia. aquique yn. a. culhuaquehe cuix amo anquitta. ca oquixipeuhque y nochpochtzin. amo nican yezque yn tlahuelliloque. tiquinmictizque tiquinpopollozque. nican tlamizque yn tlahueliloque auh

\$36 CC, p. 96 (f. 32r-v): achitometl. niman oyahque / ma quimotlapalhuiqui yn iteotzin.

$\$ 37$ CC, p. 96 (f. 32v): itlahtocahuan / -cohuanotza / copalli. amatl / tlacatlaqualli. $\$ 38$ CC, p. 96; 98 (f. 32v-33r): tiçaapan / yn Mexica / quihualnamiqui / tlacatlaqualli / quitlamamaca yxpan / yn çan tlapic yteouh / quinquechcotona in çoçoltin / ca ayemo huel quittaya in aqui yn yxpan / quitlenamaquilia quixahuilia / tlemaytl / onmaquiticac. yn ehuatl / tzatzi / -macehualhuan / oquixipeuhque y nochpochtzin / tlahuelliloque. tiquinmictizque tiquinpopollozque / tlamizque. 
Huitzilopochtli dijo: "Padres míos, vayan a llamar a Achitómetl." Luego los mexicas se fueron, fueron a llamarlo, le dicen: "Señor nuestro, mi preciado nieto, señor gobernante, nosotros tus vasallos te trastornaremos, te perturbaremos, porque tus abuelos los mexicas te suplican, dicen: "Que venga a ver, que venga a saludar a su dios." Nosotros lo vamos a llamar."

\$37[79] Luego Achitómetl dijo: “Está bien, vayamos." Después Achitómetl dijo a sus señores: "Vayamos a Tizaapan, nos invitan los mexicas." Le contestaron, le dijeron: "Está bien, señor, vaya usted." Entonces traen hule, copal, papel, flores y tabaco y lo que se llama comida para ofrecer, la cual ofrendarían al dios como le habían dicho a Achitómetl cuando lo fueron a llamar, pero en realidad no es ése, sino la que habían desollado.

$\$ 38[80]$ Llegado Achitómetl a Tizaapan, los mexicas le dicen mientras vienen a recibirlo: "Te has cansado, mi preciado nieto, señor gobernante, nosotros tus abuelos, tus vasallos, te confesaremos un pecado, ¡ve, saluda a tu venerado dios!” Luego les contestó: "Está bien, abuelos míos." Entonces toma el hule, el copal, las flores, el tabaco y la comida de la gente, y ya la dispone, la acomoda en frente de su falso dios, al que habían desollado. Achitómetl en seguida corta cabezas de codornices en frente del dios, pero no veía bien [f. 33r] en frente de quién cortaba las cabezas de las codornices. Entonces le ofrece copal y el bracero aclara con su luz al que estaba vestido con la piel, a un sacerdote. Cuando pudo ver que era su hija, Achitómetl se espantó y en seguida da grandes voces, gritó a sus señores y a sus vasallos, les dice: “¿Quiénes son éstos? Ah, colhuaques, ¿`no ven que han desollado a mi hija querida? No estarán aquí esos hombres tan malos, los mataremos, los destruiremos, aquí no quedará rastro de esos infelices." Entonces se pelea y después

\$36 HI, p. 85 (f. 13r-v): Achitometl... luego... van / que venga á adorar á la diosa.

\$37 HI, p. 85-86 (f. 13v): señores / convidan- / papel, copal / comida- para ofrecer.

$\$ 38$ HI, p. 86 (f. 13v): Tiçapan / Los mexicanos / los salieron a recibir / comida / poner... delante de / los ídolos / cortar las cabeças á las codornices / no via á quién, ni delante de quién / ofrecer copal... aclarándose... con el fuego / brasero / vestido con el cuero / da- grandes voces / vasallos / á mi hija... la han desollado / hombres tan malos... mueran y sean destruidos / no quede rastro... dellos. 
niman ye ic moyaotla. niman ye quimilhuia yn itahuan yn huitzilopochtli. ca nehuatl nicmati çan iviā çan iyollic xonquiçacan.

\$39[81] Auh niman ye tetoca yn culhuaque quintoca yn Mexica. niman ye quimonquequetza yn atlah in Mexica. ynic quinhuallehuitiqquintepehuaco. yn oncan ytocayocā Acatzintitlan. yn momatque culhuaque aço oncan oyxpoliuhque yn atlan. niman oncan valchimalpanoque. yc panoq yn mitl. yn chimalli. auh yn mitl yn mitohua yn tlacochtli. yn motocayotia tlatzontectli. quicuitlalpique. ypā motlallique yn atlan ynic hualpanoque. [...] yhuan yn chimalli ypan motlallique. yn atlan. ynic hualpanoque. ynic quinhualtocaque yn culhuaque.

$\$ 40[82]$ Auh niman yc oncā acico yn oncā tollihtic. acayhtic. yn Mexicatzinco. oncan quitzonicpilloque yn itoca Acatzin. oncā quitillique. yn itzinco quiminque yc on ${ }^{\text {can }}$ tlatocayoti [f. 33v] que. Mexicatzinco.) niman. ye oncan quihuahuātza yn opaltic yn inyaotlatqui yn intlahuitz. yn inchimal yn ixquich. yn intlatqui.

\$41[83] auh in yehuātin yn incihuahuan. yn inpilhuan niman ye mochoquillia. quitohua campan tihui ma çā nican tiyecā. yn acayhtic. niman oncan motlalliq-, niman ye oncan quiquetza yn temazcalli: oncan callacque yn ihtic yn temazcalli. niman yc motema.

$\$ 42[84]$ auh ynic tlaquallanique oncan tetzinco mayauhque yn temazcalco. niman ye yc quinhualtoca [...] atlan quintepehuato. çā no tollihtic. acayhtic. yn motlallico. oncan ce tlacatl momiquilli ytoca huito. oncan quitlatique. yn inacayo. mochi yn amapanitl. ynic mitohua motenehua mopantlatillique yn Mexica huehuetq- ynic nexticpac mitohua //

$\$ 43[85]$ Auh nimā ye yc huitze hualmiquanique çā no oncan Acayhtic. y tollihtic. yn motlallico ytocayocan yztacalco yn Mexica. quinhualyacantia yn itoca tenochtzin. niman oncan ye quichihua. quitlacatillia ytoca

\$39 CC, p. 98 (f. 33r): yn culhuaque / yn Mexica / atlah / quintepehuaco / panoq/ yn mitl / quicuitlalpique / atlan ynic hualpanoque / chimalli.

$\$ 40$ CC, p. 98 (f. 33r-v): tollihtic. acayhtic / Acatzin / tlatocayotique. Mexicatzinco / quihuahuātza / -yaotlatqui / -chimal / intlatqui.

$\$ 41$ CC, p. 98 (f. 33v): yn incihuahuan. yn inpilhuan / mochoquillia / quiquetza yn temazcalli / motema.

$\$ 42$ CC, p. 98 (f. 33v): quitlatique.

$\$ 43$ CC, p. 98; 100 (f. 33v-34r): ytocayocan yztacalco. 
Huitzilopochtli dice a sus padres: "Yo sé que poco a poco y despacio van a salir."

$\$ 39[81]$ Entonces expulsan a la gente, los colhuaques persiguen a los mexicas. Luego empujan a los mexicas en el agua, los vinieron a dispersar, los vinieron a arrojar en el lugar llamado Acatzintitlan. Los colhuaques pensaron que tal vez se perderían en el agua. Luego allí vinieron a atravesar en sus escudos, pasaron con las flechas, con los escudos; con las flechas que se dicen dardos, que se nombran jabalinas hicieron unos atados y se sentaron sobre ellos para venir a pasar al otro lado del agua [...] y se sentaron sobre los escudos para venir a pasar al otro lado del agua, mientras los venían persiguiendo los colhuaques.

$\$ 40[82]$ Entonces vinieron a llegar entre los juncos y las cañas, en Mexicatzinco. Allí pusieron de cabeza al llamado Acatzin, allí le vieron su trasero y lo flecharon, por eso llama- [f. 33v] -ron al lugar Mexicatzinco. Luego ponen a secar sus armas mojadas, sus divisas, sus escudos y todas sus ropas.

$\$ 41[83]$ Sus mujeres y sus hijos entonces lloran, dicen: “¿Adónde vamos? Sólo estemos aquí, en medio de las cañas." Luego se asentaron allí y después levantan un baño de vapor: entonces entraron adentro del temazcal, así que se bañan.

$\$ 42[84]$ Por haberse enojado en Tetzinco, se retiraron del temazcal. Entonces los viene a perseguir, [...] los fueron a empujar en el agua, vinieron a asentarse otra vez en medio de los juncos, de las cańas. Allí murió un hombre de nombre Huito y en ese lugar quemaron su cuerpo, todas las banderas de papel, así que se dice, se declara que los ancianos mexicas quemaron banderas, por eso se dice Nextícpac.

$\$ 43[85]$ En seguida vienen, vienen a apartarse en medio de las mismas cañas, de los mismos juncos, vienen a asentarse en el lugar que llaman Iztacalco. Viene guiando a los mexicas el llamado Tenochtzin. Entonces allí hacen,

\$39 HI, p. 87 (f. 13v-14r): los de Culhuacan / los mexicanos / hácia el agua / los metieron / pasaron / con las... fizgas / haciendo balsas / pasados de la otra parte del rio / rodelas.

$\$ 40 \mathrm{HI}$, p. 87 (f. 14r): en los carriçales y tulares / Acatzin- / llamaron... Mexicatzinco / enjugar / armas / rodelas / sus ropas.

$\$ 41 \mathrm{HI}$, p. 87 (f. 14r): mugeres y niños / llantos / edificar un baño... temazcal- / se bañaron.

$\$ 42$ HI, p. 88 (f. 14r): quemaron.

$\$ 43$ HI, p. 88 (f. 14r): un lugar que agora llaman Iztacalco. 
amatepetl. tzohualli yn quichiuhque. quitzontecontique. quitlactique. quimahmatique. quicxitique. yn oquitlacaquetzque nimā ye yc quitlaquētia quipantique. niman ye yc quicuicatia cenyohual yn quicuicatique yn oncan yztacalco. [...] niman ye yc huitze yn ayhtic ytocayocan pantitlan. ōcan motlallique huecauhque yn oncan catca yn pantitlan. auh niman ye huitze oncan çan no tollihtic. acayhtic yn oncan motlallique. nimā oncan ce tlacatl mixiuh yn inpiltzin. yn imichpoch [f. 34r] Yn imichpoch in Mexica. ytoca quetzalmoyahuatzin. auh yn iconeuh ytoca contzallan.

\$44[86] auh ypan yn cemilhuitonalli chiuhcnahui hecatl. yehuatl ypampa yn axcan ytocayocan mixiuhcan. nimā ye yc huitze oncan motlallico yn oncan ihcac. ycaltzin Sant. Pablo. ytepotzco yn oncan quichiuhque. quiquetzque yn temazcalli. oncā quitēque yn imichpoch. yn mexica. yn itoca quetzalmoyahuatzin. oncan omote yn inan. yn contzallan ynic motocayotia yn temazcaltitlan. oncan motenque mochintin yn mexica. oncan motlallique. ye cate.

$\$ 45[87]$ auh niman oncan onehuaque oyahque yn tollihtic. yn acayhtic yn oncan yn axcan motocayotia toltzallan. acatzallan. niman ynic oyahque yn Mexica huehuetque yn itoca yn quauhtlequetzqui. [...] yhuan no yehuatl yn itoca yn axollohua tlamacazqui. ym omextin yahque yn tlatemoto yn canin motlalizque.

$\$ 46[88]$ auh yn oypan quiçato. yn oquittaque cenca miec tlamantli. yn tlamahuiçolli. yn oncan ca yn acayhtic ca yehica ypampa ynnahuatil yuh quimilhui yn huitzilopochtli. yn teomamaque yn itahuan yn quauhtlequetzqui [...] yn axollohua tlamacazqui. ca quinnahuati. ca yuh quimilhui yn ixquich yn oncan yn onoc yn tollihtic yn acayhtic. yn oncā yhcaz. yn oncan tlapiez. in yehuatl yn huitzilopochtli. ca ytencopa quimilhui. ca yuh quinnahuati. yn mexica auh niman oquittaque. yztac yn ahuehuetl. yztac yn huexotl. yn oncan yhcac. yhuan yztac yn acatl yztac yn tolli. yhuan yztac yn cueyatl. yztac yn michin. yztac yn cohuatl [f. 34v]

$\$ 43$ CC, p. 98; 100 (f. 33v-34r): -tepetl / quichiuhque. / mixiuh / yn imichpoch. $\$ 44$ CC, p. 100 (f. 34r): axcan ytocayocan mixiuhcan / quiquetzque yn temazcalli I motocayotia yn temazcaltitlan.

$\$ 45$ CC, p. 100 (f. 34r): toltzallan. acatzallan / tlatemoto yn canin motlalizque. $\$ 46$ CC, p. 100 (f. 34r-v): oquittaque / tlamantli. yn tlamahuiçolli / huitzilopochtli / ytencopa / yztac yn ahuehuetl. yztac yn huexotl / yztac yn acatl / yn tolli / yztac yn cueyatl. yztac yn michin. yztac yn cohuatl. 
engendran al que se llama Amatépetl (cerro de papel). Lo hicieron de amaranto, le pusieron cabeza, busto, brazos y pies, lo levantaron como una persona, luego lo visten, lo arreglaron. Entonces le cantaron una noche entera, le cantaron ahí en Iztacalco. [...] Después vienen en medio del agua, en el lugar llamado Pantitlán. Allí se asentaron, se quedaron un tiempo, estuvieron allí en Pantitlán. Luego vienen otra vez en medio de los juncos, de las cañas, donde se asentaron. Entonces allí una jovencita, una hija [f. 34r] de los mexicas llamada Quetzalmoyahuatzin parió. El nombre del párvulo era Contzalan.

$\$ 44[86]$ Eso fue en el día de fiesta nueve viento, por esta razón hoy se llama Mixiuhcan. En seguida vienen ahí, vinieron a establecerse donde está la iglesia de San Pablo Itepotzco, en donde hicieron, levantaron un baño de vapor. Allí bañaron a la hija de los mexicas llamada Quetzalmoyahuatzin, allí se bañó la madre de Contzalan, por eso se llama Temazcaltitlan, allí todos los mexicas se bañaron, allí se asentaron, ya están.

$\$ 45[87$ ] Luego partieron de allí, se fueron en medio de los juncos y de las cañas donde ahora se nombra Toltzalan Acatzalan (Entre Espadañas y Carrizales). Después se fueron los ancianos mexicas, el llamado Cuauhtliquetzqui [...] y también el sacerdote llamado Axolohua, ambos fueron a buscar un lugar donde pudieran establecerse.

$\$ 46[88]$ Cuando fueron a salir, los cargadores del dios, sus padres Cuauhtliquetzqui [...] y el sacerdote Axolohua vieron muchísimas cosas maravillosas en ese lugar que está en medio de las cañas, y eso conforme a la promesa de Huitzilopochtli, quien así lo había dicho. De hecho, Huitzilopochtli les ordenó, así les dijo a todos que donde se encuentra el centro de los juncos y de las cañas, allí estaría, allí se guardaría. Por su mandato les dijo, así lo ordenó a los mexicas. Entonces vieron una sabina blanca, un sauce blanco que allí estaba, y también las cañas eran blancas, las espadañas eran blancas, las ranas blancas, el pescado blanco, las serpientes blancas [f. 34v] que

$\$ 43 \mathrm{HI}$, p. 88 (f. 14r): cerro- / hicieron / parió / una hija.

$\$ 44$ HI, p. 88-89 (f. 14r-v): el dia de oy le llaman Mixihtlan / edificaron el baño / llaman Temazcaltitlan.

\$45 HI, p. 88-89 (f. 14r-v): entre las espadańas y carriçales / vinieron buscando... algun lugar... para poder hacer asiento.

$\$ 46$ HI, p. 88; 91 (f. 14r; 15r): vieron / cosas maravillosas / Vitzilopochtli / por mandado de / una sabina blanca... sauce-... blanco- / las cańas... eran blancas... las espadañas / ranas... blancas... pescado... blanco... culebras... blancas. 
yn oncan nemi atlan. auh niman oquittaque nepaniuhticac yn texcalli yn oztotl. $^{3}$ ynic ce yn texcalli. yn oztotl. Tonatiuh. yquiçayan ytztoc. ytoca tleatl. atlatlayan. Auh ynic ome $\bar{y}$ texcalli yn oztotl. mictlampa ytztoc ynic nepaniuhtoc. ytoca matlallatl. yhuan ytoca toxpallatl.

\$47[89] Auh yn oquittaque niman ye choca yn huehuetque quitohua Anca ye nican yez ca otiquittaque. yn techilhui ynic technahuati yn tlamacazqui yn huitzilopochtli. yn quihto. yn iuhqui anquittazque yn tollihtic yn acayhtic. miec tlamantli. yn oncan ca. auh yn axcan ca otiquittaque. oticmahuiçoque. ca ye nelli ca omochiuh. ca oneltic yn itlahtol ynic technahuati. niman oquihtoque. mexicaye ma oc tihuian ca otitlamahuiçoque ma oc tictlahtolchiyecan yn tlamacazqui yehuatl quimati quenin mochihuaz. niman ohuallaque. motlallico yn oncan temazcaltitlan.

$\$ 48[90]$ auh niman yohualtica yn oquittac. yn oquimottiti. yn teomama yn itoca quauhtlequetzqui [...] in yehuatl yn huitzilopochtli. oquilhui [quauhtlequetzquihe]. ca ohuanquittaque yn ixquich yn oncan onoc yn acayhtic ohuantlamahuiçoque. Auh tla xiccaquica oc cêtlamantli yn ayemo anquitta. auh ynin xihuian xiquittati. ${ }^{\mathrm{yn}}$ tenocbtli yn oncan anquittazq-icpac ca ycpac iyhcac. in yehuatl. yn quauhtli. oncan tlaqua. oncan mototonia. auh ca ye pachihui yn amoyollo. ca yehuatl. yn iyollo in copil yn tiqual mayauh yn oncā timoquetz tlalcocomocco Auh niman oncan buetzico yn oanquittaque texcaltenpa. oztotenpa. yn acatzallan. yn toltzallan. auh ca ōcā yxhuac [f. 35r] yxhuac. yn iyollo. yn copil. yn axcan motocayotia tenochtli. auh ca oncan yn tiezque. yn titlapiezque. yn titechiezque. yn

$\$ 46$ CC, p. 100 (f. 34r-v): atlan / yn texcalli yn oztol / -atl / ynic ome ỳ texcalli yn oztotl / matlal-l.

$\$ 47$ CC, p. 100; 102 (f. 34v): choca yn huehuetque quitohua / technahuati / tlamantli / anquittazque / otiquittaque. oticmahuiçoque / tihuian / tictlahtolchiyecan / quenin mochihuaz. niman ohuallaque / temazcaltitlan.

$\$ 48$ CC, p. 102 (f. 34v-35r): auh niman yohualtica / oquimottiti / quauhtlequetzqui / huitzilopochtli. oquilhui / ohuanquittaque / oc cêtlamantli yn ayemo anquitta / tenochtli / icpac / ycpac / yn quauhtli / tlaqua / mototonia / iyollo / copil / tiqualmayauh / huetzico / yn acatzallan. yn toltzallan / yxhuac.

3 En la paleografía de Anderson y Schroeder se encuentra "oztotol" (CC, p. 100), pero la lectura correcta es "oztotl”, siguendo el Manuscrito 374, vol. III (f. 24v).

El difrasismo "in texcalli in oztotl" 'la peña, la cueva' significa probablemente "fuente, manantial." 
allí andaban por el agua. Luego vieron unas peñas y cuevas (fuentes) que se estaban cruzando: la primera fuente estaba mirando hacia la salida del sol y se llamaba agua de fuego, lugar del agua hirviendo, mientras que la segunda fuente estaba mirando hacia el norte, de manera que estaban cruzándose la que se llamaba agua azul con la que se llamaba agua amarilla.

$\$ 47[89]$ Después de haber visto eso, los viejos lloran, dicen: "Entonces será aquí, dado que hemos visto lo que nos dijo, lo que nos ha prometido el sustentador Huitzilopochtli. Él dijo que muchas cosas de esta suerte verian ustedes entre las espadañas y carrizales y allí están. Ahora lo hemos visto, lo hemos admirado, porque en verdad se realizó, han sido verdad las palabras que él nos prometió." Entonces dijeron: "Mexicas, vámonos porque nos hemos maravillado, aún esperemos el mandamiento del sustentador, él sabe lo hay que hacer." Luego vinieron, vinieron a asentarse en Temazcaltitlan.

$\$ 48[90]$ Luego de noche el cargador del dios llamado Cuaubtliquetzqui [...] vio a Huitzilopochtli, se le apareció y le dijo: "[Cuauhtliquetzqui], ustedes han visto todo, en el lugar que se encuentra en medio de las cañas se han maravillado. Escuchen, aun una cosa les falta por ver. ¡Vayan a ver al tunal de piedra! Ahí lo verán, encima de él se encuentra, encima de él está parada un águila. Allí come y se calienta al sol. Ya está enterrado vuestro corazón, aquel corazón de Cópil que viniste a arrojar en ese lugar de Tlalcocomocco donde tú te paraste. Después de que allí vino a caer, ustedes vieron la orilla de la peña, la entrada de la cueva entre las espadañas y los carrizales. Allí brotó [f. 35r] el corazón de Cópil que ahora se llama Tenochtli. Allí estaremos, aguardaremos, esperaremos y encontraremos a

\$46 HI, p. 88; 91 (f. 14r; 15r): del agua / peña-... fuente / agua / el segundo arroyo / açul.

\$47 HI, p. 88-89 (f. 14r-v): llorar... viejos... diciendo / nos a sido prometido / cosas / veria- / emos visto... emos / vámonos / esperemos el mandamiento / lo que emos de acer...así se vinieron / Temazcaltitlan.

$\$ 48$ HI, p. 89-91 (f. 14v-15r): Luego aquella noche / apareció / Cuauhtloquetzqui / Vitzilopochtli... dixole / aueis visto / aun mas os falta por ver / tunal... piedra / encima de / encima del / una aguila / come / recive el calor del sol / coraçon / Copil / arroja- / fué a caer / entre los carriçales y espadañas / nació. 
titenamiquizque. yn nepahpan. tlaca. telchiquiuh totzonteco. tomiuh tochimal. ynic tiquimittazque yn ixquich yn techyahuallotoc yxquich tiquinpehuazque tiquimaçizque. yc maniz yn taltepeuh mexico. tenochtitlan. quauhtli ypipitzcayan ynetomayan. quauhtli ytlacuayan. yhuan michin ypatlanian. yhuan cohuatl yçomocayan. yn mexico yn tenochtitlan. auh ca miec tlamantli. yn mochihuaz. niman oquilhui yn [quauhtliquetzqui] ca ye qualli tlamacazque. Otlacauhqui y moyollotzin ma quicaquican y mottahuan yn huehuetque yn ixquichtin. yc niman oquincentlalli yn Mexica [quauhtliquetzqui] oquincaquilti yn itlahtol yn huitzilopochtli. yn oquicacque mexica.

$\$ 49[91]$ Auh niman ono ceppa yahque yn toltzallan. yn acatzallan. yn oztotenpa. auh yn oypan quiçato. Acatitlan yhcac yn tenochtli. yn oncan / oztotenpa yn oquittaque ycpac ca ycpac yhcac. moquetzticac yn quauhtli. in yehuatl yn tenochtli. oncan tlaqua. oncan quiqua quitzotzopitzticac. yn quiqua. auh in yehuatl yn quauhtli. yn oquimittac. yn Mexica cenca omopechtecac. yn quauhtli. çan huecapa yn conittaque.) Auh in itapaçol yn ipepech çan moch yehuatl yn ixquich y nepahpan tlaçoyhuitl. yn ixquich yn xiuhtotoyhuitl. yn tlauhquecholyhuitl. yn ixquich quetzalli.

$\$ 50[92]$ auh ca no oncan quittaque yn oncan tetepeuhtoc. yn intzonteco $\bar{y}$ nepahpan totome yn tlaçototome. yntzonteco oncan çoçoticate. yhuan cequi totoycxitl. cequi omitl. auh oncan quinnotz in diablo quimilhui mexicaye ye onca yecin. auh yece amo quitta yn mexica yn aquin quinnozta. yc oncā tlahtocayotique Tenochtitlan) Auh niman ye yc choca yn Mexica. quitohua / otocnopiltic. otomace [f. 35v] hualtic ca oticmahuiçoque yn taltepeuh yez: ma oc tihuian ma oc titocehuiti. niman ye yc huitze ōcan Temazcaltitlan [...].

$\$ 51[93]$ Auh ca niman ye yc quimilhuia in yehuatl in quaubtlequetzqui. [...] yn Mexica quimilhui nopilhuane ma titlachtequicā ma achitzin

$\$ 48$ CC, p. 102 (f. 34v-35r): tlaca / tiquinpehuazque / -altepe- / tenochtitlan / tenochtitlan / oquincentlalli / oquincaquilti.

$\$ 49$ CC, p. 102 (f. 35r): yahque yn toltzallan. yn acatzallan / -nochtli / ycpac / yn quauhtli. yn oquimittac / omopechtecac / tlaçoyhuitl / xiuhtotoyhuitl / quetzalli. $\$ 50$ CC, p. 102 (f. 35r-v): tlahtocayotique Tenochtitlan / choca / otomacehualtic / oticmahuiçoque / taltepeuh / huitze ōcan Temazcaltitlan.

$\$ 51$ CC, p. 102; 104 (f. 35v): quauhtlequetzqui / quimilhui nopilhuane. 
diferentes pueblos, veremos nuestro pecho, nuestra cabeza, nuestra flecha, nuestro escudo, todos nos están rodeando, todos los sujetaremos, todos los haremos prisioneros. Por eso estará extendida nuestra ciudad de México Tenochtitlan, donde el águila chilla, donde extiende sus alas, donde el águila come, donde el pez nada y donde la serpiente ronca, en México Tenochtitlan. Muchas cosas se cumplirán." Luego [Cuauhtliquetzqui] dijo: "Está bien, sustentador, se ha complacido tu venerado corazón. Que lo escuchen tus padres, todos los ancianos." Por eso luego [Cuauhtliquetzqui] convocó a los mexicas, les reveló las palabras de Huitzilopochtli y los mexicas lo escucharon.

$\$ 49[91]$ Luego otra vez fueron entre las espadañas y los carrizales, a la orilla de la cueva. Fueron a salir allá, a Acatitlan, donde está parado el tunal de piedra, allí a la orilla de la cueva lo vieron, encima del tunal de piedra se encuentra, encima de él está parada, se está levantando el águila. Allí come algo, allí lo come, está picoteando lo que come. El águila vio a los mexicas, mucho bajó la cabeza el águila, sólo de lejos fueron a verla. Su nido, su cama es de todo eso, todo es de una multitud de plumas preciosas, todo es de plumas del cotinga azul, del espátula rosa, todo es de plumas de quetzal.

$\$ 50[92]$ También en ese lugar vieron que allí estaban esparcidas las cabezas de una multitud de aves, de aves preciosas, sus cabezas allí estaban ensartadas y algunas patas de las aves, algunos huesos. Entonces los llamó el diablo, les dijo: “¡Mexicas, allí será esto!” Pero no ven los mexicas quién los llama. Así fue que pusieron a ese lugar el nombre de Tenochtitlan. Entonces lloran los mexicas, dicen: “iHas hecho servicio, has hecho [f. 35v] merecimiento, ya que nos asombramos de lo que será nuestra ciudad! ¡Vámonos a descansar!” En seguida vuelven a Temazcaltitlan [...].

$\$ 51$ [93] En seguida Cuauhtliquetzqui [...] habla a los mexicas, les dijo: “Hijos mios, edifiquemos el juego de pelota, establezcamos modestamente

\$48 HI, p. 89-91 (f. 14v-15r): pueblos / sujetar / ciudad / Tenochtitlan / Tenochtitlan / mandó a convocar / revelar.

$\$ 49$ HI, p. 89; 91 (f. 14v; 15v): entraron por los carriçales y espadañas / tunal / encima del / el aguila... los vido / bajando la cabeça / plumas muy preciadas / plumas... pájaros... açules / plumas verdes.

$\$ 50$ HI, p. 89; 92 (f. 14v; 15v): le pongo por nombre Tenochtitlan / llorar / merecim- / nos... de / nuestra ciudad / descansar. CM, p. 76 (f. 3v): Bueltos... en Temazcaltitlan.

$\$ 51$ CM, p. 76 (f. 3v): Cuauhtloquetzqui / les dixo... Hijos... míos. 
tictlallican tlachcuitectzintli. yhuan totlalmomoz. yn oncā otiquittato yn quauhtli. Aço quenmanian / oncan mocehuiquiuh yn tlamacazqui yn toteouh yn huitzilopochtli. niman oquihtoque in mexica. ca ye qualli ma ticchihuacan niman oquitlallique yn tlachcuitetelli yhuā yn intlalmomoz. yn oncan / oztotenpa yn oncan yhcac yn tenochtli. auh ca ypampa. ca yuh quilhui ca yuh quinahuati yn huitzilopochtli. in yehuatl yn quauhtlequetzqui. [...] ca ynahuatil yn quichihuazque yn Mexica.

\$52[94] Auh ca cenca ycnoyotica netoliniliztica in ye quichibua in ye quitlallia yn ical yn huitzilopochtli. ynic quiquetzque ca çaçan oc tepiton ytoca Ayauhcalli. campa nel quicuizque yn tetl. $\bar{y}$ quahuitl auh ca nel tetlalpan yn cate yn motlallico yn tollitic yn acayhtic. ca yn intlalpā yn tepaneca yn azcapotzalcatl. yhuan ca yntlalpan yn aculhuacatl. ca tequaxochco yn cate yhuan ca ynquaxochco yn culhuaque auh ca ypampa yn cenca motolliniaya.

\$53[95] Auh ca niman ye no ceppa monahuatia yn Mexica. quihtohua. tla xihualhuian mexicaye ma titlatlatlauhtiti. yn tepanohuayan yhuā yn azcapotzalco. Auh niman mochintin. oquihtoque ca amo huel mochihuaz yn ompa titlatlatlauhtitihui ma çan ic tiquinquallaniti [f. 36r] yn tepanohuayan tlaca yhuan yn azcapotzalca $=$.

$\$ 54[101]$ Auh niman ye no ceppa monahuatia yn Mexica ye quitohua ma ticcohuacan yn tetl. yn quahuitl. ma yehuatl yca. yn atlan chaneque yn atlan onoque $\bar{y}$ michin yn axollotl yhuan in cueyatl. yn acocillin. yn anenez yn acohuatl. yn axaxayacatl. yn izcahuitli. yhuan yn canaubtlit yn quachilli = yn yacaçintli. yn ixquich yn totome yn atlan chaneque. ma yehuatl yc ticcohuati. yn tetzintli yn quauhtzintli. niman oquihtoque ma yuhqui

\$51 CC, p. 102; 104 (f. 35v): yn oncā otiquittato yn quauhtli / quenmanian oncan -quiuh yn tlamacazqui yn toteouh yn huitzilopochtli / in mexica / yuh quilhui / quinahuati yn huitzilopochtli / ynahuatil.

$\$ 52$ CC, p. 104 (f. 35v): cenca... netoliniliztica / quichihua / yn ical / yn tollitic yn acayhtic / tepaneca / azcapotzalcat / aculhuacatl / ynquaxochco yn culhuaque auh ca ypampa yn cenca motolliniaya.

$\$ 53$ CC, p. 104 (f. 35v): monahuatia / azcapotzalco / mochintin / ca amo / tiquinquallaniti.

$\$ 54$ CC, p. 106 (f. 37r): quitohua ma ticcohuacan yn tetl. yn quahuitl / yn atlan chaneque / michin / axollotl / cueyatl / acocillin / axaxayacatl / izcahuitli / canauhtli / yn totome.

4 "Canauahtli" en Anderson y Schroeder (CC, p. 106), pero "canauhtli" en el Manuscrito 374, vol. III, f. 37r. 
un pequeño montículo y nuestro altar de tierra a donde fuimos a ver el águila! Quizá algún día querrá venir allí a descansar el tlamacazqui, nuestro dios Huitzilopochtli." Luego hablaron los mexicas: "Está bien, ¡hagámoslo!" Entonces asentaron el montículo y el altar de tierra en la orilla de la cueva, donde se yergue el tunal de piedra. La razón de esto es que Huitzilopochtli asi le dijo, así se lo mandó a Cuauhtliquetzqui [...] y su mandato lo tienen que cumplir los mexicas.

\$52[94] Muy pobremente, con mucho trabajo hacen, asientan la casa de Huitzilopochtli, así que levantaron aunque sea algo pequeño, llamado Ayauhcalli. ¿De dónde por cierto tomarán las piedras, las maderas? Porque en verdad están sobre la tierra de otra gente, vinieron a asentarse en medio de los tules y los carrizos, sobre la tierra de los tepanecas, azcapotzalcas, sobre la tierra de los acolhuaques, estaban en los términos de otra gente, en los términos de los colhuaques. Por esta causa padecian mucho.

$\$ 53[95]$ Entonces una vez se aconsejan los mexicas, dicen: “¡Vamos, mexicas, vamos a rogar a Tepanoayan y a Azcapotzalco!" Pero todos dijeron: "No será bueno hacerlo, ir a rogar allá, con eso sólo vamos a hacer enojar a la gente de Tepanoayan y a los azcapotzalcas."

$\$ 54[101]$ Entonces otra vez los mexicas se aconsejan, ya dicen: “Compremos piedra y madera a cambio de eso, de los animales que viven en el agua, que están en el agua, el pescado, el ajolote y la rana, el camarón lacustre, las larvas de libélulas, la serpiente de agua, las larvas de moscos acuáticos axaxayácatl, el gusano de la laguna izcahuitli, el pato, las fochas cuachilli y yacacintli, todas las aves que viven en el agua! ¡Vayamos a comprar estas cosas, piedritas y maderitas!” Luego dijeron: “¡Así se haga!”

\$51 CM, p. 76 (f. 3v): a donde bimos el águila / algún día querrá benir allí n[uestr]o dios el tlamacazqui Huitzilopochtli / los mexicanos / así, les dixo / le mandó... Huitzilopochtli / mandato del.

$\$ 52$ CM, p. 76 (f. 3v): con mucho trabajo / hizieron / una hermita / çerçado... de carrizo y tulle / tepanecas / Azcapuçalco / aculhuacaques / estando [en] términos de... los de Culhuacan... , que a esta causa padesçían estrema nesçesidad.

$\$ 53$ CM, p. 76 (f. 3v): ordenauan / Azcapuçalco / todos / no / mobelles a yra. $\$ 54$ CM, p. 76 (f. 3v): dixero[n] ... compremos... piedra y madera / en el agua se cría / pescado / axolotes / rranas / camarones / axaxayacatl / yzcahuitle / patos / las aues. 
mochihua. niman ye yc tlatlama quimana quimaci yn michin. yn axolotl. aneneztli. acocillin. in cueyatl. yhuan yn ixquichtin $\bar{y}$ totome yn atlan nemi.

$\$ 55[102]$ Auh niman oyahque yn tlanamacato, yhuan tlacohuato niman ohualmocuepque ohuallaque oquicuito yn tetl yn quahuitl. atle huehuei çan mochi tepitoton. auh yn quahuitl çan no yuhqui. atle tomahuac çan mochi pitzatoton yn quahuitl. niman ye yc quaubtzotzona yn oztotenpa ynic oncan quinelhuayotique yn yehuatl altepetl. yn ical yn iteocal yn huitzilopochtli. Auh in yehuatl in. ca çan mochi tepitoton catca yn ayauhcalli. auh yn onez tetl. yn onez quahuitl. niman ye quipehualtia yn ayauhcalli. oquiquechillique.

\$56[103] Auh niman ye no ceppa yohualtica in ye quitohua ye no ceppa tenahuatia in yehuatl. yn huitzilopochtli. niman quilhui in ye quihtoa. tla xiccaqui quauhtlequetztquihe. [...] Nauhcampa ximotlallicā ximoxellocā. xitlahtocayotican. auh niman oquitlacamatque. nauhcampa [f. 37v] omotlallique yn mexica. auh yn oyah ye naubcan omotlallique (oquilhui yn [quauhtlequetzqui]) ca omochiuh tlamacazque. ynic otinechnahuati. omoxelloque yn motahuan. niman oquihto yn huitzilopochtli. ca ye qualli. Auh xiquinmomamacacan yn ixquichtin yn tiquinhualhuicaque yn amocalpolteovā yn tlacochcalca. yn cihuatecpan. yn huitznahuac yn tlacatecpan. in yopico. yn tezcacohuac. tlamatzinco in molloco itlillan: yn chalmeca. yn tzomolco. yn cohuatlan. yn chillilico. yn izquitla. yn milnahuac. yn cohuatl xoxouhca. ma yxnecican nauhcampa xiquinquixtican yn moyotlan yn axcan ye mitoa San Juan. yn teopan yn axcan ye mitoa San Pablo. yn atzaqualco yn axcan ye mitoa San Sebastian. yhuan cuepopan yn axcan ye mitoa Sancta maria Redonda.

$\$ 57[104]$ auh niman oquihtoque yn Mexica. ca ye qualli. tlamacazque ma yuh mochihua. nimā oquinmomamacaq yn incapolteohuan yn Mexica. auh yn iquac in ye huecauh [...] in ye cate $y n$ tollihtic. in acayhtic. in yehuantin.

$\$ 54$ CC, p. 106 (f. 37r): tlatlama.

$\$ 55$ CC, p. 108 (f. 37r): tetl / quahuitl / tepitoton / pitzatoton yn quahuitl. niman ye yc quauhtzotzona yn oztotenpa / yn ical / yn huitzilopochtli.

$\$ 56$ CC, p. 108 (f. 37r-v): yohualtica / quauhtlequetztqui- / Nauhcampa / ximoxellocā / nauhcampa / nauhcan / otinechnahuati. omoxelloque / oquihto yn huitzilopochtli / xiquinmomamacacan / -calpolteo- / axcan ye mitoa San Juan / San Pablo / San Sebastian / Sancta maria Redonda.

$\$ 57$ CC, p. 108 (f. 37v): -capol- / yn tollihtic. in acayhtic. 
Entonces cazan, capturan, agarran los pescados, los ajolotes, las larvas de libélulas, los camarones lacustres, las ranas y todas las aves que viven en el agua.

$\$ 55[102]$ Luego se fueron a vender y a comprar. Después volvieron, vinieron, fueron trayendo piedra y madera. No era para nada grande, todo era tan sólo pequeño, y la madera también es así, para nada gruesa, toda era tan sólo madera menuda. Luego estacan con madera la orilla de la cueva, por eso allí echaron la raíz de la ciudad, de la casa, del templo de Huitzilopochtli. El adoratorio era tan sólo todo pequeńo. Apareció la piedra, apareció la madera, entonces empiezan el adoratorio, lo levantaron.

\$56[103] Otra vez de noche Huitzilopochtli habla, otra vez manda a la gente, entonces dijo, ya dice: “¡Escucha, Cuaubtliqueztqui! [...] ;En cuatro partes asiéntense, divídanse, dense gobierno!” Entonces le obedecieron, en cuatro parcialidades se asentaron los mexicas, se fue cada uno en uno de los cuatro lugares, se asentaron. Dijo [Cuauhtliquetzqui]: "Se hizo, sustentador, como me mandaste, se han dividido tus padres." Luego habló Huitzilopochtli: "Está bien. ;Repartan todos sus dioses de los barrios (-calpolteo-) que trajimos acá entre los de Tlacochcalco, Cihuatecpan, Huitznáhuac, Tlacatecpan, Yopico, Tezcacóac, Tlamatzinco, Moloco Itlillan, Chalman, Tzonmolco, Coatlan, Chillilico, Izquitlan, Milnáhuac y Coatlxoxouhcan! Que se manifiesten, envíenlos por las cuatro parcialidades, en Moyotlan (que hoy en dia se dice San Juan), en Teopan (que ahora se nombra San Pablo), en Atzacualco (que hoy se llama San Sebastián) y en Cuepopan (que actualmente se denomina Santa María la Redonda)."

\$57[104] Entonces los mexicas dijeron: "Está bien, sustentador, así se haga." Luego los mexicas se repartieron a sus dioses de los barrios. Cuando ya hace mucho tiempo [...] que los antiguos mexicas están en medio de los juncos y de las cañas, en el lugar en el que se yergue el tunal

$\$ 54 \mathrm{CM}$, p. 76 (f. 3v): caçar.

$\$ 55 \mathrm{CM}$, p. 76 (f. 3v): piedra / madera / pequeńos / la madera era menuda... luego estaca-n la boca del ojo de agua / la casa / Huitzilopochtli.

$\$ 56$ CM, p. 76 (f. 3v): de noche / Quauhtloquetztqui / en quatro partes / os dibidáis. HI, p. 93 (f. 16r): en quatro barrios / cuatro lugares / mandoles... repartiesen / habló Vitzilopochtli / se diuidan / Calpolteo-... dios del barrio / hoy en dia... dicen... San Juan / San Pablo / San Sebastian / Santa María la Redonda. $\$ 57$ HI, p. 94 (f. 16r): barrios / entre... carriçales y espadañales. 
yn Mexica. yn huehuetque yn oncan yhcac yn tenochtli. niman ye yc moxellohua. yn Mexica. yn oyuh quittato. yn tollihtic. yn acayhtic. yn oncan ca yn tlatilli. ytoca xaltilolli. niman omoxelloque. [...] yn ompa / oyaque $\bar{y}$ Mexica huehuetque. auh yn axcan tiquitohua tictocayotia. tlatilolco Santiago.

$\$ 58[105]$ Auh in yehuantin yn ompa quitzitzquito yn altepetl. yzca yn intoca ynic ce Atlanquahuitl. ynic ome ytoca huicton. yniquey ytoca opochtli. ynic nahui ytoca Atlahçol. [...] yn ompa yahque xaltilolco. yn ompa motlallito cenca tlahuelliloque catca niman yuh motlallito. in amo tlaca cate tlatilolca cenca moxicohuani. yn axcan ca ye yuhqui yn imixhuihuan yn iuhqui yn iuhqui amo tlaca nemi $[\ldots]$

\$59[97] Auh in yehuantin yn Mexica huehuetque $\bar{y}$ nican yn quitzitzquique yn altepetl. ynic mitohua ynic motenehua yn toltzallan yn acatzallan yn Mexico yn tenochtitlan. yzca yn intoca ynic ce ytoca atl tenoch [...] ynic ome ytoca quauhtli yolqui) yniquey ytoca Acacitli. ynic nahui ytoca tençacatetl. ynic macuilli ytoca Ahuexotl. [f. 36v] Ynic chiquacen ytoca Ocelopan [...] ynic chicome ytoca quauhtliquetzqui [...] ynic chicuey ytoca tzompantzin. ynic chiuhcnahui ytoca yzhuac tlaxquitl. ynic matlactli ytoca Ocomecatzin. ynic matlactlohce ytoca chicopach mani. ynic matlactlomome ytoca Ahatzin. ynic matlactlome ytoca copil [...]

$\$ 60$ [98] auh yn teomamaque yn quitlacayttaya yn iuhqui yn quitlacanotzaya. yn huitzilopochtli. [...] ce tlacatl ytoca quaubtlequetzqui [...]. ynic ome ytoca ococal. ynic yey ytoca chachallayotl. [...] auh in yehuatl ynic nahui yn itoca yn tlamacazqui yn axollohua [...].

\$61[110] Auh yn ihquac in ye huecahua in ye cate yn Mexica [f. 39r] yn Mexica yn tenochca. yn oyuh onmic yn tenochtzin. yhuan in ye

\$57 CC, p. 108 (f. 37v): yn tlatilli. ytoca xaltilolli / omoxelloque / huehuetque / yn axcan / tictocayotia. tlatilolco Santiago.

$\$ 58$ CC, p. 108; 110 (f. 37v-38r): ynic ce Atlanquahuitl. ynic ome ytoca huicton. yniquey ytoca opochtli. ynic nahui ytoca Atlahçol / tlahuelliloque / tlaca.

$\$ 59$ CC, p. 104; 106 (f. 36r-v): huehuetque / intoca / atl tenoch / Acacitli / tençacatetl / Ahuexotl / Ocelopan / Ahatzin.

$\$ 60$ CC, p. 106 (f. 36v): yn quitlacayttaya / qui- notzaya. yn huitzilopochtli / ytoca quauhtlequetzqui / ynic ome ytoca ococal. ynin yey ytoca chachallayotl / ynic nahui / axollohua.

5 "Ynin" en Anderson y Schroeder (CC, p. 106), pero "ynic" en el Manuscrito 374, vol. III, f. 36v. 
de piedra, entonces los mexicas se dividen. Pasado ese tiempo, fueron a ver en medio de los juncos y de las cañas, donde está un montículo que se llamaba Xaltilolli. Entonces se dividieron [...], los viejos mexicas se fueron allá. Ahora a ese lugar le decimos, lo llamamos Santiago Tlatelolco.

$\$ 58[105]$ De aquellos quienes fueron allá a tomar posesión de la ciudad he aquí sus nombres: el primero se llamaba Atlancuábuitl, el segundo Huicton, el tercero Opochtli, el cuarto Atlázol. [...] Fueron allá a Xaltilolco, fueron allá a asentarse los tlatelolcas, quienes eran muy malos. Entonces así se fueron a asentar los tlatelolcas, quienes no son hombres, son muy envidiosos y los que ahora están como sus nietos, asimismo no viven como gente de bien. [...]

$\$ 59[97]$ De aquellos viejos mexicas quienes aquí tomaron posesión de la ciudad que se dice, que se nombra Toltzalan Acatzalan, México Tenochtitlan, he aquí sus nombres: el primero se llamaba Atl Ténoch [...], el segundo Cuáuhtli Yolqui, el tercero Acacitli, el cuarto Tenzacátetl, el quinto Ahuéxotl, el sexto Ocelopan, [...] el séptimo Cuauhtliquetzqui [...], el octavo Tzompantzin, el noveno Ízhuac Tláxquitl, el décimo Ocomecátzin, el décimo primero Chicópach Mani, el décimo segundo Ahátzin y el décimo tercero Cópil [...].

$\$ \mathbf{6 0}[98]$ Los cargadores de los dioses los cuales veian a Huitzilopochtli en persona y así le hablaban personalmente eran: [...] primero el que se llamaba Cuauhtliquetzqui [...], el segundo Ocócal, el tercero Chachaláyotl [...] y el cuarto el tlamacazqui Axolohua [...].

\$61[110] Cuando los mexicas tenochcas ya permanecen, ya están estables después de que murió Tenochtzin y también los tlatelolcas ya están

\$57 HI, p. 94 (f. 16r): una albarrada... se llamaba Xaltelulli / se dividieron / viejos / agora / llamamos Tlatilulco... Santiago.

$\$ 58 \mathrm{HI}$, p. 94 (f. 16r): el uno... se llamaba Atlaquauitl, el segundo Huicto, el tercero Opochtli, el cuarto Atlacol / hombres / malas.

\$59 HI, p. 98-99 (f. 17v-18r): viejos / nombres de / Tenoch / Acaçitli / Teçacatetl / Ahuexotl / Oçelopan / Aatl.

$\$ 60 \mathrm{HI}$, p. 98 (f. 17v): los quales le veian visiblemente / le hablaban... Vitzilopochtli / se llamaua- Cuauhtloquetzqui, el segundo Ococal, el tercero Chachalaitl / el cuarto / Axoloua. 
huecauh cate yn tlatilolca yn ocececni motlallique. niman ye mononotza yn mexica tenochca huehuetque. ye quimolhuia tla xihualhuian in yehuātin in yn tlahueliloque yn otechcaubtiquizque yn omotlallito. yn xaltilolco. ma quenmanian ytla quimoyollotitin ca tlahuelliloque ca amo tlaca yn atlanquahuitl. yn huictō yn opochtli, yn atlaçol. ma ytla toca quitlallitin auh ynin ma xiccemitocan campan tiazque ca tetlalp $\bar{a}$ in ticate ca tequaxochco. ca tetepāco yn iyhyotl. ticmati ca yntlalpan yn tepanecatl yn azcapotzalcatl. yn aculhuacatl. auh yn culhuacan tlaca ca ynquaxchoco yn ticate $\bar{y}$ tlah totlahtocauh tictlallizque. campa yehuatl yn tiazque mexicaye. tenochcaye. Ma xitlahtocan

$\$ 62[111]$ Auh niman oquihtoque in yehuantin yn yzca yn intoca yn acacihtli [...]. yn tençacatetl. in ahuexotl. yn ahatl. [...] Oquihtoque. mexicaye. intla ye ompa tihuian yn azcapotzalco ca amo huel mochihuaz. auh îtla noce ompa tihuian yn acalhuacā anoço Aculhuacan yn cohuatl ychan ca amo huel mochihuaz)

\$63[112] quihtoque yn oc cequintin mexica. auh campa yn amontlatohua campan tiazque) Auh ynin maçompa ma ye ompa tihuian yn culhuacan. yn ompa tiqualcauhque yn opochtli yn yztahuatzin yhuan yn ixquichtin yn totelpochhuan yn tochpochhuā quen cate. quen nemi. yn incah. yn culhuaque [f. 39v] Aço quintollinia. auh ca yuh ticmati yn topampa y nauhxiuhtique yn cocontitlan. yn quintecaq yn quintlallique ynic quintlahtique. yn inmonttahuan yn inmonnanhuan. in yehuātin in culhuaque açoc ceme onnemi. auh ca oticmatque yn omic in yehuatl yn opochtli yn iztahuatzin. yehuatl tiquitztihui yn itechcopa oquiz. yn ipiltzin yn opochtli tequihua auh ca tomexicapiltzin. ca tochichichimecapiltzin. ca yehuatl technequiz. yn quipiez. yn mexicayotl. yn tenochcayotl. Auh ca necoc oyol. otlacat tlacamecayotica. yn culhuaq ca yn ixhuiuh yn teteuhctin yn tlahtoque $=$ auh in tehuantin yn timexica tichichimeca auh ynin ma tihuian Mexicaye.

\$61 CC, p. 112 (f. 38v-39r): mononotza / -cauh- / quimolhuia / ca tlahuelliloque / tetlalpā in ticate / azcapotzalcatl / mexicaye / Ma xitlahtocan.

$\$ 62$ CC, p. 112 (f. 39r): tihuian yn azcapotzalco.

$\$ 63$ CC, p. 112 (f. 39r-v): culhuacan. yn ompa / yn totelpochhuan yn tochpochhuā / nemi / -pil- / necoc / tlacamecayotica / ixhui- / -teuhc-. 
asentados por separado, entonces los ancianos mexicas tenochcas hacen consejo, se dicen: "Vengan, esos malvados han salido dejándonos, se fueron a establecer a Xaltilolco. Que no vayan algunas veces a delatar algo, porque Atlancuáhuitl, Huicton, Opochtli y Atlázol son malos, no son gente de bien, que no vayan a poner alguna cosa en contra de nosotros. Que éstos tomen una decisión acerca de dónde iremos, porque estamos en tierra ajena, en términos ajenos, en fronteras ajenas, conocemos la aflicción porque ésta es la tierra de los tepanecas azcapotzalcas y de los acolhuaques. Estamos en los términos de la gente de Colhuacan, si nosotros hemos de poner nuestro gobernante, ¿adónde iremos, mexicas tenochcas? Hablen."

\$62[111] Entonces hablaron ellos, cuyos nombres aparecen aquí, Acacitli, [...] Tenzacátetl, Ahuéxotl y Áhatl [...], dijeron: "Mexicas, si vamos a Azcapotzalco no saldrán bien las cosas y tampoco si vamos a Acalhuacan o Acolhuacan y Coatlichan saldrán bien las cosas.”

$\$ 63[112]$ Respondieron algunos mexicas: “¿Adónde irán a hablar ustedes, adónde iremos? Tal vez vayamos a Colhuacan, allá venimos a dejar a Opochtli Iztahuatzin y a todos nuestros hijos e hijas. ¿Cómo están, cómo viven en la casa de los colhuaques? ¿Acaso los maltratan? Como sabemos por nuestra culpa estuvieron cuatro años en Cocontitlan, donde los juntaron, los establecieron, los escondieron sus suegros, sus suegras de ellos, los colhuaques. Tal vez algunos de ellos sobreviven. Supimos que murió Opochtli Iztahuatzin, pero vamos a ver a aquél que de él desciende, el hijo querido del capitán Opochtli. Nuestro venerado hijo mexica, nuestro venerado hijo chichimeca nos querrá, cuidará de lo mexica, de lo tenochca, porque vino a la vida, nació del linaje de los unos y de los otros, es nieto de los señores y gobernantes colhuaques y de nosotros que somos mexicas chichimecas. Así que vayamos, mexicas."

\$61 HI, p. 94-95 (f. 16r-v): hicieron junta / dexaron / dixo / ser malos / estamos en sus tierras / Azcaputzalco / mexicanos / Hablad.

$\$ 62 \mathrm{HI}$, p. 95 (f. 16r): fuesen... á Azcaputzalco.

$\$ 63 \mathrm{HI}$, p. 95 (f. 16v): Culhuacan... allí / hijos y hijas / auian vivido / hijo / de los unos y de los otros / de la... casta / nieto- / señor. 
\$64[113] auh niman oyahque yn ompa culhuacan yn Mexica. yn onacique niman ye quilhuia ye quitlatlaubtia yn itoca teuhctlamacazqui. nauhyotl tlahtohuani culhuacan. yn Mexica. quilhuique co tihuallaque tlacatle noxhuiuhtzine tlahtohuanie timitztotlalcahualtilizque. timitztotlapololtilizque. yn timocolhuan yn timotahuan yn timexica tichichimeca) ca tiquicnoytoco yn matzin y motepetzin yn tenochtitlan) ca ticanaco y momacehualtzin catca yn opochtli yn iztahuatzin. yn inecauhca = yehuatl yn piltzintli y conetzintli. yn tocozqui yn toquetzal. yn itoca yn iteheca yn itzpapalotl. (yn acamapich.) auh ca ticmomacahuiliz. ca nel tomexicapiltzin. auh ca toyollo quimati. ca culhuaca yxhuiuhtli. ca yntzon ynizti [f. 40r] ynizti. yn teteuhctin. yn tlahtoque. yn culhuaque. auh ynin ca tiquitohua ma conmopielliqui yn matzin yn motepetzin. yn toltzallan. yn acatzallan yn mexico yn tenochtitlan. auh ynin ma conmochihuilitiuh yn tochpotzin. yn cibuapilli. yn illancueytl.

$\$ 65[114]$ Auh niman quimilhui in yehuatl yn tlahtohuani yn teuhctlamacazqui nauhyotl. oquihto. ma yhui ca ye qualli) oc xicchiyecan tenochcaye. yn tlahtolli. ma oc titononotzacan ma oc nenonotzallo. auh yn onmononotzqueque yn culhuaque. nimā ye quitohua yn teuhctlamacazqui nauhyotl.) ca ye qualli mexicaye. tle niquilhuiz $\bar{y}$ nicā yn culhuacan. auh ca nel amopiltzin amoxhuiuh ma conyauh xichuicacan ca nel oquichtli. yntla cibuatl. amo huel mochihuaz. yn anquihuicazque. auh ynin ma quipacho. yn cuitlapilli yn atlapalli. yn imacehual yn tloque yn nahuaque. yn yohualli yn ehecatl. yn aotzin yn tezcatlipoca. auh ma contlapielli. yn tlamacazqui yn huitzilopochtli. auh cuix oc quihualmati y nochpochtzin. yn cihuapilli. yn atotoztli. yntla oc yxpan acaço quicahualiztlamatizquia. ca nel yconetzin. auh ynin cuix nell oc quihualmati. xicmohuiquillitibuian ca nel ichan)

\$64 CC, p. 112; 114 (f. 39v-40r): oyahque yn ompa culhuacan / quitlatlauhtia yn itoca teuhc- / nauhyotl tlahtohuani culhuacan / tlahtohuanie / timexica / tiquicnoytoco / yn opochtli yn iztahuatzin / inecauhca / pil- / itoca / acamapich / ticmomacahuiliz / quimati / yxhuiuhtli / yn teteuhctin. yn tlahtoque. yn culhuaque / yn toltzallan. yn acatzallan / cihuapilli / illancueytl.

$\$ 65$ CC, p. 114 (f. 40r): teuhc- / oquihto / tle / -xhuiuh / xichuicacan / yntla cihuatl. amo / quipacho / imacehual / yohualli / ehecatl / huitzilopochtli / -chpoch- / atotoztli. yntla oc yxpan / xicmohuiquilli. 
\$64[113] Luego los mexica fueron a Colhuacan y llegados en seguida dicen, piden al sacerdote señor que se llamaba Náuhyotl, gobernante de Colhuacan, los mexicas le dijeron: "Hemos venido, señor, mi nieto querido, gobernante, a molestarte, a perturbarte nosotros quienes somos tus abuelos, quienes somos tus padres, los mexicas chichimecas. Venimos a pedirte humildemente tu agua y tu cerro, [tu poblado] Tenochtitlan. Venimos a tomar a la descendencia del que era tu venerado súbdito Opochtli Iztahuatzin, a aquel hijo y niño querido, nuestra joya y pluma de quetzal, cuyo nombre es Itzpapálotl tercero (Acamápich). Nos lo darás porque en verdad es nuestro hijo mexica. Nuestro corazón sabe que es nieto colhuaca, es cabello y uña [f. 40r] de los señores y gobernantes colhuaques. Nosotros decimos que éste venga a custodiar tu agua, tu cerro [tu poblado] entre las espadañas y carrizales, en México Tenochtitlan. Y que ésta venga a hacerse nuestra hija querida, la señora Ilancuéitl."

\$65[114] Luego habló él, el gobernante y sacerdote señor Náuhyotl, respondió: "Así sea, está bien, pero aún esperen la palabra, tenochcas, aún tenemos que consultarnos, aún va haber consejo." Los colhuaques fueron a consultarse y después habla el sacerdote señor Náuhyotl: "De acuerdo, mexicas, ¿qué tengo que decir aquí en Colhuacan? Es cierto que es vuestro hijo querido, es vuestro nieto, que se vaya, llévenselo ya que es hombre. Si fuera mujer, no sería posible que ustedes se lo llevaran. Que éste gobierne la cola, las alas [el pueblo], que sea el servidor del dueño de lo que está junto y de lo que está cerca, de la noche y del viento, de Yaotzin Tezcatlipoca. Que vaya a ser guardián del dador de la vida Huitzilopochtli. ¿Aún vendrá a visitar a mi querida hija, a la noble mujer Atotoztli, si aún estuviera frente a él, no hubiera querido concederlo, porque por cierto es su hijo querido? ¿Sí vendrá éste todavía a visitarla? ¡Vayan a llevárselo!, porque en verdad es su casa."

\$64 HI, p. 95-96 (f. 16v-17r): fueron... á Culhuacan / pedir... el qual se llamaua... señor / Nauhyotl... rey de Culhuacan / Seńor / nosotros... los mexicanos / suplicámoste / Opochiztauatzin / lignia / hijo / por nombre / Acamapich / nos lo des / sabiendo / nieto / de los reyes y seńores de Culhuacan / entre las espadańas y carriçales / señora / Ilancueitl.

$\$ 65$ HI, p. 96 (f. 16v-17r): Señor / respondió / ¿qué? / nieto / llevadlo / si fuera mujer... no / gobierne / sirva / noche / viento / Vitzilopochtli / hija / Atotoztli... si... fuera / llevadle. 
$\$ 66[115]$ niman quitoq ${ }^{-}$nn mexica. ca ye qualli. oticmocnellili yn matzī yn motepetzin. ma ticuicatihuian, niman quihtoque yn culhuaque camo nican nemi. ma ompa xicmanilliti. yn ompa cohuatl ichan yn itoca acamapich. auh yc niman ompa yahque in mexica yn cohuatl ichan

\$67[116] Auh yn onacito. niman ye quinonotza. yn aculmiztli. ye quilhuia ca ticanaco. yn acamapich. niman quimilhui. ac amehuantin [f. 40v] campa ohuahuallaque conilhuique ca ompa tenochtitlan quihto ca ye qualli ma oc [...] xicmohuiquillitihuian ma quihuica yn inantzin illancueytl. yc nimā ye quihuicatze yn mexica yn acamapich. ycihuauh valmochiuhtia yn illancueytl.

\$68[117] Auh niman quihualhuicaque. caxitico yn Mexico = yn tenochtitlan. yc motlallico ynpetlapan. yn icpalpan ynehuan yn icihuauh yn itoca illancueytl [...]. auh yn oconaxitico yn tenochtitlan. yn tlahtohuani. yn oteanato mexica. niman ye quimonilhuia yn oc cequitin Mexica tenochca quimilhuique tocnihuane. ca otoconaxitico yn tlahtohuani ez. quimonnanquillique quimilhuique ca ye qualli. oquimihiyohuilti. auh tle ytoca quinhualilhuique quil mach acamapich. auh quih ${ }^{\text {to }}$ que ca ye qualli $=$ Auh yn ocontlallique tlahtohuani)

\$69[118] Auh yn Mexica, nima ye quitlatlauhtia yn tlacatl. quilhuia = noxhuiuhtzine tlahtohuanie / oticmihiyohuilti oticmociyahuilti. otimaxitico yn mochantzinco. yn toltzallan. yn acatzallan. auh motollinia yn mocolhuan yn motlahuan yn mexica yn chichimeca. Auh ca tocontlapielliz. yn tlamacazqui yn tetzahuitl yn huitzilopochtli. auh yhuan ca yuh quimati yn moyollotzin. yn tequaxochco. yn tepepanco yn amo totlalpan yn ticate. auh ca ticiahuiz. ca tiquihiyohuiz. ca titequitiz. ca titlacotiz. ca yci. yn tlalhuacpā yn azcapotzalco.

$\$ 66$ CC, p. 114 (f. 40r): yn mexica.

$\$ 68$ CC, p. 114; 116 (f. 40v): quihualhuicaque / icpalpan ynehuan / oconaxitico / yn tlahtohuani. yn oteanato mexica / ocontlallique.

$\$ 69$ CC, p. 116 (f. 40v): quilhuia / tlahtohuanie / otimaxitico yn mochantzinco. yn toltzallan. yn acatzallan / motollinia / mocolhuan / yn mexica / tocontlapielliz / huitzilopochtli / quimati / tequaxochco / amo totlalpan yn ticate / ca titequitiz. ca titlacotiz. 
\$66[115] Entonces los mexicas dijeron: "Muy bien, nos hiciste merced de tu agua, de tu cerro [de tu poblado]. ¡Vayamos a llevárnoslo!" Luego los colhuaques dijeron: "No vive aquí. ¡Vayan a tomar al que se llama Acamápich allá en Coatlichan!” Así que los mexicas fueron allá a Coatlichan.

\$67[116] Llegados allá, hablan con Acolmiztli, le dicen: "Venimos a tomar a Acamápich." Entonces les preguntó: “¿Quiénes son ustedes? ¿De dónde han venido?" Le contestaron: "De Tenochtitlan." Él dijo: "Está bien, [...] también váyanse llevando, llévense a su madre Ilancuéitl." Así que los mexicas trajeron a Acamápich y a la que viene haciéndose su mujer, Ilancuéitl.

\$68[117] Entonces lo trajeron, lo vinieron a llevar a México Tenochtitlan para que viniera a sentarse en el petate, en el asiento junto con su mujer llamada Ilancuéitl [...]. Los mexicas fueron a llevar a Tenochtitlan al gobernante, fueron a recibir a la gente y luego algunos otros mexicas tenochcas les van diciendo, les dijeron: "Amigos nuestros, nosotros hemos venido a traer al que será gobernante." Les respondieron, les dijeron: "Muy bien, los ha cansado. ¿Cuál es su nombre?” Les contestaron: "Le dicen Acamápich." Dijeron: "Está bien” y fueron a sentar al gobernante.

\$69[118] Los mexicas entonces ruegan al hombre, le dicen: "Nieto mío, gobernante, te has cansado, te has fatigado y has llegado a tu casa honrada, entre las espadañas y los carrizos. Tus abuelos, tus tíos, los mexicas chichimecas son pobres. Vas a tener que custodiar al que nos da la vida, al prodigio Huitzilopochtli. Así que sabe tu venerable corazón que estamos en términos ajenos, en fronteras ajenas, no estamos en nuestra tierra. Padecerás, sufrirás, trabajarás, serás esclavo, porque este lugar es una isla de Azcapotzalco.”

$\$ 66$ HI, p. 96 (f. 16v-17r): los mexicanos.

$\$ 68$ HI, p. 96 (f. 17r): trayéndolo / asentaderos juntos / lo llevaron / saliendo toda la nacion mexicana... á recibir á su rey / sentándolo.

\$69 HI, p. $96-97$ (f. 17r): diciendo / rey / llegado á esta vuestra casa...entre estos carriçales y espadañas / pobres / vuestros... aguelos / los mexicanos / venis á ser amparo / Vitzilopochtli / sabeis / en tierra agena / no estamos en nuestra tierra / venis... á trabajar y á ser esclavos. 


\section{TEXTO GLOSADO}

[f. 20r]

1. tlatol-peuhcayo-tl

relato-inicio-ABS

Inicio del relato

$\$ 1[8]$

2. Yzcatqui Nican om-pehua yn chronica Mexica-yotl. He.aquí aquí DIR-comenzar DET crónica mexica-ABs.TR He aqui que aqui va a comenzar la crónica mexicana.

3. yn oncan qu-itauhca-teneuh-t-oc yn in-temoca DET allí 0.3.sG-gloria-declarar-LIG-estar DET Pos.3.PL-descendencia yn in-tlacatiliz. yn huel yehuatl yn in-tzintiliz DET Pos.3.PL-nacimiento DET mismo aquello DET pos.3.PL-origen

i-pehualiz yhuan yn in-huallaliz yn im-ecoliz. in yehuantin. pos.3.PL-principio y DET POS.3.PL-venida DET POS.3.PL-llegada DET ellos

y nican i-pan in nueua españa mo-tenehua DET aquí PRoN.3.sG-LoC DET Nueva España REF.2.sG-llamar Alli está declarada gloriosamente su descendencia, su nacimiento, aquello mismo, su origen, su principio y su venida, su llegada de ellos aquí, en la que se llama Nueva España.

4. o-mo-teca-co yhuan o-qui-macehua-co y mochi yn ixquich PAS-REF.3.PL-juntar-DIR y PAS-0.3.SG-merecer-DIR DET todo DET entero Vinieron a juntarse y vinieron a merecerla toda entera,

5. yc huey. yehuatl. auh yhuan ynic o-tzinti-c ynic o-peuh por.eso grande él y también poreso PAs-fundar-PAS poreso pas-comenzar por eso ella es grande, y también por eso se fundó, por eso comenzó,

6. ynic o-nelhuayohua-c in huey altepe-tl yn Mexico tenochtitlan. poreso PAS-arraigarse-PAS DET gran ciudad-ABS DET México Tenochtitlan por eso se arraigó la gran ciudad de México Tenochtitlan. 
7. ca yn in-toca. Mexitin chichimeca aztlan tlaca chicomoztoca. PARTI DET POS.3.PL-nombre mexitin chichimecas Aztlán gente chicomoztocas Sus nombres son mexitin, chichimecas, gente de Aztlán, chicomoztocas.

8. auh yn iquac yn i-pā cahui-tl amo huel mo-lnamiqui PARTI DET cuándo DET PRON.3.SG-LOC tiempo-ABS no vaUX REF.2.SG-recordar

yn iquin quehma

DET cuándo en.quémomento

Cuándo, en qué tiempo no se puede recordar, cuándo, en qué momento. ${ }^{1}$

$\$ 2[13]$

$\begin{array}{lllllll}\text { 9. Capitulo } & \text { achto } & \text { oncan } & \text { m-itohua } & \text { yn } & \text { in-huallaliz } & \text { yn } \\ \text { Capítulo } & \text { primero } & \text { en.el.que } & \text { REF.3.sG-hablar } & \text { DET } & \text { POs.3.PL-venida } & \text { DET }\end{array}$ im-ecoliz in yehuantin Mexica pos.3.PL-llegada DET ellos mexicas

Capitulo primero, en el que se habla de su venida, de su llegada de ellos, los mexicas,

10. in nicā $y$-pan yancuic nueua españa.

DET aquí PRON.3.SG-LOC nuevo Nueva Espańa

yhuan yn ixquich tlaca-tl yn o-qui-hual-huica-qu-e calpol-e-que. y DET todo persona-ABS DET PAS-O.3.SG-DIR-traer-PAS-PL barrio-PosE-PL aqui a la nueva Nueva España, y de todas las personas que habian traído los dueños de los barrios,

1 Traduzco "yn iquin quehma" como si fuera un difrasismo, "in iquin in queman" (cuándo, en qué momento); asimismo lo traduce Adrián León (Tezozómoc, 1998: 11). Arthur J. O. Anderson y Susan Schroeder (Chimalpahin Quauhtlehuanitzin, 1997: I, 65) no traducen la expresión, interpretándola como una repetición de "yn iquac yn ipā cahuitl." Riese (2004: 45) entiende "quehma" como el verbo "mati” o el adverbio "sí", pero prefiere no traducirlo porque no le encuentra sentido. Tena (Chimalpáhin, 2012: 32-33) trascribe la palabra "quehma" como "quenma" (algunas veces), pero traduce la expresión "in iquin quenma" simplemente con el adverbio "cómo". 
$\begin{array}{ccllll}\begin{array}{c}\text { 11. yhuan } \\ \text { y }\end{array} & \text { yn } & \text { quenin } & \text { qui-hual-huica-c } & \text { y-tlan } & \text { hualla } \\ \text { DET } & \text { cómo } & \text { o.3.SG-DIR-traer-PAS } & \text { PRON.3.SG-LOC } & \text { vino }\end{array}$ in yehuatl yn çan tlapic teu-tl huitzilopochtli. DET él DET sólo falso dios-ABs Huitzilopochtli y de cómo los trajo consigo, vino él, el falsísimo dios Huitzilopochtli

12. yn ihueltiuh huitzilopochtli y-toca Malinalxoch DET POs.3.sG-hermana.mayor Huitzilopochtli Pos.3.sG-nombre Malinálxoch y su hermana de Huitzilopochtli, llamada Malinálxoch.

$\$ 3[35]$

13. Auh ca cenca nohuian Nen-qu-e yn mexica PARTI PARTI mucho por.todas.partes andar-PAS-PL DET mexicas

yn chichimeca-tlal-pan

DET chichimeca-tierra-LOC

Por muchas partes anduvieron los mexicas en la tierra de los chichimecas.

14. yn cana qual-can huecahua-ya cen-pohual-xiuhtia.

DET en.algunas.partes bueno-LOC permanecer-IMPE uno-veinte-trascurrir.años

yn mo-tlallia yn tla-huel-mati.

DET REF.3.SG-asentar DET OINDI-bien-parecer

En algunas partes, en un lugar bueno permanecian, trascurren veinte años, en los que se asientan, en los que les parece bien,

15. yn cana caxtol-li xihui-tl yn mo-tlallia.

DET en.algunas.partes quince-ABS año-ABS DET REF.3.SG-establecer

yn cana matlac-xiuhtia

DET en.algunas.partes diez-trascurrir.años

en algunas partes se establecen quince años, en algunas partes trascurren diez años, en algunas partes trascurren cinco años,

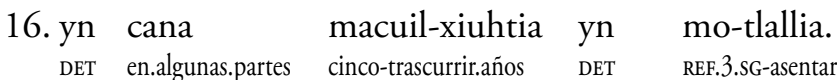

$\bar{y}$ cana nauh-xihui-tl ye-xihui-tl. yn mo-tlallia.

DET en.algunas.partes cuatro-año-ABS tres-ańo-ABS DET REF.3.SG-asentar

en los que se asientan, en algunas partes cuatro años, tres años en los que se asientan, 
17. yn cana on-xiuhtia. yn cana ce-xiuhtia yn mo-tlallia DET en.algunas.partes dos-trascurrir.años DET en.algunas.partes uno-trascurriraños DET REF.3.PL-asentar en algunas partes trascurren dos años, en algunas partes trascurren un año en el que se asientan,

18. yn amo tlahuelmati. yn cana cem-pohual-ilhui-tl DET no gustar DET en.algunas.partes uno-veinte-día-ABS

om-pohual-ilhui-tl yn mo-tlallia dos-veinte-día-ABS DET REF.3.SG-asentar en el que no les parece bien, en algunas partes se asientan veinte dias, cuarenta dias

19. Auh ca nohuian qui-hual-toca-t-ia-qu-e yn tlal-li. PARTI PARTI por.todas.partes o.3.SG-DIR-sembrar-LIG-ir-PAS-PL DET tierra-ABS Por todas partes vinieron sembrando la tierra,

20. auh yn qui-hual-qua-t-ia-qu-e. yn in-tech mo-nequi-a. PARTI DET O.3.SG-DIR-comer-LIG-ir-PAS-PL DET PRON.3.PL-de REF.3.sG-hacer.falta-IMPE vinieron comiendo lo que a ellos les hacia falta,

21. naca-tl yn tonacayo-tl. yhuā yn e-tl. huauh-tli. carne-ABS DET comida-ABS y DET frijol-ABS amaranto-ABS

chian yhuan chil-li. xitoma-tl. chía y chile-ABS jitomate-ABS

carne era la comida y frijol, amaranto, chia, chile y jitomate.

\section{$\$ 4[36]$}

22. auh y cana cenca huecahua-ya, Mo-teocaltia-ya. PARTI DET en.algunas.partes mucho permanecer-IMPE REF.3.PL-hacer.un.templo-IMPE En algunas partes en las que permanecian mucho tiempo, hacian sus templos.

23. oncan qui-quetz-qu-e yn i-cal yn in-teo-uh Ahí 0.3.SG-levantar-PAS-PL DET POS.3.sG-casa DET POs.3.PL-dios-pos

yn huitzilopochtli.

DET Huitzilopochtli

Ahi levantaron la casa de su dios Huitzilopochtli 
24. auh ca oc no cequin-tin. yn quin-hual-huica-c yn in-teo-huan PARTI PARTI aún también alguno-PL DET 0.3.PL-DIR-traer-PAS DET POS.3.PL-dios-PL y también de algunos otros de sus dioses que trajeron,

25. ynic m-itohua yn chicome calpol-li yn Mexica in hualla-qu-e por.eso REF.3.PL-mencionar DET siete barrio-ABS DET mexicas DET venir-PAS-PL por eso se mencionan los siete barrios de los mexicas que vinieron.

26. Auh ynic ce calpol-li yopica. ynic ome calpol-li tlacochcalca. PARTI ORD uno barrio-ABS yopicas ORD dos barrio-ABS tlacochcalcas El primer barrio era de los yopicas, el segundo de los tlacochcalcas,

27. ynic yey calpol-li. huitznahuac. ynic nahui calpol-li cihuatecpaneca. ORD tres barrio-ABS Huitznáhuac ORD cuatro barrio-ABS cihuatecpanecas el tercer barrio era de Huitznábuac, el cuarto barrio de los cibuatecpanecas,

28. ynic macuilli calpolli chalmeca. ynic chicuacen calpol-li ORD cinco barrio-ABS chalmecas ORD seis barrio-ABS

tlacatecpaneca. ynic chicome calpol-li yzquiteca. tlacatecpanecas ORD siete barrio-ABs izquitecas el quinto barrio de los chalmecas, el sexto barrio de los tlacatecpanecas y el séptimo barrio de los izquitecas.

$\$ 5[37]$

29. Auh ye o-m-ito ca cēca nohuian hual-nen-t-ia-q-'. PARTI ya PAS-REF.3.sG-dijo que mucho por.todas.partes DIR-vagar-LIG-ir-PAS-PL

yn chichimeca-tlal-pan

DET chichimeca-tierra-LOC

Ya se dijo que por muchas partes vinieron a vagar en la tierra de los chichimecas,
30. yn cana
qui-hual-cauh-t-ia-qu-e
toc-tli
miahuati.
DET en.algunas.partes
o.3.sG-DIR-dejar-LIG-ir-PAs-PL
maíz-ABS echar.espigas
en algunas partes vinieron dejando el maiz echando espigas, 
31. yn cana qui-hual-cauh-t-ehua-qu-e.

DET en.algunas.partes o.3.SG-DIR-dejar-LIG-partir-PAS-PL

xilloti helloti. coçahuia.

estar.jloteando estar.la.mazorca.madura hacerse.amarillo

en alguna otra parte partieron dejándolo en flor, en mazorcas tiernas, en mazorcas maduras, haciéndose amarillo.

32. auh yn cana oc qui-pixca. qui-hual-qua-t-ehua

PARTI DET en.alguna.parte aún o.3.sG-cosechar o.3.sG-DIR-comer-LIG-partir

yn tonaca-yotl.

DET sustento-ABSTR

En alguna parte aún lo cosechan, vienen a partir comiendo el sustento.

33. auh ca cenca. miyec tlaman-tli. yn qui-chiuh-qu-e PARTI PARTI mucho muy cosa-ABS DET o.3.SG-hacer-PAS-PL

yn otli-pā ynic hualla-qu-e.

DET camino-LOC en.el.que venir-PAs-PL

Muchísimas cosas hicieron en el camino por el que vinieron.

34. nohuian nen-qu-e in culhuacan yn hueca culhuacan. Por.muchas.partes andar-PAS-PL DET Colhuacan DET lejos Colhuacan Por muchas partes anduvieron, por Colhuacan, por el lejano Colhuacan.

$\begin{array}{clllll}\text { 35. Yhuan } & \text { yn } & \text { tona } & \text { y-ehua-can } & \text { anoço } & \text { tonallan } \\ \text { PARTI } & \text { DET } & \text { hacer.calor } & \text { pos.3.sG-levantar-LOC } & 0 & \text { Tonallan }\end{array}$

ca cenca moch ic nen-qu-e.

PARTI mucho todo PARTI andar-PAS-PL

En el lugar donde se levanta el calor, o Tonallan, mucho por todo anduvieron.

36. auh ca yn-cotonca-huan yn michhuaque. $\bar{y}$ mexica. PARTI PARTI POS.3.PL-pariente-PL DET michhuaques DET mexicas

Yhuan yn Malinalca. también DET malinalcas Los michhuaques eran parientes de los mexicas y también los malinalcas. 
37. auh ca mochi-ntin hualla-qu-e. auh ynic quin-cauh-qu-e. PARTI PARTI todo-PL venir-PAS-PL PARTI por.eso o.3.PL-dejar-PAS-PL

yn michhuaque

DET michhuaques

Todos juntos vinieron. Por eso dejaron a los michhuaques,

38. a-tlan mahuiltia-ya yn oquich-tin. yhuan yn cihua. agua-LOC jugar-IMPE DET todo-PL $\quad y$ DET mujeres

yn oncan bazquallo. y-toca-yo-can.

DET allí Pátzcuaro POs.3.sG-nombre-ABSTR-LOC

en el agua jugaban los hombres y las mujeres, alli en el lugar nombrado Pátzcuaro.

39. auh quin-hual-cui-li-t-ehua-qu-e yn yn-tilma yn in-maxtli. PARTI O.3.PL-DIR-tomar-APL-LIG-partir-PAS-PL DET POS.3.PL-tilma DET POS.3.sG-taparrabo Partieron tomándoles sus tilmas y sus taparrabos,

40. yn cihua yn in-cue yn in-huipil. quin-cui-lli-qu-e. DET mujeres DET POs.3.SG-falda DET POs.3.PL-huipil o.3.PL-tomar-APL-PAS-PL les tomaron las faldas y los huipiles a las mujeres.

41. Auh yn oquich-tin aocmo maxtl-e-que. PARTI DET todo-PL ya.no taparrabo-POSE-PL

ça tzintlapan-ti-nemi-a. sólo tener.el.trasero.descubierto-LIG-andar-IMPE

Los hombres ya no tuvieron taparrabo, sólo andaban con el trasero descubierto

42. anoço ça tzintlapā-ti-nemi maxauh-ti-nemi.

o sólo tener.el.trasero.descubierto-LIG-andar tener.la.entrepierna.descubierta-LIG-andar o sólo andan con el trasero descubierto, con la entrepierna descubierta,

43. auh yn cihua ça yn-cicuil y c-om-ana. PARTI DET mujeres sólo POS.3.SG-cuicuilli DET o.3.sG-DIR-ponerse y las mujeres sólo se ponen el cicuilli. 
44. auh yn oquich-tin. yc huipil-e-que o-mo-chiuh-qu-e. PARTI DET hombre-PL por.eso huipil-posE-PL PAS-REF.3.PL-PAs-PL o yhui $\bar{y}$. yn quin-cauh-qu-e michhuaque PARTI así DET DET O.3.PL-dejar-PAS-PL michhuaques Los hombres por eso se pusieron huipiles. Asi fue como dejaron a los michhuaques.

$\$ 6[38]$

45. Auh in yehuatl yn i-toca yn Malinalxoch PARTI DET ella DET pos.3.sG-nombre DET Malinálxoch

yn i-huelti-uh yn huitzilopochtli.

DET Pos.3.sG-hermana.mayor-pos DET Huitzilopochtli

A ella, a la llamada Malinálxoch, hermana mayor de Huitzilopochtli,

46. ynic qui-cauh yn otli-pan mochi-tin yn i-ta-huan por.eso 0.3.sG-dejó DET camino-LOC todo-PL DET POs.3.SG-padre-PL

ca qui-coch-cauh-qu-e

PARTI 0.3. SG-dormir-dejar-PAS-PL

por eso la dejó en el camino, todos sus padres la dejaron dormida,

47. ypampa amo tlaca-tl cèca tlahuelilo-ca-yotl

porque no humano-ABS mucho malo-PART-ABSTR

yn qui-mo-tequiuhtia te-yollo-qua-ni

DET O.3.sG-REF.3.SG-ocupar OINDA-corazón-comer-AG

porque no es humana, se ocupa de grandes maldades, es comedora de corazones bumanos,

48. te-cotz-ana-ni te-yx-cuepa-ni. te-otl-axilia-ni.

oINDA-pantorilla-coger-AG OINDA-cara-torcer-AG OINDA-camino-desviar-AG

cogedora de pantorrillas, torcedora de caras, desviadora del camino de la gente,

49. te-coch-mama-ni te-cohua-qua-ltia-ni. Te-colo-qua-ltia-ni.

OINDA-dormir-cargar-AG OINDA-serpiente-comer-CAUS-AG OINDA-alacrán-comer-CAUS-AG cargadora de gente dormida, ofrecedora de comida hecha de serpientes, hecha de alacranes. 
50. ca mochi qui-notza yn petlaçolcohua-tl. yn toca-tl. PARTI todo o.3.sG-llamar DET ciempiés-ABS DET araña-ABS

yhuan tlahuipoch-in mo-cuepa

y bruja-ABs o.3.sG-volver

Invoca todos los ciempiés, las arañas y se vuelve bruja,

51. ca cenca huey tlahuellilo-c. auh ca yehuatl ynic amo

es mucho grande perverso-PART PARTI es ella por.eso no

c-ō-nec yn huitzillopochtli.

o.3.sG-DIR-quiso DET Huitzilopochtli

es una grandísima perversa. Asi es ella, por eso no la quiso Huitzilopochtli,

52. ynic amo qui-hual-huica-c yn i-Veltiuh.

poreso no o.3.SG-DIR-traer-PAS DET POS.3.sG-hermana.mayor

yn i-toca mallinalxoch.

DET POs.3.sG-nombre Malináxoch

por eso no vino a traer a su hermana mayor, la llamada Malinálxoch,

53. yn mochi-ntin yn i-ta-huā yn çan quin-coch-cauh-qu-e. DET todo-PL DET POs.3.sG-padre-PL DET sólo 0.3.PL-dormir-dejar-PAS-PL a todos sus padres tan sólo los dejaron dormidos.

\$7[39]

54. auh niman o-qu-ihto yn tlamacazqui, PARTI luego PAS-O.3.SG-decir DET tlamacazqui

yn huitzilopochtli. auh quim-ilhuia yn i-ta-huā DET Huitzilopochtli PARTI 0.3.PL-decir DET POs.3.sG-padre-PL Luego dijo el tlamacazqui Huitzilopochtli, les dice a sus padres,

55. yn mo-tenehua yn teo-mama-qu-e. ye cuel yehuātin DET REF.3.PL-llamar DET dios-cargar-PART-PL ya en.breve ellos yn i-toca quauhtlequetzqui

DET POs.3.SG-nombre Cuauhtliquetzqui

a los que se llaman cargadores de los dioses, en seguida a ellos, al llamado Cuauhtliquetzqui, 
56. ynic ome y-toca Axollohua tlamacazqui ynic yei ORD dos POs.3.sG-nombre Axolohua tlamacazqui ORD tres y-toca quauhcohuatl. POs.3.sG-nombre Cuauhcóatl al segundo llamado Axolohua tlamacazqui, al tercero llamado Cuauhcóatl

57. ynic nahui y-toca ococaltzin. auh o-quim-ilhui ORD cuatro POs.3.sG-nombre Ococaltzin PARTI PAS-0.3.PL-decir

no-ta-huan-e ca amo no-tequi-uh Pos.1.sG-padre-PL-voc no Pos.1.sG-oficio-Pos y al cuarto llamado Ococaltzin. Les dijo: "Padres míos, no es mi oficio

58. yn qui-mo-tequiuhtia yn malinalxoch. yn ompa ynic o-ni-quiça-co DET 0.3.sG-REF.3.sG-ejercer DET Malinálxoch DET allá por.eso PAS-s.1.SG-salir-DIR el que ejerce Malinálxoch. De allá por eso vine a salir,

59. ynic o-ni-huall-ihua-lo-c ca mi-tl. ca chimal-li. yn o-ni-ma-co-c. por.eso PAS-S.1.SG-DIR-partir-PASI-PAS es flecha-ABS es escudo-ABS DET PAS-S.1.SG-dar-PASI-PAS por eso fui enviado, es flecha, es escudo lo que se me dio,

60. ca yaoyo-tl y no-tequi-uh. auh ca n-elchiqui-uh ca no-tzonteco es guerra-ABS DET POS.1.SG-oficio-POS PARTI es POS.1.sG-pecho-POS es POs.1.sG-cabeza es guerra mi oficio. Es mi pecho, es mi cabeza,

61. ynic ni-qu-itta-z. y nohuian yn altepe-tl. con.eso s.1.sG-0.3.sG-ver-FUT DET por.todas.partes DET pueblo-ABS

auh ca ni-te-chia-z

PARTI PARTI s.1.sG-OINDA-esperar-FUT

con eso veré por todas partes y pueblos, esperaré a la gente,

62. ca ni-te-namiqui-z. yn nauh-campa ca ni-te-atli-ti-z. PARTI s.1.SG-OINDA-encontrar-FUT DET cuatro-rumbo PARTI s.1.sG-OINDA-beber-CAUS-FUT ca ni-te-tlamaca-z. PARTI s.1.SG-OINDA-dar.de.comer-FUT encontraré a la gente de los cuatro rumbos, daré de beber a la gente, daré de comer a la gente. 


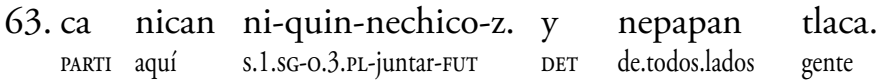

Auh ca amo çā nen.

PARTI es no sólo vano

Aqui juntaré la gente de todos lados. $Y$ eso no es en vano.

64. ca ni-quin-pehua-z. ynic ni-qu-itta-z. yn chalchiuh-cal-li. PARTI s.1.sG-0.3.PL-conquistar-FUT por.eso s.1.sG-0.3.sG-ver-FUT DET chalchihuite-casa-ABS

yn teocuitla-cal-li. yn quetzal-cal-li. yn quetzalitz-cal-li.

DET oro-casa-ABS DET quetzal-casa-ABS DET esmeralda-casa-ABS

Los conquistaré, por eso veré la casa de chalchihuite, la casa de oro, la casa de pluma de quetzal, la casa de esmeralda,

65. yn tapach-cal-li. yn tlapal-tehuillo-cal-li. y nepapan yhui-tl. DET coral-casa-ABS DET color-cristal-casa-ABS DET multitud.de pluma-ABS la casa de coral, la casa de cristal colorado, la multitud de plumas,

66. yn xiuhtoto-tl. yn tlauhquechol. yn tzinitzca. DET contiga.azul-ABS DET espátula.rosada DET trogon.mexicano el cotinga azul, el espátula rosada, el trogon mexicano,

67. yn ye yxquich yn tlaço-ihui-tl auh yn tlapapal-cacahua-tl. DET ya todo DET precioso-pluma-ABS PARTI DET vario.color-cacao-ABS

yn tlapapal-ychca-tl DET vario.color-algodón-ABS todas las plumas preciosas, el cacao multicolor, el algodón multicolor,

68. ca mochi ni-qu-itta-z. ca nel no-tequi-uh ca yc PARTI todo s.1.sG-0.3.SG-ver-Fut es en.verdad POs.1.sG-tarea-POs porque por.eso o-ni-huall-ihua-lo-c. PAS-S.1.SG-DIR-partir-PASI-PAS todo lo veré, en verdad es mi tarea, porque por eso fui enviado. 
69. auh ynin no-ta-huan-e xi-m-itacati-can ma PARTI esto POs.1.sG-padre-PL-VOC IMP-REF.2.PL-proveer.de.provisiones-PL OPT

ti-hui-an ca nechca yn ti-tlamati-hui.

s.1.PL-ir-PL PARTI allá DET s.1.PL-hacer.prisionero-ir

¡Por esto, padres míos, provéanse de provisiones, vayamos allá donde iremos a hacer prisioneros!"

70. auh niman ho-hualla-qu-e yn oncan yn y-toca-yo-can

PARTI luego PAS-venir-PAS-PL DET allí DET POs.3.SG-nombre-ABSTR-LOC

yn ocopipillah.

DET Ocopipilla

Luego vinieron alli en el lugar que se llama Ocopipilla.

71. nimā huall-ehua-qu-e. oncan mo-tlalli-co yn i-toca-yo-can luego DIR-partir-PAS-PL allí REF.3.PL-asentar-DIR DET POS.3.sG-nombre-ABSTR-LOC

Acahualtzinco.

Acahualtzinco

Luego vinieron a partir, vinieron a asentarse alli en el lugar llamado Acahualtzinco.

72. oncan huecahua-qu-e oncan yn xiuh-mo-lpi-lli chiuhcnahui allí permanecer-PAS-PL allí DET año-REF.3.PL-atar-APL nueve

aca-tl yn in-xiuh-tlapohual yn huehue-tque.

cańa-ABS DET POS.3.PL-año-cuenta DET anciano-PL

Alli permanecieron, alli ataron los años en nueve caña, la cuenta anual de los ancianos.

73. ye o-m-ito yhuan oncan quiz-qu-e oncan mo-tlalli-qu-e

ya PAS-REF.3.SG-decir y allí salir-PAS-PL allí REF.3.SG-establecer-PAS-PL

yn ocopipilla yhuan yn i-toca-yo-can Acahualtzinco.

DET Ocopipilla y DET POs.3.sG-nombre-ABSTR-LOC Acahualtzinco

Ya se dijo que alli salieron, que alli se establecieron en Ocopipilla y Acahualtzinco. 
74. auh niman yc aci-co yn oncan cohuatepec yn ihuicpa PARTI después de.eso llegar-DIR DET allí Coatépec DET cerca

yn tullam

DET Tollan

Después de eso vinieron a llegar alli en Coatépec, cerca de Tollan.

$\$ 8[40]$

75. Capitulo ynic ome oncan m-itohua in yehuatl Capítulo ORD dos en.el.cual REF.3.sG-tratar DET ella $\begin{array}{llll}\text { yn } & \text { i-huelti-uh } & \text { yn } & \text { huitzilopochtli } \\ \text { DET } & \text { POs.3.sG-hermana.mayor-pos } & \text { DET } & \text { Huitzilopochtli }\end{array}$

yn i-toca Malinalxoch

DET POs.3.sG-nombre Malinálxoch

Capitulo segundo, en el cual se trata de ella, de la hermana de Huitzilopochtli, llamada Malinálxoch,

76. yn iquac qui-coch-cauh-qu-e yn o-qu-icxicauh-qu-e DET cuando 0.3.SG-dormir-dejar-PAS-PL DET PAS-0.3.SG-dejar.atrás-PAS-PL cuando la dejaron dormida, la dejaron atrás.

77. yn o-huall-iça-c niman ye choca yn mallinalxoch. DET PAS-DIR-despertar-PAS luego ya llorar DET Malinálxoch

quim-ilhuia yn i-tta-huan

o.3.PL-decir DEt $\quad$ pos.3.sG-padre-PL

Despertó Malinálxoch y luego se pone a llorar, dice a sus padres:

78. no-tta-huan campan t-ia-z-que ca nel o-tech-nahual-cauh pos.1.sG-padre-PL adónde s.1.PL-ir-FUT-PL porque realmente PAs-o.1.pL-engańo-dejar "Padres mios, ¿adónde iremos?, porque realmente nos dejó con engaño

79. y no-quichti-uh yn huitzillopochtli. campan o-huia yn tlahueliloc DET POS.1.PL-hermano-POS DET Huitzilopochtli adónde PAS-irse DET malvado mi hermano Huitzilopochtli. ¿Adónde se fue el malvado? 
80. auh ma ti-c-temo-can yn tlal-li. yn canin t-ie-z-que

PARTI OPT s.1.PL-0.3.sG-buscar-PL DET tierra-ABS DET dónde s.1.PL-estar-FUT-PL

ca ye nohuian onohuac

que ya por.todos.lados estar.acupado

¡Busquemos la tierra dónde estaremos!, ya que por todos lados está ocupada.”

81. Auh niman o-qu-itta-qu-e yn tepe-tl y-toca texcaltepetl. PARTI luego PAS-O.3.SG-ver-PAS-PL DET cerro-ABS POS.3.SG-nombre Texcaltépetl

yn icpac o-mo-tlalli-qu-e

DET sobre PAS-REF.3.PL-establecer-PAS-PL

Luego vieron el cerro llamado Tlaxcaltépetl, sobre el cual se establecieron.

82. auh quin-tlatlauhti-qu-e in yehuantin oncan chan-e-que

PARTI O.3.PL-rogar-PAS-PL DET ellos ahí casa-POSE-PL

yn texcaltepeca.

DET texcaltepecas

Les rogaron a ellos, a los habitantes de ahi, a los texcaltepecas.

83. Niman o-quim-ilhui-qu-e ca ye qual-li. oncan on-xi-mo-tlalli-can entonces PAS-O.3.PL-decir-PAS-PL es ya bueno-ABS allí DIR-IMP-REF.3.PL-establecer-PL

ycpac yn texcaltepetl.

arriba DET Texcaltépetl

Entonces les dijeron: “Está bien, vayan a establecerse alli arriba, en el Texcatépetl!"

84. auh in yehuatl yn Malinalxoch. ye otz-tli ye huey yn i-ti.

PARTI DET ella DET Malinálxoch ya preñada-ABS ya grande DET POs.3.sG-vientre

Auh yn o-tlacat yn i-cone-uh yn Malinalxoch.

PARTI DET PAs-nacer DET POs.3.sG-hijo-POs DET Malinálxoch

Ella, Malinálxoch, ya está preñada, ya está grande su vientre, y nació el hijo de Malinálxoch, 
85. oquich-tli y-toca copil. yn i-ta y-toca varón-ABS POs.3.sG-nombre Cópil DET POs.3.sG-padre POs.3.sG-nombre

chimalquauhtli tla-tohua-ni mallinalco.

Chimalcuauhtli OINDI-gobernar-AG Malinalco

un varón llamado Cópil, su padre es el llamado Chimalcuauhtli, gobernante de Malinalco.

$\$ 9[41]$

86. Auh yn oc centlama-ntin in yn oncan o-mo-tlalli-qu-e PARTI DET otro grupo-PL DET DET allí PAS-REF.3.PL-establecer-PAS-PL

yn cohuatepec

DET Coatépec

Los del otro grupo se establecieron alli en Coatépec,

87. quin oncan huel o-mo-nexti-qu-e yn mexica chichimeca. después allí bien PAS-REF.3.PL-mostrar-PAS-PL DET mexicas chichimecas después de que alli se mostraron bien los mexicas chichimecas.

88. auh in yehuantin yn oncan chan-e-que yn otomi. PARTI DET ellos DET ahí morada-POSE-PL DET otomíes

çan quin-mo-tetzanhuia qu-itohua-ya sólo o.3.PL-REF.3.PL-tomar.como.mal.augurio o.3.SG-decir-IMPE Ellos, los moradores de ahi, los otomies, los tomaban como mal augurio, decian:

89. aqui-que yn campa o-hualla-qu-e $\bar{y}$ nican o-mo-tlalli-co. quién-PL éstos dónde PAS-venir-PAS-PL éstos aquí PAS-REF.3.SG-establecer-DIR “QQuiénes son éstos? ¿De qué parte vinieron éstos? ¿Vinieron a establecerse aqui?

90. campa yn-chan ca amo tlaca ca cenca tlahueliloqu-e dónde Pos.3.PL-casa porque no gente es muy malo-PL ¿Dónde están sus casas? Porque no son gente, son muy malos.” 
$\$ 10[42]$

91. auh in yehuantin yn Mexica. niman ye qui-quetza PARTI DET ellos DET mexicas luego ya o.3.sG-levantar yn iteocal. yn i-chan yn huitzilopochtli. DET pos.3.sG-templo DET pos.3.sG-casa DET Huitzilopochtli Ellos, los mexicas, en seguida levantan su templo, la casa de Huitzilopochtli,

92. nimā ye qui-mana oncā. yn quauh-xical-li. yhuan in yopico. luego ya o.3.sG-poner allí DET águila-jícara-ABS y yhuā tlacochcalco. huitznahuac. tlacatecpan. tzonmolco. y Tlacochalco Huitznáhuac Tlacatecpan Tzonmolco atempā. tezcacohuac. tlamatzinco. mollocotitla. nonohualco. Atempan Tezcacóac Tlamatzinco Molocotitlan Nonoalco cihuatecpan. yzquitlan. milnahuac. cohuatlxoxouhcan. aticpac. Cihuatecpan Izquitlan Milnáhuac Cóatlxoxouhcan Atícpac luego ponen allí la jicara del águila y las parcialidades de Yopico. Tlacochcalco, Huitznáhuac, Tlacatecpan, Tzonmolco, Atempan, Tezcacóac, Tlamatzinco, Molocotitlan, Nonoalco, Cihuatecpan, Izquitlan, Milnábuac, Cóatlxoxouhcan y Aticpac.

93. ca huel oncan quin-cenquixti. quin-tecpan. quin-pouh PARTI VAUX allí o.3.PL-reunir o.3.PL-ordenó o.3.PL-contó yn ixquich-tin tla-tlaca-tecollo. in yehuatl. yn huitzilopochtli. DET todo-PL RED-persona-búho DET él DET Huitzilopochtli Alli pudo reunirlos, ordenarlos, contarlos a todos los demonios, él, Huitzilopochtli,

94. ca yehica yn-teyacanca-uh ym-achca-uh yn diablos-me. es poreso Pos.3.PL-guía-Pos Pos.3.PL-principal-pos DET diablos-PL por ser el guía, el principal de los diablos.

$\$ 11[43]$

95. auh in yehuatl yn huitzilopochtli. niman ye qui-teca PARTI DET él DET Huitzilopochtli luego ya o.3.sG-poner

yn i-tlach

DET $\quad$ Pos.3.sG-juego.de.pelota

A él, a Huitzilopochtli, en seguida le ponen su juego de pelota, 
96. nimā ye qui-mana. yn i-tzonpan. auh niman ye yc luego ya o.3.sG-colocar DET POs.3.sG-tzompantli pARTI luego ya por.eso

qu-eltzaqua. yn atlauh-tli yn tlamimilol-li.

o.3.sG-obstruir DET barranco-ABS DET altozano-ABS

luego le colocan su tzompantli, a continuación obstruyen el barranco, el altozano,

97. oncan o-mo-teca-c yn a-tl. o-ten-ti-moma.

allí PAS-REF.3.SG-estancar-PAS DET agua-ABS PAS-orilla-LIG-llenarse

y-tencopa o-mo-chiuh yn huitzilopochtli.

POS.3.SG-por.mandado PAS-REF.3.SG-hacer DET Huitzilopochtli

alli se estancó el agua, se llenó hasta la orilla, se hizo por mandado de Huitzilopochtli.

98. auh niman o-quim-ilhui yn i-tta-huan yehuantin Mexica. PARTI luego PAS-0.3.SG-decir DET POs.3.sG-padre-PL ellos mexicas

Luego dijo a sus padres, a ellos, a los mexicas:

99. no-ta-huan-e ca ye o-moma yn a-tl Pos.1.sG-padre-PL-VOC PARTI ya PAs-llenarse DET agua-ABS

"Padres míos, ya está lleno de agua.

100. xi-c-aqui-can xi-c-toca-can huexo-tl, yhuan yn ahuehue-tl IMP-0.3.sG-plantar-PL IMP-0.3.sG-sembrar-PL sauce-ABS $\quad \mathrm{y} \quad$ DET ahuehuete-ABS

yn aca-tl. yn tol-li. atlacueçonal-xochi-tl.

DET cańa-ABS DET tule-ABS lirio.acuático-flor-ABS

¡Planten, siembren sauces y ahuehuetes, cañas y tules, flores de lirio acuático!”

101. yhuan ye qui-xinachohua yn mi-mich-tin. yn cueya-me y ya o.3.sG-multiplicar DET RED-pescado-PL DET rana-PL

yn axollo-me. yn acocil-tin. anenez-tin. ahuihuitla-me

DET ajolote-PL DET camarón-PL larva.de.libélula-PL gusano.lacustre-PL

yn axaxayaca-tl. yn quatecoma-tl. yoyol-li.

DET mosco.acuático-ABS DET mosco.lacustre-ABS animalito-ABS

$Y$ ya los multiplican, los pescados, las ranas, los ajolotes, los camarones, las larvas de libélulas, los gusanos lacustres, las larvas de moscos acuáticos de mosco lacustre, los animalitos. 
102. Auh yhuan yn izcahui-tli. yhuan yn toto-me. yn canauh-tli PARTI y DET gusano.de.la.laguna-ABS y DET pájaro-PL DET pato-PL $Y$ el gusano de la laguna izcahuitli, y los pájaros, los patos,

103. yn yacacin-tli yn quechilton. yn acatzana-tl acol-lalauhqu-e. DET gallineta-ABS DET gallineta DET tordo-ABS hombro-bermejo-PL

tozca-coztiqu-e

pecho-amarillo-pL

las gallinetas yacacintli y cuachilton, los tordos de hombro bermejo, de pecho amarillo.

104. Auh yn huitzilopochtli. nimā o-qu-ihto. Ynin yzcahui-tli. PARTI DET Huitzilopochtli después PAs-0.3.sG-decir este gusano.de.la.laguna-ABS ca huel no-naca-yo. n-eç-o no-tlapal-lo. es en.verdad pos.1.sG-carne-ABSTR pos.1.sG-sangre-ABSTR Pos.1.sG-color-ABSTR Huitzilopochtli después dijo: "Este gusano de la laguna izcahuitli en verdad es mi cuerpo, mi sangre, mi color."

105. Auh niman oncan o-qu-euh yn i-cuic cuic-o-ya PARTI luego ahí PAs-o.3.sG-comenzar DET POS.3.sG-canto cantar-PAS-IMPE

no hual-m-itotia. yn cuica-tl. también DIR-REF.3.PL-bailar DET canto-ABS Luego ahí comenzó su canto, se cantaba y también venían a bailar,

106. y-toca tlaxotecayotl. yhuan tecu-ilhui-cuica-tl. Pos.3.sG-nombre tlaxotecáyotl y señor-fiesta-canto-ABS

yn oncan qui-tlalli. DET allí o.3.sG-componer

el canto llamado tlaxotecáyotl y el canto de la fiesta de los señores, allí lo compuso. 
$\$ 12[44]$

107. Auh nimā o-qu-ihto-qu-e yn i-ta-huan centzonhuitznahuatl. ${ }^{2}$ PARTI luego PAs-decir-PAs-PL DET POS.3.sG-padre-PL Centzonhuitznáhuatl

qu-ilhuia in yehuatl huitzilopochtli.

o.3.SG-decir DET él Huitzilopochtli

Luego dijeron sus padres, Centzonhuitznáhuatl, le dicen a él, a Huitzilopochtli,

108. tlamaca-z-qu-e ca ye nican ye-z. yn mo-tequi-uh

dar.vida-fUT-PART-VOC PARTI ya aquí ser-FUT DET POS.2.SG-cargo-pos

ynic ti-hualla. yn ti-te-chia-z.

por.lo.que s.2.sG-vino DET s.2.SG-OINDA-sperar-FUT

"Dador de vida, ya aqui será tu cargo por lo que viniste, esperarás a la gente,

109. yn ti-te-namiqui-z. yn nauhcampan

DET $\quad$ s.2.SG-OINDA-enfrentar-FUT DET por.cuatro.partes

enfrentarás a la gente de las cuatro partes del mundo,

110. yn ti-c-to-topehua-z. yn altepe-tl. ynic ti-c-aci-z DET s.2.sG-o.3.sG-RED-empujar-FUT DET poblado-ABS por.eso s.2.sG-o.3.sG-alcanzar-fUT

m-elchiqui-uh. mo-tzonteco yca. yhuan mo-yollo m-eç-o. pos.2.SG-pecho-pos pos.2.SG-cabeza con y pos.2.SG-corazón pos.2.SG-sangre-ABSTR

mo-tlapal-lo.

POS.2.SG-color-ABSTR

empujarás por todas partes el poblado, por eso alcanzarás con tu pecho, con tu cabeza y con tu corazón, tu sangre, tu color,

2 Traduzco Centzonhuitznahuatl como nombre propio singular respetando la terminación absolutiva del singular $-t l$, sin embargo creo que este término debe ser entendido en sentido colectivo como el conjunto de los "centzonhuitznahuas". León (Tezozómoc, 1998: 33) considera esta paricularidad del náhuatl en su traducción más apegada (traducción de abajo), pero vierte el nombre propio al plural, Centzonhuitznahuâ, en su traducción más libre (traducción de arriba). Riese (2004: 88) toma en cuenta la forma singular y, cotejando los pasajes paralelos de las obras de Durán y Sahagún, opina que se trata de un error gramatical. Por otra parte, Anderson y Schroeder (Chimalpahin Quauhtlehuanitzin, 1997: I, 81) y Tena (Chimalpáhin, 2012: 49) no notan la particularidad del nombre en singular y traducen como si fuera un plural. 
111. ynic ti-qu-itta-z. yn ti-tech-tenehuilli y nepahpan chalchihui-tl. por.eso s.2.SG-0.3.SG-ver-FUT DET $\quad$ s.2.sG-0.1.PL-revelar DET multitud.de esmeralda-ABS por eso verás lo que nos revelaste, la multitud de esmeraldas,

112. yn tlaço-te-tl. yn teocuica-tl. yn quetzal-li. $\bar{y}$ nepahpan DET precioso-piedra-ABS DET oro-ABS DET quetzal-ABS DET multitud.de tlaço-yhui-tl. yn tlapapal-cacahua-tl yn tlapapal-ychca-tl. precioso-pluma-ABS DET multicolor-cacao-ABS DET multicolor-algodón-ABS las piedras preciosas, el oro, las plumas de quetzal, la multitud de plumas preciosas, el cacao multicolor,

113. yhuan $\bar{y}$ nepahpan xochi-tl. yhuā y nepahpan xochiqual-li. y DET multitud.de flor-ABS y DET multitud.de fruta-ABS el algodón multicolor y la multitud de flores y la multitud de frutas,

114. yn nepahpan netlamachtil-li ca nel o-ti-c-nelhuayoti. DET multitud.de cosa.placentera-ABS porque en.verdad PAS-s.2.sG-0.3.sG-arraigar o-ti-c-tzonteconti. y m-altepe-uh $\bar{y}$ nican cohuatepec. PAS-s.2.SG-0.3.sG-hacer.cabeza DET POs.2.SG-pueblo-Pos DET aquí Coatépec la multitud de cosas placenteras, porque en verdad arraigaste, hiciste cabeza tu pueblo, aqui en Coatépec.

115. ma ye nican mo-centlalli-cā yn mo-ta-huā y mo-macehual-huan opt ya aquí REF.3.PL-juntar-PL DET Pos.2.SG-padre-PL DET POS.2.SG-vasallo-PL

yn azteca yn Mexitin DET aztecas DET mexitin

Que se junten ya aqui tus padres, tus vasallos, los aztecas, los mexitin."

116. qui-tlatlauhtia. in yehuatin yn centzonhuitznahuatl. o.3.sG-rogar DET ellos DET Centzonhuitznáhuatl Le ruegan a ellos, a Centzonhuitznáhuatl.

$\$ 13[45]$

117. Auh niman o-quallan yn huitzilopochtli. niman o-quim-ilhui PARTI luego PAS-enojarse DET Huitzilopochtli luego PAs-o.3.PL-decir Entonces se enojó Huitzilopochtli, luego les dijo: 
118. tleyn an-qu-itohua cuix amehuan an-qui-matin qué s.2.sG-0.3.sG-decir INT ustedes s.2.PL-0.3.sG-saber

cuix amo-tequi-uh cuix ā-nech-panahuia

INT Pos.2.PL-cargo-pos INT s.2.PL-o.1.SG-ser.más.que

"¿Qué es lo que ustedes dicen? ¿Ustedes acaso lo saben? ¿Es vuestro cargo? ¿Ustedes son más que yo?

119. ca nehuatl ni-c-mati yn tlein ni-c-chihua-z. en.realidad yo s.1.sG-0.3.sG-saber DET lo.que s.1.sG-0.3.sG-hacer-fUT ¿En realidad sólo yo sé lo que he de hacer!”

120. Auh niman ye mo-chichihua yn huitzilopochtli. PARTI luego ya REF.3.SG-preparar DET Huitzilopochtli En seguida se prepara Huitzilopochtli,

121. yn oncan yn i-chan. yn i-teocal-ticpac. yn on-mo-chichiuh DET allí DET POS.3.sG-Casa DET pos.3.sG-templo-sobre DET DIR-REF.3.sG-preparó

ynic on-mo-yao-chichiuh con.eso DIR-REF.3.sG-guerra-preparó

alli en su casa, sobre su templo, fue a prepararse, fue a prepararse para la guerra,

122. çan i-cone-cuitl ynic on-mo-xa-xauh yn qui-m-ix-teyayahualti sólo pos.3.SG-niño-estiércol con.eso DIR-REF.3.SG-RED-pintó DET o.3.SG-REF.3.sG-ojo-pintó.con. círculos

sólo con su estiércol de niño, con eso fue a pintarse toda la cara, con eso pintó sus ojos con círculos

123. yhuan y-chimal yn c-on-cuic ynic quin-namic y pos.3.sG-escudo DET o.3.sG-DIR-agarró con.eso o.3.PL-enfrentó

yn i-tla-huan ynic mical-qu-e.

DET Pos.3.sG-tío-PL por.eso pelear-PAS-PL

y agarró su escudo, con eso se enfrentó a sus tíos, por eso pelearon. 
124. oncan yn i-nan huitzilopochtli y-toca coyolxauhcihuatl allí DET Pos.3.sG-madre Huitzilopochtli pos.3.sG-nombre Coyolxauhcihuatl

yn on-mo-yao-chichiuh niman ye huitz.

DET DIR-REF.3.sG-guerra-preparó luego ya venir

Alli la madre de Huitzilopochtli, llamada Coyolxauhcíhuatl, fue a prepararse para la guerra y luego ya viene.

125. yn quin-polo-quiuh yn quin-micti-quiuh yn i-tla-huan

DET o.3.PL-derrotar-DIR DET o.3.PL-matar-DIR DET $\quad$ POs.3.SG-tío-PL

yn centzonhuitznahuatl

DET Centzonhuitznáhuatl

Él vino a derrotar, vino a matar a sus tíos, a Centzonhuitznáhuatl,

126. oncan yn teo-tlach-co. yn quin-qua yn i-tla-huan allí DET sagrado-juego.de.pelota-LOC DET o.3.PL-comió DET POS.3.SG-tío-PL allí en el juego de pelota sagrado, donde comió a sus tíos.

127. Auh in yehuatl yn i-nan yn qui-mo-nanti-ca PARTI DET ella DET 0.3.sG-madre DET 0.3.sG-REF.3.sG-hacer.madre-estar Ella, su madre, la que está haciéndose su madre,

128. yn i-toca coyolxauhcihuatl catca $\mathrm{ni}^{\mathrm{ma}}$ achtopa DET POS.3.sG-nombre Coyolxuauhcíhuatl fue luego primero la llamada Coyolxauhcíhuatl, que luego fue primero,

129. y-tech o-peuh yn qui-micti. yn oncan teo-tlach-co. PRON.3.sG-con PAs-empezar DET 0.3.SG-mató DET allá sagrado-juego.de.pelota-LOC empezó con ella, la mató allá en el juego de pelota sagrado,

130. qui-quechcoton. oncan qui-qua yehuatl yn i-yollo o.3.sG-degolló allí o.3.sG-comió él DET POs.3.sG-corazón in coyolxauhcihuatl qui-qua yn huitzilopochtli. DET Coyolxauhcíhuatla o.3.sG-comió DET Huitzilopochtli la degolló, alli él comió el corazón de Coyolxauhcíhuatl, la comió Huitzilopochtli. 
$\$ 14[46]$

131. Auh ca coyolxauh ca y-huelti-uh catca

PARTI PARTI Coyolxauh PARTI POS.3.sG-hermana.mayor-POS era

yn centzonhuitznahuatl

DET Centzonhuitznáhuatl

Coyolxauh era la hermana mayor de Centzonhuitznáhuatl.

132. auh yn iquac yn o-quin-qua yohual-nepantla.

PARTI DET cuando DET PAS-O.3.PL-comer noche-medio

auh yn o-tlathui-c tlahuizcal-pan.

PARTI DET PAS-amanecer-PAS alba-LOC

Cuando los comió era medianoche. Amaneció a primeras horas de mañana

133. niman o-quim-itta-qu-e yn i-ta-huan yn i-macehual-huā entonces PAS-0.3.PL-ver-PAS-PL DET POS.3.SG-padre-PL DET POS.3.SG-vasallo-PL $y$ entonces los vieron sus padres, sus vasallos,

134. yn mexica. ça mochi hel-coyon-t-oqu-e yn coyolxauh. DET mexicas sólo todo pecho-agujerar-LIG-estar-PL DET Coyoxauh los mexicas, todos estaban con los pechos agujerados, Coyolxauh

135. yhuan yn centzonhuitznahua. yn oncan teo-tlach-co. y DET centzonhuitznahuas DET allí sagrado-juego.de.pelota-LOC

aocmo tley yn i-yollo.

ya.no algo DET POS.3.sG-corazón

y los centzonhuitznahuas alli en el juego de pelota sagrado ninguno tenía su corazón.

136. mochi o-qui-qua. yn huitzilopochtli. ca cenca huey tzitzimi-tl, todo PAS-O.3.SG-Comer DET Huitzilopochtli PARTI muy gran brujo-ABS

huey collele-tli o-mo-chiuh yn huitzilopochtli. gran demonio-ABS PAS-REF.3.SG-hacer DET Huitzilopochtli Todos los comió Huitzilopochtli, asi que se volvió un muy gran brujo, un gran demonio Huitzilopochtli. 
$\$ 15[47]$

137. Auh yn Mexica. cenca o-mo-mauhti-qu-e PARTI DET mexicas mucho PAS-REF.3.PL-espantar-PAS-PL Los mexicas se espantaron mucho.

138. auh in yehuantin yn centzonhuitznahuatl ynic mo-mati-a PARTI DET ellos DET Centzonhuitznáhuatl PARTI DIR-pensar-IMPE yn oncan cohuatepec.

DET allí Coatépec

Ellos, Centzonhuitznáhuatl, pensaban que allí en Coatépec,

139. oncan ye-z. yn altepe-tl. ye oncan mexico ye-z. allí ser-fUT DET poblado-ABS ya allí México ser-fUT alli sería el poblado, que ya alli sería México.

140. auh ca amo qui-nec in yehuatl huitzilopochtli. ni ${ }^{\text {mä }}$ pero PARTI no o.3.sG-querer DET él Huitzilopochtli entonces qui-cuitlacoyoni yn a-tl o.3.sG-perforar DET agua-ABS Pero no quiere Huitzilopochtli, entonces perfora el agua, destruye

141. qui-xitini. ynic qu-eltzac-ca yn atlauh-tli. yn oncā catca o.3.SG-destruye con.lo.que 0.3.sG-obstruir-estar DET barranco-ABS DET donde estaba yn oncā mani-a in a-tl. DET donde enxtenderse-IMPE DET agua-ABS aquello que está obstruyendo el barranco, donde estaba, donde se extendía el agua.

142. niman mochi huac yn ahuehue-tl yn huexo-tl. yn aca-tl. yn tol-li. entonces todo secó DET ahuehuete-ABS DET sauce-ABS DET caña-ABS DET tule-ABS yn atlacueçonal-xochi-tl.

DET lirio.acuático-flor-ABS

Entonces todo se secó, el abuehuete, el sauce, la caña, el tule, la flor del lirio acuático. 
143. auh mochi mic-qu-e yn a-nemi-a yn mich-in yn cueya-tl. PARTI todo morir-PAS-PL DET agua-vivir-IMPE DET pez-ABS DET rana-ABS Murieron todos los animales que vivian en el agua, los peces, las ranas,

144. axollo-tl. axaxayaca-tl. yn quatecoma-tl. yoyol-li. ajolote-ABS larva.de.mosco.acuático-ABS DET mosco.acuático-ABS animalito-ABS los ajolotes, las larvas de moscos acuáticos axaxáyacatl y cuatecómatl, los animalitos,

145. yhuan acocil-in. anenetz-in. yhuan y camarón.lacustre-ABs larva.de.libélula-ABs y o-poliuh-qu-e omochi PAS-desaparecer-PAS-PL todo

yah-qu-e. yn ca-canauh-tin. yacacin-tin. quachil-tin.

irse-PAS-PL DET RED-pato-PL gallineta-PL gallineta-PL y los camarones lacustres, las larvas de libélulas desaparecieron, todos se fueron, los patos, las gallinetas yacacintin y cuachiltin,

146. yn teotzana-me. yn azta-tl. yn acol-tlatlauhqu-e. tozca-coztiqu-e. DET mirlo-PL DET garza-ABS DET hombro-bermejo-PL pecho-amarillo-PL

in ye yxquich toto-me.

DET ya todo ave-PL

los mirlos, las garzas, los pájaros de hombro bermejo, de pecho amarillo, todas las aves.

\section{$\$ 16[48]$}

147. auh niman ye hual-peuh yn huitzilopochtli. yn quin-hual-huica-c PARTI luego ya DIR-partió DET Huitzilopochtli DET o.3.PL-DIR-traer-PAS

yn i-ta-huan yn i-macehual-huan yn mexica.

DET POs.3.SG-padre-PL DET POs.3.SG-vasallo-PL DET mexicas

Luego vino a partir Huitzilopochtli, vino a traer a sus padres, a sus vasallos, a los mexicas.

148. auh yn oncā cohuatepec. oncan qu-ilpi-qu-e yn in-xiuh-tlapohual PARTI DET allí Coatépec allí o.3.sG-atar-PAS-PL DET POs.3.PL-año-cuenta

ce tecpa-tl

uno pedernal-ABs

Alli en Coatépec, alli ataron su cuenta de los años en uno pedernal. 
$\$ 17[49]$

149. Capitulo ynic yei y-pan m-itohua ce tecpa-tl yn tonal-li Capítulo ORD tres PRON.3.SG-LOC REF.3.sG-tratar uno pedernal-ABS DET día-ABS

y-pan tlacat. yn huitzilopochtli.

PRON.3.SG-LOC nació DET Huitzilopochtli

Capitulo tercero en el que se trata de uno pedernal, el día en el que nació Huitzilopochtli.

$\$ 18[50]$

150. Auh niman ye huitz-e aci-co. yn tollan amo huecauh-qu-e yn oncan PARTI luego ya venir-PL llegar-DIR DET Tollan no permanecer-PAS-PL DET allí En seguida vienen, vinieron a llegar a Tollan, pero no permanecieron alli mucho tiempo.

151. nimā hual-miquani-qu-e yn atlitlallacyan. hual-miquani-qu-e luego DIR-trasladarse-PAS-PL DET Atlitlalacyan DIR-trasladarse-PAS-PL

tequixquiac

Tequíxquiac

Luego vinieron a trasladarse a Atlitlalacyan, vinieron a trasladarse a Tequixquiac,

152. oncan qui-chiuh-que yn in-chinan qui-toca-qu-e yn chinamitl allí 0.3.SG-hacer-PAs-PL DET Pos.3.PL-sementera o.3.SG-sembrar-PAS-PL DET chinámitl alli hicieron sus sementeras, sembraron la chinámitl.

$\$ 19[51]$

153. Auh niman huall-ehua-qu-e mo-tlalli-co oncan aci-co in atēco PARTI luego DIR-partir-PAS-PL REF.3.PL-establecer-DIR ahí llegar-DIR DET Atenco Luego partieron hacia acá, vinieron a establecerse ahi, vinieron a llegar a Atenco.

154. nimā on oncan qui-man-qu-e yn in-tzonpan oncan luego - allí o.3.sG-colocar-PAs-PL DET pos.3.PL-tzompantli allí o-qu-ihto-qu-e ynic axcan y-toca-yo-can tzompanco PAS-0.3.SG-nombrar-PAS-PL por.eso ahora 0.3.SG-nombre-ABSTR-LoC Tzompanco Luego también alli colocaron su tzompantli, alli lo nombraron, por eso ahora el lugar se llama Tzompanco. 
155. niman on-mo-tlalli-co. yn mexica yn quachilco. luego DIR-REF.3.PL-esteblecer-DIR DET mexicas DET Cuachilco Luego vinieron a establecerse los mexicas en Cuachilco.

156. auh niman aci-co yn xaltocan oncan yc ye mo-chinantia PARTI luego llegar-DIR DET Xaltocan allí por.eso ya REF.3.PL-hacer.una.sementera Luego vinieron a llegar a Xaltocan, alli entonces se hacen sementeras,

157. oncan qui-toca-qu-e yn tlaol-li y huauh-tli. yn e-tl. allí 0.3.SG-sembrar-PAS-PL DET maíz-ABS amaranto-ABS DET frijol-ABS

yn ayo-tli. yn chilcho-tl. yn xitoma-tl. DET calabaza-ABS DET chílchotl-ABS DET jitomate-ABS alli sembraron maiz, amaranto, frijol, calabaza, chilchotl y jitomate.

158. nimā ye yc huitz-e yn epcohuac. ca no luego ya con.esto venir-PL DET Epcóac PARTI también oncā mo-chinanti-qu-e. allí REF.3.PL-hacer.sementara-PAS-PL

Entonces con esto vienen a Epcóac y alli también se hicieron sementeras.

$\$ 20[52]$

159. Auh niman mo-tlalli-co yn ecatepec. yhuan y-toca-yo-can PARTI luego REF.3.PL-establecer-DIR DEt Ecatépec y POS.3.sG-nombre-ABSTR-LOC acalhuacan.

Acalhuacan

Luego vinieron a establecerse en Ecatépec y en el lugar llamado Acalhuacan.

160. niman hualla-qu-e yn oncan tolpetlac. ye no ceppa luego venir-PAs-PL DET allí Tolpétlac ya también otra.vez

huall-ehua-qu-e oncan mo-tlalli-co y-toca-yo-can huixachtitla. DIR-partir-PAS-PL allí REF.3.PL-establecer-DIR POS.3.sG-nombre-ABSTR-LOC Huixachtitlan Después vinieron alli a Tolpétlac y otra vez partieron hacia acá, vinieron a establecerse alli en el lugar llamado Huixachtitlan.

161. Auh niman hualla-qu-e mo-tlalli-co y-toca-yo-cā tecpayocan PARTI entonces venir-PAS-PL REF.3.PL-establecerse-DIR POS.3.SG-nombre-ABSTR-LOC Tecpayocan Entonces vinieron hacia acá, vinieron a establecerse en el lugar llamado Tecpayocan, 
162. oncan ye no ceppa yn xiuh-mo-lpi-lli ome aca-tl allí ya también otra.vez DET año-ReF.3.PL-atar-APL dos cańa-ABS allí otra vez se ató el año dos caña.

163. niman hualla-qu-e mo-tlalli-cot yn oncā atepetlac. luego venir-PAs-PL REF.3.PL-establecer-DIR DET allí Atepétlac Luego vinieron hacia acá, vinieron a establecerse alli en Atepétlac.

164. Auh niman huall-ehua-qu-e oncan mo-tlalli-co PARTI luego DIR-partir-PAS-PL allí REF.3.PL-establecer-DIR y-toca-yo-can cohuatlyayauhcan. POs.3.SG-nombre-ABSTR-LOC Coatlyayauhcan En seguida partieron de alli, vinieron a establecerse en el lugar llamado Coatlyayauhcan.

165. nimā hualla-qu-e yn oncan y-toca-yo-can tetepanco luego venir-PAs-PL DET allí Pos.3.sG-nombre-ABSTR-Loc Tetepanco Luego vinieron alli en el lugar llamado Tetepanco.

166. huall-ehua-qu-e oncan mo-tlalli-co yn i-toca-yo-cā DIR-partir-PAS-PL allí REF.3.PL-establecer-DIR DET POS.3.sG-nombre-ABSTR-LOC aculnahuac. Acolnáhuac Partieron de alli, vinieron a establecerse en el lugar llamado Acolnábuac.

167. niman hualla-qu-e mo-tlalli-co yn oncan popotlan. luego venir-PAS-PL REF.3.PL-esteblecer-DIR DET allí Popotlan Luego vinieron, vinieron a establecerse alli en Popotlan.

168. auh niman hualla-qu-e yn oncan chapoltepec yn i-cuitlapil-co. PARTI luego venir-PAs-PL DET allí Chapoltépec DET POs.3.sG-espalda-LOC Luego vinieron alli, a las espaldas de Chapoltépec,

169. y-toca-yo-can techcantitlan quin yehuantin yuh POs.3.sG-nombre-ABSTR-LOC Techcatitlan después ellos así qui-tocayoti-qu-e yn mexica. 0.3.SG-nombrar-PAs-PL DET mexicas en el lugar llamado Techcatitlan, después ellos, los mexicas, así lo nombraron. 
170. Auh yn oncan chapoltepec oncan ye no yn xiuh-qu-ilpi-qu-e PARTI DET allí Chapoltépec allí ya también DET año-o.3.sG-atar-PAS-PL

yn xiuh-tlapohual-li ome aca-tl

DET año-cuenta-ABs dos caña-ABs

Alli en Chapoltépec también ataron el año, la cuenta anual en dos caña.

$\$ 21[53]$

171. auh nimā oncan ye quin-nahuatia yn Mexica in yehuatl PARTI luego allí ya o.3.PL-hablar DET mexicas DET él

yn huitzilopochtli.

DET Huitzilopochtli

Entonces alli habla a los mexicas él, Huitzilopochtli,

172. ye quim-ilhuia in yehuantin teo-mama-qu-e

ya o.3.PL-decir DET ellos dios-cargar-PART-PL

yn i-toca quauhtlequetzqui.

DET POS.3.sG-nombre Cuauhtliquetzqui

ya les dice a ellos, a los cargadores del dios, al llamado Cuauhtliquetzqui,

173. ynic ome y-toca axollohua tlamacazqui. yhuan yniqu-ey

ORD dos pos.3.sG-nombre Axolohua tlamacazqui y oRD-tres

y-toca ococaltzin.

pos.3.sG-nombre Ococaltzin

al segundo llamado Axolohua, tlamacazqui, y al tercero llamado Ococaltzin,

174. auh in yehuantin in yn teo-mama-qu-e o-quim-ilhui yn PARTI DET ellos DET estos dios-cargar-PART-PL PAS-0.3.PL-decir DET

huitzilopochtli.

Huitzilopochtli

a ellos, a estos cargadores del dios, les dijo Huitzilopochtli:

175. no-ta-huan-e. yn tleyn mo-chihua-z. oc xi-c-chiye-can POS.1.SG-padre-PL-vOC DET que REF.3.sG-hacer-FUT todavía IMP-o.3.sG-esperar-PL

ca an-qu-itta-z-que.

PARTI s.2.PL-0.3.SG-ver-FUT-PL

“Padres míos, lo que se tiene que hacer todavía espérenlo y lo verán! 
176. tla oc xi-c-chiye-can ca nehuatl ni-c-mati.

OPT todavía IMP-0.3.sG-esperar-PL ya.que yo s.1.sG-0.3.sG-saber

¡Todavía espérenlo ya que yo lo sé!

177. xi-mo-chicahua-can xi-mo-tlapallo-can. xi-mo-chichicahua-can.

IMP-REF.2.PL-fortalecer-PL IMP-REF.3.PL-atrever-PL IMP-REF.2.PL-preparar-PL

xi-mo-cencahua-can macamo nican yn t-ie-z-que.

IMP-REF.2.PL-disponer-PL que.no aquí DET s.1.PL-estar-FUT-PL

¡Fortalézcanse, atrévanse, prepárense, dispónganse, que no es aqui donde tenemos que estar!

178. oc nechca yn ti-tlamati-hui yn oncan ti-tla-pie-z-que.

todavía más.adelante DET s.1.PL-hacer.cautivos-DIR DET allí s.1.PL-OINDI-guardar-FUT-PL Todavía más adelante vamos a hacer cautivos, alli guardaremos las cosas.

179. Auh inin ma oc ti-quin-chiye-can yn tech-pollo-quihui. PARTI esto OPT todavía s.1.PL-o.3.PL-esperar-PL DET o.1.PL-destruir-DIR

on-tlaman-tin in ye huitz-e.

dos-grupo-PL DET ya venir-PL

¡Por esto todavía esperemos los que nos vienen a destruir, dos grupos de ellos ya vienen!"

$\$ 22[54]$

180. Auh in yehuatl yn i-toca Mallinalxoch. yn i-huelti-uh PARTI DET ella DET Pos.3.sG-nombre Malinálxochitl DET Pos.3.sG-hermana.mayor

yn huitzilopochtli.

DET Huitzilopochtli

A ella, a la llamada Malinálxoch, hermana mayor de Huitzilopochtli,

181. o-qu-ilhui yn i-cone-uh in yehuatl yn i-toca Copil. qu-ilhui pAs-0.3.sG-decir DET pos.3.sG-hijo-pos DEt él DET pos.3.sG-nombre Cópil o.3.sG-dijo le dijo su hijo, él, el llamado Cópil, le dijo:

182. no-nan-tzin-e. ca cenca ni-c-mati oncan mo-quichti-uh POs.1.sG-madre-HON-VOC PARTI mucho s.1.sG-0.3.sG-saber dónde POs.2.sG-hermano-POS Madre mía, sé muy bien dónde está tu hermano" 
183. niman o-qu-ilhui ca quemaca ca onca yn mo-tla. luego PAs-o.3.sG-decir parTI es cierto.que ahí DET POs.2.sG-tío y-toca huiztilpochtli. ynic nech-cauh çan nech-coch-cauh, pos.3.sG-nombre Huitzilopochtli PARTI o.1.sG-dejó sólo o.1.sG-dormir-dejó Entonces le dijo: "Sí, es cierto que ahi está tu tío, llamado Huitzilopochtli, quien me dejó, sólo me dejó dormida,

184. nech-nahual-cauh yn otli-pan o.1.sG-engaño-dejó DET camino-LOC me dejó con engaño en el camino.

185. auh nimā yc nican ti-to-tlalli-qu-e yn texcaltepe-ticpac. PARTI luego por.eso aquí s.1.PL-REF.1.PL-establecer-PAS-PL DET Texcaltépett-arriba Entonces nos establecimos aqui, arriba del Texcaltépetl."

186. niman o-qu-ihto. yn copil ca ye qual-li no-nan-tzin-e luego PAs-0.3.sG-decir DET Cópil está ya bueno-ABS POs.1.sG-madre-HON-VOC Luego le dijo Cópil: "Está bien, madre mía,

187. ca ye nehuatl ni-c-mati ca ni-c-temo-tiuh yn canin PARTI ya yo s.1.sG-0.3.sG-saber PARTI s.1.sG-0.3.sG-buscar-DIR DET donde o-tlahuelmati-to. PAS-sentirse.a.gusto-DIR yo ya lo sé, lo voy a buscar en donde fue a sentirse a su gusto,

188. yn canin o-mo-tlalli-to. ca ni-c-po-pollo-tiuh DET donde PAS-REF.3.SG-establecer-DIR PARTI $\quad$ s.1.sG-RED-destruir-DIR

ca ni-c-qua-tiuh PARTI $\quad$ s.1.SG-0.3.SG-Comer-DIR en donde fue a establecerse, voy a destruirlo por completo, voy a comérmelo.

189. Auh ca ni-quin-po-pollo-tiuh ca ni-quin-pehua-l-tiuh PARTI PARTI s.1.SG-0.3.PL-RED-destruir-DIR PARTI 5.1. .sG-0.3.PL-conquistar-APL-DIR yn o-quin-huica-c yn i-ta-huan yn i-macehual-huan DET PAs-o.3.PL-traer-PAS DET POs.3.sG-padre-PL DET POs.3.sG-vasallo-PL Voy a destruir, voy a conquistar a los que trajo, a sus padres, a sus vasallos. 
190. auh ca cenca ni-c-mati yn ixquich y-nemac PARTI PARTI mucho s.1.sG-0.3.sG-conocer DET todo pos.3.sG-bien Conozco muy bien todos sus bienes,

191. yn i-tech pouh-qui yn qu-itta-z. yn qui-mahuiço-z. DET PRON.3.SG-de pertenecer-PART DET o.3.sG-ver-FUT DET o.3.sG-admirar-fUT y nepahpah netlamachtil-li. DET multitud.de riqueza-ABS sus pertenencias que él verá, que él admirará, la multitud de riquezas.

192. auh ca nehuatl ni-ye-z ca nehuatl no-nemach e-z. PARTI PARTI yo s.1.sG-ser-FUT PARTI yo POS.1.sG-conocimiento ser-FUT yn ixquich y nepahpan chalchihui-tl. DET todo DET multitud.de chalchihuite-ABS Seré yo, yo tendré conocimiento de todo, la multitud de chalchibuites,

193. yn teocuitla-tl. yn quetzal-li. y nepahpā yhui-tl yn DET oro-ABS DET quetzal-ABS DET multitud.de pluma-ABS DET tlapahpal-cacahua-tl. multicolor-cacao-ABS de oro, de plumas de quetzal, la multitud de plumas, de cacao multicolor,

194. yn tlapahpal-ychca-tl. y nepapan xochi-tl. DET multicolor-algodón-ABS DET multitud.de flor-ABS

y nepahpan xochiqual-li. DET multitud.de fruta-ABS de algodón multicolor, la multitud de flores, la multitud de frutas.

195. auh ynin no-nā-tzin-e. maca xi-tlaocoya. PARTI por.esto POs.1.sG-madre-HON-VOC que.no IMP-aflijirse ye ni-yauh ni-c-temo-tiuh ya $\quad$ s.1.sG-ir s.1.sG-0.3.sG-buscar-DIR Por esto, madre mía, ino te aflijas!, ya me voy, voy a buscar

196. yn tlahuelliloc no-tlah. cenca xi-nech-mo-chi-lli DET malvado POS.3.SG-tío mucho IMP-o.1.SG-REF.3.SG-esperar-APL al malvado de mi tió, jespérame mucho!" 
$\$ 23[55]$

197. auh ca nimā ye yc huitz. o-mo-cencauh o-mo-chichiuh PARTI PARTI luego ya por.eso venir PAS-REF.3.sG-preparar PAs-REF.3.SG-ataviar yehuatl yn i-toca copil. ca cenca huey tlahueliloc. él DET pos.3.sG-nombre Cópil porque muy gran malvado Entonces viene él, el llamado Cópil, se ha preparado, se ha ataviado, porque es un muy gran malvado.

198. Auh ca cenca huey nahual-le amo mach iuhqui yn i-nan PARTI PARTI muy gran brujo-ABS no parece así.como DET POS.3.sG-madre

yn i-toca Mallinalxoch.ca cenca huey tlahueliloc. yn copil. DET POS.3.sG-nombre Malinálxoch PARTI muy gran malvado DET Cópil Es un muy gran brujo, aunque no parece serlo tanto como su madre llamada Malinálxoch, es un muy gran malvado Cópil.

199. niman ye huitz. ipan ce cal-li xihui-tl oncan luego ya venir PRON.3.s-LOC uno casa-ABS ańo-ABS allí mo-cuepa-co. yn i-toca-yo-can çoquitzinco. REF.3.SG-transformar-DIR DET POS.3.SG-nombre-ABSTR-LOC Zoquitzinco Luego ya viene en el año uno casa, vino a transformarse alli en el lugar llamado Zoquitzinco.

200. ye no ceppa huitz. oncan mo-cuepa-co yn ya también otra.vez venir allí REF.3.sG-transformar-DIR DET i-toca-yo-can atlapalco. POs.3.sG-nombre-ABSTR-LOC Atlapalco Otra vez viene, se transforma alli en el lugar llamado Atlapalco.

201. ye no ceppa huitz. oncan mo-cuepa-co yn ya también otra.vez venir allí REF.3.SG-transformar-DIR DET i-toca-yo-can ytztapaltemoc. pos.3.SG-nombre-ABSTR-LOC Itztalpaltémoc Otra vez viene, se transforma alli en el lugar llamado Itztapaltémoc. 


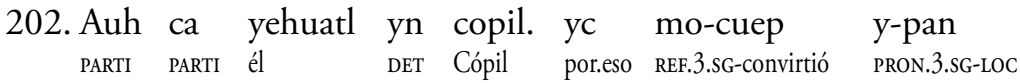
mo-quixti ytztapal-te-tl.

REF.3.SG-convirtió loza-piedra-ABS

Con eso él, Cópil, se transformó, se convirtió en una loza de piedra,

203. yc mo-tocayotia. yn axcan ca ti-qu-itohua yn mochi por.eso REF.3.SG-dar.nombre DET ahora PARTI s.1.PL-0.3.SG-decir DET todo

tlaca-tl. ytztapaltetitla

persona-ABS Itztapaltetitlan

por eso se le da el nombre al lugar, ahora todo mundo le decimos Itztapaltetitlan.

204. Auh ca in yehuatl yn copil. ca y-necuepca mo-chiuh PARTI PARTI DET él DET Cópil es POs.3.sG-transformación REF.3.sG-hizo

yn ytztapal-te-tl.

DET loza-piedra-ABS

Esa es la transformación de él, de Cópil, se volvió una loza de piedra.

205. in yehuatl yn copil auh ye no ceppa mo-cuepa yn i-chan DET él DET Cópil pARTI ya también una.vez REF.3.SG-volver DET POs.3.sG-casa yn texcaltepeticpac y-toca. Auh yn axcan yn mallinalco. DET Texcaltepetícpac POs.3.sG-nombre PARTI DET ahora DET Malinalco Otra vez él, Cópil, regresó a su casa llamada Texcaltepetícpac, que ahora es Malinalco,

206. ca yehuatl qui-tocayoti-ca ypampa ca yehuatl yca-ca ya.que ella o.3.sG-dar.nombre-estar porque PARTI ella morar-estar y-toca yn Mallinalxoch POS.3.SG-nombre DET Malinálxoch ya que ella le está dando este nombre, porque ella, la nombrada Malinálxoch está morando alli,

207. ynic mo-notza altepe-tl Malinalco. por.eso REF.3.sG-llamar pueblo-ABs Malinalco por eso el pueblo se llama Malinalco. 
208. quin yehuatl oncan yc tlatoca-Maca-t-aci-to yn i-toca después él allí para.que gobierno-dar-LIG-alcanzar-DIR DET POs.3.sG-nombre

Malinalxoch. ynic aci-co.

Malinálxoch poreso llegar-DIR

Despues él vino a llegar alli para que alcanzara a darle el gobierno la dicha Malináxoch, por eso vino a llegar.

209. auh in yehuatl yn copil. ye no ceppa huitz. qui-huicatz PARTI DET él DET Cópil ya también una.vez venir o.3.sG-traer y-chpoch $y$-toca azcatlxochtzin. POS.3.sG-hija POS.3.sG-nombre Azcatlxochtzin

Él, Cópil, otra vez viene, trae a su hija llamada Azcatlxochtzin,

210. oncan mo-cuepa-co yn i-toca-yo-can tecpantzinco. allí REF.3.SG-regresar-DIR DET POS.3.SG-nombre-ABSTR-LOC Tecpantzinco vino a regresarse alli en el lugar llamado Tecpantzinco.

$\$ 24[56]$

211. Auh in yehuatl yn huitzilopochtli. niman huell o-qui-mah PARTI DET él DET Huitzilopochtli entonces bien PAS-0.3.sG-saber

huell o-qu-ita-c in ca yehuat

bien PAS-0.3.SG-ver-PAS DET que aquél

Él, Huitzilopochtli, entonces supo bien, vio bien que aquél,

212. yn i-mach in ye huey yn i-toca copil. DET POs.3.sG-sobrino DET ya grande DET POs.3.sG-nombre Cópil su sobrino llamado Cópil, ya era grande.

213. niman o-quim-ilhui yn i-ta-huan luego PAS-0.3.PL-decir DET POS.3.sG-padre-PL Luego dijo a sus padres:

214. no-ta-huan-e xi-mo-chichihua-can. xi-mo-cencahua-can ca ye POS.1.SG-padre-PL-VOC IMP-REF.2.PL-preparar-PL IMP-REF.2.PL-arreglar-PL que ya

huitz. yn tlahueliloc y no-mach. venir DET malvado DET Pos.1.sG-sobrino "Padres mios, iprepárense, arréglense! que ya viene el malvado de mi sobrino. 
215. ye ni-yauh ni-c-po-polo-tiuh ni-c-micti-z

ya s.1.sG-ir s.1.sG-O.3.sG-ReD-destruir-DIR $\quad$ s.1.sG-0.3.sG-matar-FUT

Yo ya me voy, voy a destruirlo por completo, lo mataré."

216. auh niman o-qui-namic yn oncan y-toca-yo-can tepetzinco PARTI luego PAs-o.3.sG-encontrar DET allí Pos.3.sG-nombre-ABSTR-LOC Tepetzinco En seguida lo encontró alli en el lugar llamado Tepetzinco.

217. auh yn o-qu-itta-c o-qu-ilhui ac tehuatl campa ti-huitz. PARTI DET PAS-0.3.SG-ver-PAS PAS-0.3.SG-decir quién tú dónde s.2.SG-venir Lo vio y le dijo: “Quién eres tú? ¿De dónde vienes?"

218. qui-hual-ilhui ca nehuatl o.3.SG-DIR-dijo es yo Le contestó: "Soy yo."

219. oc ceppa c-on-ilhui campa mo-chan. qui-hual-ilhui ca ompa aún una.vez 0.3.sG-DIR-decir dónde pos.2.sG-casa o.3.sG-DIR-dejo está allá yn texcaltepe-ticpac.

DET Texcaltépet-arriba

Otra vez fue a preguntarle: “Dónde está tu casa?" Le contestó: "Está allá sobre el Texcaltépetl."

220. niman o-qu-ihto. yn huitzilopochtli. ca ye qual-li cuix amo luego PAS-0.3.sG-decir DET Huitzilopochtli está ya bueno-ABS INT no

tehuatl. yn o-michiuh ${ }^{3}$ y no-huelti-uh in Malinalxoch. tú DET PAs-parir DET POs.1.sG-hermana-POS DET Malinálxoch Luego Huitzilopochtli dijo: "Está bien, ¿acaso no eres tú a quien parió mi hermana Malinálxoch?"

221. niman o-qu-ihto yn copil. ca quemaca. ca nehuatl. entonces PAs-o.3.sG-decir DET Cópil es cierto es yo Entonces Cópil dijo: "Es cierto, soy yo.

3 Léase "omixiuh". 
222. auh ca ni-mitz-aci-z. ca ni-mitz-po-polo-tiuh tle ypampa PARTI PARTI 5.1. SG-0.2.SG-agarrar-FUT PARTI $\quad$ s.1.SG-0.2.SG-RED-destruir-DIR qué porque

yn ti-c-coch-cauh yn ti-c-nahual-cauh y no-nan-tzin DET s.2.SG-0.3.sG-dormir-dejó DET s.2.SG-0.3.sG-engaño-dejó DET pos.1.sG-madre-HON Te alcanzaré, voy a destruirte por completo porque dejaste dormida a mi madre, la dejaste con engaño.

223. auh ca ni-mitz-tlatlati-z c-on-ilhui yn huitzilopochtli. PARTI s.1.SG-O.2.sG-acabar.con 0.3.sG-DIR-dijo Huitzilopochtli Acabaré contigo." Dijo Huitzilopochtli:

224. ca ye qualli tla xi-huallauh Niman ye yc mo-nahual-totoca. está ya bueno-ABS OPTIMP-venir luego ya por.eso REF.3.PL-nahual-perseguir nimā o-c-aci-qu-e yn copil. yn oncan tepetzinco. luego PAS-0.3.SG-alcanzar-PAS-PL DET Cópil DET allí Tepetzinco "Está bien, ¡ven!” Entonces se persiguen como nahuales y alcanzaron a Cópil allí en Tepetzinco.

225. auh yn iquac yn o-mic ca nimā qui-quechcoton niman ye PARTI DET cuando DET PAS-morir PARTI luego o.3.sG-degolló luego ya qu-el-tequi. yn o-qu-el-tec c-on-anilli yn i-yollo. o.3.SG-pecho-cortar DET PAS-0.3.sG-pecho-cortar o.3.sG-DIR-sacar DET POS.3.sG-corazón Cuando murió luego lo degolló y entonces le corta el pecho y habiéndole cortado el pecho fue a sacarle el corazón.

226. auh ycpac qui-tlalli yn tepe-tzin-tli yn i-tzonteco. PARTI arriba o.3.sG-puso DET cerro-DIM-ABS DET POs.3.sG-cabeza

yn axcan ye y-toca-yo-can Acopilco.

DET ahora ya POs.3.SG-nombre-ABSTR-LOC Acopilco Arriba del cerrito puso su cabeza, ahora ya se le dice al lugar Acopilco.

227. auh y-tzonteco yn copil oncā mic PARTI POS.3.sG-cabeza DET Cópil allí murió La cabeza de Cópil murió allí. 
$\$ 25[57]$

228. Auh in yehuatl yn huitzilopochtli. yn o-c-on-micti niman ye PARTI DET él DET Huitzilopochtli DET PAs-o.3.sG-Dir-matar luego ya yc hual-mo-tlallotia yca. yn i-yollo yn copil. por.eso DIR-REF.3.SG-correr con DET pos.3.sG-corazón DET Cópil Él, Huitzilopochtli, fue a matarlo, en seguida viene corriendo con el corazón de Cópil.

229. auh in yehuatl yn teo-mama yn i-toca quauhtlequetzqui PARTI DET él DET dios-cargar DET POs.3.sG-nombre Cuauhtliquetzqui Él, el cargador del dios llamado Cuaubtliquetzqui,

230. qui-namic-tiuh yn huitzilopochtli. yn o-qui-namic. o-qu-ilhui o.3.SG-encontrar-DIR DET Huitzilopochtli DET PAS-0.3.sG-encontrar PAS-0.3.sG-decir va a encontrar a Huitzilopochtli, lo encontró y le dijo:

231. O-ti-c-m-ihiyohui-lti tlamaca-z-qu-e. o-qui-hual-ilhui tla PAS-S.2.sG-0.3.sG-REF.2.SG-cansar-APL dar.vida-FUT-PART-VOC PAS-0.3.SG-DIR-decir OPT xi-huallauh quauhtlequetzqu-e. Yzca yn i-yollo. Imp-venir Cuauhtliquetzqui-voc toma DET pos.3.sG-corazón

yn tlahueliloc. yn copil. ca o-ni-c-micti-to. DET infame DET Cópil que PAs-S.1.sG-0.3.sG-matar-DIR "Te has cansado, dador de vida." Le contestó: “'Ven, Cuaubtliquetzqui, toma el corazón del infame de Cópil, a quien fui a matar!

232. auh xi-c-mo-tlalochti yn toll-iti-c yn aca-yhti-c PARTI IMP-0.3.SG-REF.2.SG-llevar.de.prisa DET junco-vientre-LOC DET cańa-vientre-LOC ¿Llévatelo de prisa al interior de los juncos y de las cañas!

233. yc ti-qu-itta-z oncan mani te-petla-tl. oncan mo-cehui PARTI $\quad$ s.2.SG-0.3.sG-ver-FUT ahí hallarse piedra-petate-ABS donde REF.3.SG-descansó

yn quetzalcohuatl yn iquac yah.

DET Quetzalcóatl DET cuando sefue

Ahi verás que se halla un petate de piedra, en el que descansó Quetzalcóatl cuando se fue. 


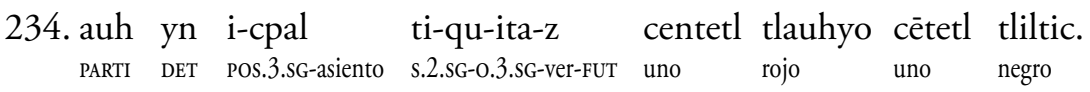
verás su asiento, uno es rojo y uno es negro.

235. oncan ti-mo-quetza-z. yn to-c-on-mayahui-z. yn yehuatl. alli $\quad$ s.2.SG-REF.2.SG-parar-FUT $\quad$ DET $\quad$ s.2.sG-0.3.sG-DIR-arrojar-fUT DET aquello yn i-yollo. yn copil. DET POS.3.sG-corazón DET Cópil Allí te pararás e irás a arrojar aquello, el corazón de Cópil."

236. auh niman ye yc huitz yn quauhtlequetzqui yn qui-mayahui-z PARTI luego ya por.eso venir DET Cuauhtliquetzqui DET 0.3.sG-arrojar-FUT yollo-tli. yn on-aci-co yn oncan o-qui-tlatenehui-li. corazón-ABS DET DIR-llegar-DIR DET allí PAS-0.3.GG-indicar-APL En seguida Cuaubtliquetzqui viene para arrojar el corazón y vino a llegar alli, al lugar que le habia indicado.

237. niman o-qu-itta-c. yn te-petla-tl. oncan mo-quetz yn entonces PAS-0.3.sG-ver-PAS DET piedra-petate-ABS allí REF.3.sG-paró DET c-on-mayauh yollo-tli. o.3.sG-DIR-lanzó corazón-ABS Entonces vio el petate de piedra, se paró allí y fue a lanzar el corazón.

238. nimā ompa huetzti-to. yn toll-oti-c ${ }^{4}$ yn aca-yhti-c. así.que lejos caer-DIR DET tule-vientre-LOC DET caña-vientre-LOC Asi que fue a caer lejos, en medio del tular y del cañaveral.

239. niman ye yc oncan mocuepa yn o-c-on-mayahui-to. luego ya por.eso allí REF.3.SG-regresar DET PAS-0.3.SG-DIR-arrojar-DIR in yollo-tli in yehuatl yn quauhtlequetzqui. DET corazón-ABS DET él DET Cuauhtliquetzqui En seguida regresa de allí, habiendo arrojado el corazón él, Cuaubtliquetzqui.

4 Léase "tollitic". 
240. auh yn axcan ti-c-tocayotia tlalcocomocco. yn oncan mo-quetz. PARTI DET ahora s.1.PL-0.3.sG-llamar Tlalcocomocco DET lugar.en.el.cual REF.3.sG-paró

yn quauhtlequetzqui ynic qui-mayahui-co yollo-tli. DET Cuauhtliquetzqui para o.3.SG-arrojar-DIR corazón-ABS Ahora llamamos Tlalcocomocco el lugar en el cual se paró Cuauhtliquetzqui para venir a arrojar el corazón.

$\$ 26[61]$

241. Auh ynic on-tlaman-tli. yn oncan mo-chiuh yn PARTI ORD dos-cosa-ABS DET allí REF.3.SG-hizo DET

chapoltepe-cuitlapil-co oncan quin-yao-yahuallo-qu-e yn mexica. Chapoltépec-cola-LOC allí o.3.PL-enemigo-cercar-PAs-PL DET mexicas Lo segundo que aconteció alli, a las espaldas de Chapoltépec, fue que alli los enemigos cercaron a los mexicas,

242. yn ixquich yn tepaneca. azcapotzalca yhuan yn culhuaque. DET todo DET tepanecas azcapotzalcas y DET colhuaques yn xochimilca. $\bar{y}$ cuitlahuaca. yhuan yn chalca. DET xochimilcas DET cuitlahuacas $y$ DET chalcas

ompa mo-cenquixti-qu-e.

allá REF.3.PL-reunir-PAS-PL

todos los tepanecas azcapotzalcas y los colhuaques, los xochimilcas, los cuitlahuacas y los chalcas se reunieron allá,

243. mo-centlalli-qu-e yn altepe-tl i-pan tlaca yn ixquich-tin. REF.3.PL-congregar-PAS-PL DET pueblo-ABS PRON.3.SG-LOC gente DET todo-PL

yn ompa yn chalco.

DET allá DET Chalco

se congregaron en el pueblo todas las gentes de allá, de Chalco,

244. y-chan yn i-toca huehue cacamatl teuhc-tli POs.3.SG-casa DET POs.3.sG-nombre Huehue Cacámatl señor-ABS

yn-tlatoca-uh catca yn chalca amaquemeque. POS.3.PL-gobernante-POS era DET chalcas amaquemeques

de la casa del señor llamado Huehue Cacámatl, quien era gobernante de los chalcas amaquemeques. 
$\$ 27[63]$

245. Auh yn chapoltepec. Oncan c-aci-qu-e yn huehue huitzilihuitl. PARTI DET Chapoltépec allí o.3.sG-capturar-PAs-PL DET Huehue Huitzilíhuitl

in yehuatl yn achtopa yn tla-htohua-ni catca huitzilihuitl. DET él DET primero DET oINDI-gobernar-AG era Huitzilíhuitl Alli en Chapoltépec capturaron a Huehue Huitzilíhuitl: él era el primer gobernante Huitzilíhuitl.

246. ompa qui-huica-qu-e yn culhuacan ompa qui-micti-qu-e allá 0.3.sG-llevar-PAS-PL DET Colhuacan allá o.3.SG-matar-PAS-PL

yn culhuaque

DET colhuaques

Lo llevaron allá a Colhuacan y allá los colhuaques lo mataron.

$\$ 28[64]$

247. Auh niman ye yc on-miquani-a yn Mexica yn oncan acuezcomac PARTI luego ya por.eso DIR-refugiarse-IMPE DET mexicas DET allí Acuezcómac

Entonces los mexicas iban a refugiarse alli en Acuezcómac,

248. oncan qui-xin-qu-e oncan qui-cui-q- ${ }^{-}$yn atla-tl. allí 0.3.sG-labrar-PAs-PL allí 0.3.sG-tomar-PAs-PL DET lanzadardos-ABS alli tallaron, alli tomaron el lanzadardos,

249. ynic axcan y-toca-yo-can Atlacuihuayan

por.eso ahora POS.3.SG-nombre-ABSTR-LOC Atlacuihuayan

por eso ahora se le denomina al lugar Atlacuihuayan.

250. niman ye yc huitz-e. on-mo-tlalli-co. yn maçatlan yhuan luego ya por.eso venir-PL DIR-REF.3.PL-asentar-DIR DET Mazatlán y

yn tepetocan mochi yc mo-teca-qu-e in Mexica.

DET Tepetocan todo PARTI REF.3.PL-establecer-PAS-PL DET mexicas

En seguida vienen, vinieron a asentarse en Mazatlán y en Tepetocan todos se establecieron.

251. auh ca nimā oncan hualla-qu-e yn culhuacan. PARTI PARTI después allí venir-PAs-PL DET Colhuacan Después vinieron alli en Colhuacan. 
252. auh yehuatl yn achitometl tla-htohua-ni yn oncan culhuacan. PARTI él DET Achitómetl oINDI-gobernar-AG DET allí Colhuacan Achitómetl es el gobernante de Colhuacan.

253. niman o-quim-ilhui yn Mexica yn huitzilopochtli. luego PAs-0.3.PL-decir DET mexicas DET Huitzilopochtli Luego dijo a los mexicas Huitzilopochtli:

254. no-ta-huan-e xi-c-tlatlauhti-can yn achitometl. canin t-ie-z-que pos.1.sG-padre-pL-voc IMP-0.3.sG-pedir-pL DET Achitómetl donde s.1.pL-estar-FuT-PL "iPadres mios, pidanle a Achitómetl un lugar en donde estaremos!"

255. niman o-qui-tlatlauhti-qu-e yn achitometl. qu-ilhui-qu-e luego PAS-0.3.SG--rogar-PAS-PL DET Achitómetl 0.3.SG-decir-PAS-PL Luego le rogaron a Achitómetl, le dijeron:

256. tlaca-tl-e tlah-tohua-ni-e. ca ti-mitz-to-tlatlauhti-lia campa nel señor-ABS-VOC OINDI-gobernar-AG-VOC PARTI s.1.PL-0.2.sG-REF.1.PL-suplicar-APL donde realmente t-ia-z-que ca onell o-ti-c-mat-qu-e. yn M-a-tzin s.1.pL-ir-fUT-PL porque en.verdad PAs-s.1.1.PL-0.3.sG-saber-PAs-PL DET POS.2.sG-agua-HON

yn Mo-tepe-tzin.

DET POS.2.sG-cerro-HON

"Señor gobernante, te suplicamos un lugar en el que realmente podamos ir, porque en verdad hemos sabido que éste es tu pueblo.

257. ma xi-tech-mo-tlaocoli-li. achi-tzin yn mo-tlal-tzin. OPT IMP-o.1.PL-REF.2.SG-ser.misericordioso-APL poco-DIM DET POS.2.s-tierra-HON

yn oncan y-pan t-on-ye-z-que.

DET allí PRON.3.SG-LOC $\quad$ s.1.PL-DIR-estar-FUT-PL

Sé un poquito misericordioso con nosotros, vamos a estar sobre tu tierra."

258. nimā o-quin-nanqui-lli o-qu-ihto. yn achitometl. entonces PAS-0.3.PL-contestar-APL PAS-0.3.sG-decir DET Achitómetl Entonces les contestó, dijo Achitómetl:

259. ca ye qual-li

está ya bueno-ABS

"Está bien." 
$\$ 29[65]$

260. Auh niman o-quin-nahuati yn i-tlahtoca-huan yn achitometl. PARTI luego PAS-O.3.PL-hablar DET POS.3.SG-gobernante-PL DET Achitómetl

yn culhuaque quim-ilhuia.

DET colhuaques o.3.PL-decir

Luego Achitómetl habló a sus gobernantes, a los colhuaques, les dice:

261. campan ye-z-que o-qu-ilhui-qu-e yn i-tlahtoca-huan en.qué.lugar estar-FUT-PL PAS-O.3.SG-decir-PAS-PL DET POS.3.sG-gobernante-PL “En qué lugar estarán?” Le contestaron sus gobernantes:

262. tlaca-tl-e tla-htohua-ni-e. ma ompa hui-an ma ye ompa ye-ti. seńor-ABs-VOC OINDI-gobernar-AG-VOC OPT allá ir-PL OPT ya allá estar-DIR

yn tepe-titlan. $\bar{y}$ nican tiçapan.

DET cerro-LOC DET aquí Tizapan

"Señor gobernante, que se vayan allá, que ya vayan a estar al cerro que está aqui en Tizaapan."

263. nimā ompa quin-cahua-to. o-quin-tlalli-to. yn ompa tiçaapā. entonces allá 0.3.PL-dejar-DIR PAs-0.3.PL-asentar-DIR DET allá Tizaapan Entonces los fueron a dejar allá, los fueron a asentar allá en Tizaapan.

264. auh niman o-qui-nonotz-qu-e yn tla-htohua-ni PARTI después PAS-0.3.SG-informar-PAS-PL DET OINDI-gobernar-AG yn achitometl qu-ilhuia DET Achitómetl 0.3.sG-decir Después informaron al gobernante Achitómetl, le dicen:

265. tlaca-tl-e tla-htohua-ni-e. ca o-ti-quin-cahua-to. yn tiçaapā señor-ABs-VOC OINDI-gobernar-AG-VOC PARTI PAS-s.1.PL-0.3.PL-dejar-DIR DET Tizaapan yn Mexica. DET mexicas "Señor gobernante, hemos ido a dejar a los mexicas en Tizaapan."

266. niman o-qu-ihto. yn achitometl ca ye qual-li. ca amo tlaca. luego PAs-0.3.SG-decir DET Achitómetl está ya bueno-ABS porque no gente Luego Achitómetl dijo: "Está bien, porque no son humanos, 
267. ca cenca tlahuellilo-que açompa tlami-z-que cohua-qua-llo-z-que. es mucho malvado-PL quizá acabarse-FuT-PL serpiente-comer-PASI-PUT-PL

ca cenca $\bar{y}$-chan yn co-cohua. ya.que mucho Pos.3.PL-casa DET RED-culebra son unos grandes malvados, quizá se acabarán, serán comidos por las serpientes, ya que es la morada de muchas culebras."

$\$ 30[66]$

268. Auh in yehuantin yn Mexica. cenca o-pah-pac-qu-e PARTI DET ellos DET mexicas mucho PAS-RED-alegrarse-PAS-PL

yn o-quim-itta-qu-e yn co-cohua.

DET PAS-O.3.PL-ver-PAS-PL DET RED-culebra

Ellos, los mexicas, se alegraron mucho en el ver las culebras.

269. çan moch yehuantin yn quin-mo-pahuaxi-llia.

sólo todo ellos DET O.3.PL-REF.3.PL-asar-APL

Ellos se las asan todas,

270. yn quin-mo-tlehuachi-llia. yn qui-qua yehuantin mexica. DET 0.3.PL-REF.3.PL-Cocer-APL DET 0.3.sG-comer ellos mexicas se las cuecen y las comen ellos, los mexicas.

$\$ 31[67]$

271. Auh niman ye qui-tohua yn achitometl. o-qu-ilnamic ye quim-ilhuia PARTI luego ya 0.3.SG-hablar DET Achitómetl PAs-0.3.SG-recordar ya o.3.PL-decir Entonces habla Achitómetl, se recordó y ya les dice:

272. culhuaque-he. yn an-quin-cahua-to tla xi-quim-itta-ti. colhuaques-Voc DET $\quad$ s.2.PL-o.3.PL-dejar-DIR OPT IMP-o.3.PL-ver-DIR

cuix o-mic-qu-e

INT PAs-morir-PAs-PL

"Colhuaques, ustedes fueron a dejarlos, vayan a verlos, tal vez han muerto." 
273. niman o-qu-ilhui-q- ${ }^{-}$ca ye qual-li tlaca-tl-e tlah-tohua-ni-e luego PAS-0.3.SG-decir-PAS-PL está ya bueno-ABS señor-ABS-VOC OINDI-gobernar-AG-VOC

ma ti-quim-itta-tin.

OPT s.1.PL-0.3.PL-ver-DIR

Luego le contestaron: "Está bien, señor gobernante, vayamos a verlos."

274. auh yn o-qui-m-on-itta-qu-e. tlapopotz-t-oqu-e. poc-tli mani. PARTI DET PAS-0.3.SG-REF.3.PL-DIR-ver-PAS-PL invadir.el.humo-LIG-estar-PL humo-ABS expandirse Aquellos que fueron a verlos fueron invadidos por el humo, el humo se expande,

275. tla-tlatia. yn i-pan on-aci-qu-e. nimā quim-ilhui-qu-e. RED-arder DET PRON.3.SG-LOC DIR-llegar-PAS-PL luego o.3.PL-decir-PAS-PL arde mucho sobre los que fueron a llegar. Luego les dijeron:

276. ohu-an-qui-hiyohui-qu-e. mexica-ye. çā t-amech-itta-co. PAS-S.2.PL-0.3.SG-sufrir.trabajo-PAS-PL mexicas-VOC sólo s.I.PL-O.2.PL-ver-DIR t-amech-tlapallo-co. quen an-cat-e. S.I.PL-o.2.PL-saludar-DIR cómo s.2.PL-estar-PL "Han sufrido trabajo, mexicas. Sólo venimos a verlos, venimos a saludarlos, ¿cómo están?”

277. nimā o-quin-hual-nanqui-lli-qu-e. o-quim-ilhui-qu-e entonces PAS-0.3.PL-DIR-responder-APL-PAS-PL PAS-0.3.PL-decir-PAS-PL Entonces vinieron a responderles, les dijeron:

278. o-an-tech-mo-cnelli-li-qu-e. ca ti-pac-ti-cat-e PAS-S.2.PL-o.1.PL-REF.2.PL-hacer.bien-APL-PAS-PL ya.que s.1.PL-estar.contento-LIG-estar-PL "Ustedes nos han hecho bien ya que nosotros estamos contentos."

279. qui-m-on-ilhui-qu-e ca ye qual-li. ye ti-hui. o.3.SG-REF.3.PL-DIR-decir-PAS-PL está ya bueno-ABS ya s.1.PL-irse Fueron a contestarles: "Está bien, ya nos vamos."

280. hualla-qu-e yn tecpan niman ye qui-nonotza. yn achitometl. venir-PAS-PL DET palacio luego ya o.3.SG-relatar DET Achitómetl

ye qu-ilhuia

ya $0.3 . s G-d e c i r$

Vinieron al palacio y entonces le relatan a Achitómetl, ya le dicen: 
281. tlaca-tl-e tla-htohua-ni-e. ca o-ti-quim-on-itta-to. señor-ABS-VOC OINDI-gobernar-AG-VOC PARTI PAS-S.1.PL-o.3.PL-DIR-Ver-DIR

ca o-quin-tla-tlami-q-'. yn co-cohua PARTI PAS-0.3.PL-RED-acabar-PAS-PL DET RED-serpiente "Señor gobernante, fuimos a verlos y acabaron con las serpientes,

282. yn o-quin-qua-qu-e cayoca-qu-e yn co-cohua ca o-tlan-qu-e. DET PAS-O.3.PL-comer-PAS-PL no.haber-PART-PL DET RED-serpiente PARTI PAS-extinguir-PAS-PL se las comieron, ya no hay serpientes, se han extinto."

283. nimā o-qu-ihto. yn achitometl. o tla xi-quim-ita-can ca entonces PAs-0.3.SG-decir DET Achitómetl PARTI OPT IMP-O.3.PL-ver-PL que tlahuelliloqu-e. ma qui-chiuh-tie-can maca xi-quin-notza-can. malo-PL OPT $\quad$ 0.3.SG-hacer-CAUs-PL que.no IMP-o.3.PL-dirigirla.palabra-PL Entonces Achitómetl dijo: "Vean que gente tan mala son, déjenlos, ¡no les dirijan la palabra!"

\$32[68]

284. Auh in mexica. in ye huecahua ye quin-mo-cihuamontia PARTI DET mexicas DET ya permanecer ya o.3.PL-REF.3.PL-casar.al.hijo

yn im-ichpoch-huā yn culhuaque in yehuantin Mexica DET POS.3.PL-hija-PL DET colhuaques DET ellos mexicas

Los mexicas permanecen mucho tiempo, casan a sus hijos con las hijas de los colhuaques ellos mismos, los mexicas.

285. auh yn culhuaque ye quin-mo-montia yn Mexica

PARTI DET colhuaques ya o.3.PL-REF.3.PL-casar.a.la.hija DET mexicas

yn in-telpoch-huā ye nellihui yn in-pil-huan

DET POS.3.PL-hijo-PL ya estar.mezclado DET POS.3.PL-hijo-PL

Los colbuaques, por su parte, casan a sus hijas con los hijos de los mexicas, ya están mezclados sus hijos.

$\$ 33[71]$

286. Auh niman o-hual-pano-qu-e. yn oncan culhuacan yn mexica PARTI entonces PAS-DIR-pasar-PAs-PL DET a Colhuacan DET mexicas Entonces los mexicas empezaron a entrar a Colhuacan, 
287. o-quin-hual-huica-qu-e yn in-cihua-huan yn im-ichpoch-huan PAS-O.3.PL-DIR-traer-PAS-PL DET POS.3.PL-mujer-PL DET $\quad$ POS.3.PL-hija-PL

yn culhuaque ye quin-pilhuatia yn oncan y-hti-c altepe-tl. DET colhuaques ya o.3.PL-engendrar.a.un.hijo DET allí POS.3.SG-vientre-LOC pueblo-ABS

yn culhuacan

DET Colhuacan

los trajeron sus mujeres, las hijas de los colhuaques, ya engendran a sus hijos adentro del pueblo de Colhuacan.

$\$ 34[76]$

288. Auh in yehuatl niman o-quim-ilhui yn i-ta-huan PARTI DET él luego PAS-O.3.PL-decir DET POs.3.sG-padre-PL

yn huitzilopochtli.

DET Huitzilopochtli

Luego Huitzilopochtli dijo a sus padres,

289. quim-ilhui no-ta-huan-e oc ce tlaca-tl $\bar{y}$ neci-z. o.3.PL-dijo POs.1.PL-padre-PL-VOC otro uno persona-ABS DET aparecer-FUT

les dijo: "Padres míos, hay otra persona quien aparecerá,

290. y-toca yao-cihua-tl. ca no-ci-tzin.

POS.3.SG-nombre guerra-mujer-ABs es POs.1.sG-abuela-HON

la cual se llama mujer de la guerra, es mi preciada abuela.

291. Auh ca ti-qu-ixnexti-z-que. auh tla xi-c-caqui-can no-ta-van-e. PARTI PARTI s.1.PL-0.3.SG-presentar-FUT-PL PARTI OPT IMP-0.3.sG-escuchar-PL POS.1.sG-padre-PL-VOC Nosotros la presentaremos. ;Escuchen, padres míos!

292. ca amo nican yn t-ie-z-que ca nechca yn ti-tlamati-hui PARTI no aquí DET s.1.PL-estar-FUT-PL porque más.adelante DET s.1.PL-hacer.cautivos-DIR

yn oncan ti-tla-pie-z-qu-e.

DET allí s.1.PL-OINDI-guardar-FUT-PL

No estaremos aquí, porque más adelante vamos a hacer cautivos, alli guardaremos las cosas. 
293. auh ca amo çan nen yn t-ia-z-que. yn ti-quin-tlalcahui-z-que PARTI PARTI no sólo vano DET s.1.PL-ir-FUT-PL DET s.1.PL-O.3.PL-apartarse.de-FUT-PL

yn culhuaque.

DET colhuaques

No iremos en vano. Nos apartaremos de los colhuaques,

294. ca ti-cacocui-z-que yn to-mi-uh yn to-chimal. porque s.1.PL-elevar-fuT-PL DET POs.2.PL-flecha-POS DET POs.1.PL-escudo porque elevaremos nuestra flecha, nuestro escudo.

295. auh yn axcan xi-mo-chicahua-cā. xi-mo-cencahua-can ca PARTI DET ahora IMP-REF.2.PL-fortalecer-PL IMP-REF.2.PL-preparar-PL ya.que

ohu-an-qui-cac-qu-e yn oncan ixneci-z yn yaocihuatl. PAS-S.2.PL-o.3.SG-escuchar-PAS-PL DET allí mostrarse-Fut DET Yaocíhuatl Ahora, ,fortalézcanse, prepárense!, ya que han escuchado que alli Yaocíhuatl,

296. $\bar{y}$ no-ci-tzī auh ca n-amech-nahuatia.

DET POs.1.SG-abuela-HON PARTI PARTI s.1.SG-O.2.PL-mandar

mi preciada abuela, se mostrará. Yo les mando

297. tla xi-hui-an xi-qui-tlani-ti yn i-pil-tzin. yn i-chpoch

que IMP-ir-PL IMP-0.3.sG-pedir-DIR DET POS.3.sG-joven-HON DET POS.3.sG-hija

yn achitometl.

DET Achitómetl

que vayan, vayan a pedir a la joven hija querida de Achitómetl,

298. huel yehuatl yn i-tlaço-pil-tzin an-qui-tlani-li-z-que ca muy ella DET POs.3.sG-noble-hija-HON s.2.PL-O.3.SG-pedir-APL-FUT-PL porque

nehuatl ni-c-mati n-amech-maca-z.

yo s.1.sG-0.3.sG-saber s.1.sG-0.2.PL-dar-FUT

ustedes pedirán su muy noble hija, porque yo sé que se la daré."

$\$ 35[77]$

299. auh niman o-yah-qu-e $\bar{y}$ mexica. o-qui-tlani-to. yn i-chpoch

PARTI luego PAS-ir-PAS-PL DET mexicas PAS-0.3.sG-pedir-DIR DET POS.3.SG-hija

yn achitometl.

DET Achitómetl

Luego los mexicas se fueron, fueron a pedir a la hija de Achitómetl, 
300. o. qui-tlatlauhti-qu-e. yn Mexica qu-ilhuia PARTI 0.3.sG-rogar-PAS-PL DET mexicas o.3.sG-decir los mexicas se la rogaron, dicen:

301. no-pil-tzi-tzin-e tlaca-tl-e tla-htohua-ni-e. POs.1.sG-hijo-HON-DIM-VOC señor-ABS-VOC OINDI-gobernar-AG-VOC "Hijito mio, señor gobernante,

302. ca ti-mitz-to-tlatlauhti-lia yn ti-mo-col-huan PARTI $\quad$ s.1.PL-o.2.SG-REF.1.PL-suplicar-APL DET s.1.PL-POS.2.sG-abuelo-PL te suplicamos nosotros que somos tus abuelos,

303. yn ti-mo-macehual-huan yhuā yn ixquich-tin yn Mexica. $\begin{array}{llll}\text { DET } & \text { s.1.PL-Pos.2.SG-vasallo-PL } \quad y \quad \text { DET todo-PL } \quad \text { DET mexicas }\end{array}$ que somos tus vasallos y todos los mexicas,

304. ca ti-c-mo-macahui-li-z ca ti-tech-mo-maqui-li-z. PARTI s.2.sG-0.3.sG-REF.2.sG-conceder-APL-FUT PARTI s.2.sG-0.1.PL-REF.2.sG-dar-APL-FUT que concedas, que nos otorgues

305. yn mo-cozqui yn mo-quetzal yn mo-chpoch-tzin DET POs.2.sG-collar DET POs.2.sG-pluma.de.queztal DET POs.2.sG-hija-HON

yn to-xhui-uh-tzin

DET POs.2.sG-nieta-POs-HON

tu collar, tu pluma de quetzal, tu preciada hija, tu nieta querida,

306. yn cihua-pil-li ca ompa mo-tla-pie-lli-t-ie-z. yn oncan DET mujer-noble-ABS PARTI allá REF.3.SG-OINDI-custodiar-APL-LIG-ser-FUT DET allí

yn tepetitlan tiçaapan.

DET Tepetitlan Tizaapan

la noble mujer quien será custodiada allá en Tepetitlan Tizaapan."

307. auh niman o-qu-ihto yn achitometl ca ye qual-li Mexica-h-ye. PARTI luego PAS-0.3.SG-decir DET Achitómetl está ya bueno-ABS mexica-PL-VOC

ma xi-c-huica-can

орт IMP-0.3.sG-llevar-PL

Entonces Achitómetl contestó: "Está bien, mexicas, llévensela." 
308. nimā o-quin-maca-c yn mexica o-qui-huica-qu-e yn i-chpoch. luego PAS-0.3.PL-dar-PAS DET mexicas PAS-0.3.SG-llevar-PAS-PL DET Pos.3.sG-hija

yn achitomel.

DET Achitómetl

Luego se la dio a los mexicas, se llevaron a la hija de Achitómetl.

309. c-axiti-qu-e o-c-on-tlalli-to yn oncan tiçaapan niman

o.3.sG-acompañar-PAS-PL PAS-0.3.sG-DIR-establecer-DIR DET en Tizaapan luego

ye qu-itohua yn huitzilopochtli.

ya 0.3. SG-hablar DET Huitzilopochtli

La acompañaron y la fueron a establecer en Tizaapan. Entonces Huitzilopochtli habla,

310. qu-ilhuia yn in-toca teo-mama-que. axollohua tlamacazqui.

o.3.sG-decir DET pos.3.PL-nombre dios-cargar-PARTI-PL Axolohua sacerdote

yhuan yn quauhtlequetzqui.

y DET Cuauhtliquetzqui

dice a los cargadores de los dioses, al sacerdote Axolohua y Cuaubtliquetzqui,

311. quim-ilhuia no-ta-huan-e n-amech-nahuatia yn i-chpoch yn

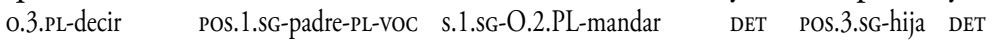
achitometl xi-c-micti-can Achitómetl IMP-0.3.SG-matar-PL les dice: "Padres míos, les mando que maten a la hija de Achitómetl

312. xi-c-xipehua-can yn iquac yn o-an-qui-xipeuh-qu-e. IMP-0.3.sG-desollar-PL DET cuando DET PAS-S.2.PL-0.3.3G-desollar-PAS-PL

xo-c-on-aqui-cā. yn tlamacazqui.

una persona-ABS IMP-O.3.SG-DIR-vestir-PL DET sacerdote

y que la desuellen y cuando ustedes la hayan desollado jvistan con ella a un sacerdote!" 
$\$ 36[78]$

313. auh niman ye qui-mictia. yn qui-xipehua yn cihua-pil-li. PARTI luego ya o.3.sG-matar DET 0.3.3G-desollar DET mujer-noble-ABS Entonces la matan, desuellan a la mujer noble,

314. yn o-c-on-xipeuh-qu-e yn i-yehua-yo nimā ye c-on-aquia. DET PAS-O.3.SG-DIR-desollar-PAS-PL DET POS.3.SG-cuero-ABSTR luego ya o.3.sG-DIR-vestir

yn ce tlaca-tl tlamacazqui.

DET una persona-ABS sacerdote

una vez desollada, visten con su cuero a un sacerdote.

315. auh niMan o-qu-ihto yn huitzilopochtli. no-ta-huan-e tla PARTI luego PAS-0.3.sG-decir DET Huitzilopochtli pos.1.sG-padre-PL-VOC OPT xi-c-notza-ti yn achitometl. IMP-0.3.SG-llamar-DIR DET Achitómetl Después, dijo Huitzilopochtli: "Padres mios, vayan a llamar a Achitómetl."

316. niman o-yah-qu-e yn mexica o-qui-notza-to. qu-ilhuia. luego PAs-ir-PAS-PL DET mexicas PAS-0.3.sG-llamar-DIR o.3.sG-decir to-tecu-iyo-ye no-xhui-uh-tzin-e. pOs.1.PL-Seńor-ABSTR-VOC POS.1.sG-nieto-HON-VOC Luego se fueron los mexicas, fueron a llamarlo, le dicen: "Señor nuestro, mi preciado nieto,

317. tlaca-tl-e tla-htohua-ni-e ti-mitz-to-tlalcahualti-z-que. señor-ABS-VOC OINDI-gobernar-AG-VOC S.1.PL-O.2.SG-REF.1.PL-trastornar-FUT-PL ti-mitz-to-tlapololti-z-que yn ti-mo-macehual-huan. s.1.PL-O.2.SG-REF.1.PL-perturbar-FUT-PL DET s.1.PL-POs.2.sG-vasallo-PL señor gobernante, te trastornaremos, te perturbaremos

318. ca mitz-mo-tlatlauhti-lia. yn mo-col-huan yn Mexica. porque 0.2 .SG-REF.3.PL-suplicar-APL DET POS.2.SG-abuelo-PL DET mexicas nosotros tus vasallos, porque tus abuelos los mexicas te suplican, 
319. ca qu-ihtohua ma qui-mo-ti-lli-qui. ma qui-mo-tlapalhui-qui PARTI $\quad$ o.3.SG-decir OPT $\quad$ o.3.SG-REF.3.SG-ver-APL-DIR OPT $\quad$ 0.3.SG-REF.3.SG-saludar-DIR

yn i-teo-tzin. ca to-c-on-to-nochi-llia.

DET POS.3.SG-dios-HON PARTI S.I.PL-0.3.SG-DIR-REF.1.PL-llamar-APL

dicen: "Que venga a ver, que venga a saludar a su dios." Nosotros lo vamos a llamar."

\$37[79]

320. auh niman o-qu-ihto. yn achitometl ca ye qual-li ma ti-hui-an PARTI luego PAS-0.3.sG-decir DET Achitómetl está ya bueno-ABS OPT s.1.PL-ir-PL Luego Achitómetl dijo: "Está bien, vayamos."

321. niman o-quim-ilhui yn i-tla-htoca-huan yn achitometl. después PAS-0.3.PL-decir DET POS.3.sG-señor-PL DET Achitómetl Después dijo a sus señores Achitómetl:

322. ma ti-hui-an yn tiçaapan, tech-cohuanotza yn Mexica OPT s.1.PL-ir-PL DET Tizaapan o.1.PL-invitar DET mexicas "Vayamos a Tizaapan, nos invitan los mexicas."

323. o-qui-nanqui-lli-qu-e. o-qu-ilhui-qu-e. ca ye qual-li tla-htohua-ni-e PAS-O.3.SG-contestar-APL-PAS-PL PAS-O.3.SG-decir-PAS-PL está ya bueno-ABS OINDI-gobernar-AG-VOC

ma xi-mo-huica.

OPT IMP-REF.3.PL-ir

Le contestaron, le dijeron: "Está bien, señor, vaya usted."

324. auh niman ye qui-huica hol-li copal-li. ama-tl. xochi-tl. in ye-tl. PARTI luego ya o.3.sG-traer hule-ABS copal-ABS papel-ABS flor-ABS DET tabaco-ABS Entonces traen hule, copal, papel, flores y tabaco,

325. yhuan yn i-toca tlaca-tlaqual-li. ye qui-tlamani-li-z-que

y DET POS.3.sG-nombre gente-comida-ABS ya o.3.sG-ofrendar-APL-FUT-PL

yn teo-tl yn iuh qu-ilhui-qu-e DET dios-ABS DET como o.3.sG-decir-PAS-PL y lo que se llama comida para ofrecer, la cual ofrendarian al dios como le habian dicho 
326. achitometl ynic qui-notza-to, auh ca ye amo nel-li in yehuatl. Achitómetl en.lo.que o.3.sG-llamar-DIR PARTI es ya no verdad-ABS DET ese a Achitómetl cuando lo fueron a llamar, pero en realidad no es ese,

327. auh ca ye yehuatl yn o-qui-xipeuh-qu-e. PARTI es ya aquélla DET PAS-0.3.SG-desollar-PAS-PL sino la que habian desollado.

\$38[80]

328. auh yn o-aci-c yn oncan tiçaapan in yehuatl yn achitometl. PARTI DET PAS-llegar-PAS DET allí Tizaapan DET él DET Achitómetl

qu-ilhuia yn Mexica ynic ye qui-hual-namiqui.

o.3.sG-decir DET mexicas PARTI ya o.3.sG-DIR-recibir

Llegado Achitómetl a Tizaapan, los mexicas le dicen mientras vienen a recibirlo:

329. o-ti-c-m-ihiyohuilti. no-xhui-uh-tzin-e tlaca-tl-e tla-htohua-ni-e. PAS-s.2.SG-0.3.SG-REF.2.SG-cansar POS.1.SG-nieto-POS-HON-VOC señor-ABS-VOC OINDI-gobernar-AG-VOC "Te has cansado, mi preciado nieto, señor gobernante,

330. cocoliz-tli ti-mitz-to-cuiti-li-z-que yn ti-mo-col-huan. pecado-ABs s.1.PL-0.2.sG-REF.1.PL-confesar-APL-FUT-PL DET s.1.PL-POS.2.SG-abuelo-PL nosotros tus abuelos, te confesaremos un pecado,

331. yn ti-mo-macehual-huan ma xi-c-mo-tti-lli. ma DET s.1.PL-Pos.2.SG-vasallo-PL OPT IMP-O.3.SG-REF.2.SG-ver-APL OPT

xi-c-mo-tlapalhui yn mo-teo-tzin. IMP-O.3.SG-REF.2.SG-saludar DET POS.2.SG-dios-HON nosotros tus vasallos, ¡ve, saluda a tu venerado dios!”

332. niman o-qu-ihto. ca ye qual-li no-col-huan-e. luego PAs-0.3.SG-decir está bueno-ABS POs.1.sG-abuelo-PL-VOC Luego les contestó: "Está bien, abuelos mios."

333. nimā ye c-on-ana yn hol-li. yn copal-li. luego ya o.3.sG-DIR-tomar DET hule-ABS DET copal-ABS Entonces toma el hule, el copal, 
334. yn xochi-tl. yn iye-tl yn tlaca-tlaqual-li. ye qui-tlamamaca DET flor-ABS DET tabaco-ABS DET gente-comida-ABS ya o.3.sG-dispone las flores, su tabaco y la comida de la gente y ya la dispone,

335. yx-pan qui-tequillia yn çan tlapic y-teo-uh. in yehuat frente-LOC 0.3.SG-acomodar DET sólo falso POs.3.SG-dios-POS DET él

yn o-qui-xipeuh-qu-e.

DET PAS-0.3.SG-desollar-PAS-PL

la acomoda en frente de su falso dios, al que habian desollado.

336. auh in yehuatl yn achitometl. niman ye yc yx-pan PARTI DET él DET Achitómetl luego ya poreso frente-LOC

quin-quech-cotona in ço-çol-tin yn i-teo-uh. o.3.PL-cuello-cortar DET RED-codorniz-PL DET POs.3.SG-dios-POS

Achitómetl en seguida corta cabezas de codornices en frente del dios,

337. auh ca ayemo huel qu-itta-ya in aqui yn yx-pan PARTI PARTI aún.no bien o.3.sG-ver-IMPE DET quién DET frente-LOC

qui-quech-cotona yn ço-çol-tin

o.3.sG-cuello-cortar DET RED-codorniz-PL

pero no veía bien en frente de quién cortaba las cabezas de las codornices.

338. niman ye yc qui-tle-namaqui-lia qui-xahui-lia. yn tlemay-tl, luego ya por.eso o.3.sG-fuego-ofrecer-APL 0.3.SG-aclarar-APL DET bracero-ABS

yn on-m-aqui-ti-ca-c. yn ehua-tl, yn ce tlaca-tl. tlamacazqui. DET DIR-REF.3.SG-vestir-LIG-estar-PAS DET cuero-ABS DET un persona-ABS sacerdote Entonces le ofrece copal y el bracero aclara con su luz al que estaba vestido con la piel, a un sacerdote.

339. auh yn iquac huell o-qu-itta-c yn ca yehuatl. yn i-chpoch. PARTI DET cuando vAUX PAS-O.3.SG-ver-PAS DET es ella DET POS.3.sG-hija Cuando pudo ver que era su hija, 
340. yn achitometl. cenca o-mo-mauhti. niman ye yc tzatzi DET Achitómetl mucho PAS-REF.3.SG-espantar luego ya por.eso gritar quin-tzatzi-llia. yn i-tlahtoca-huan o.3.PL-gritar-APL DET POS.3.SG-seńor-PL

Achitómetl se espantó mucho y en seguida da grandes voces, gritó a sus señores

341. yhuan yn i-macehual-huan quim-ilhuia.

y DET POS.3.sG-vasallo-PL O.3.PL-decir

y a sus vasallos, les dice:

342. aqui-que yn. a. culhuaque-he cuix amo an-qu-itta. quién-PL estos ah colhuques-voc INT no s.2.PL-0.3.sG-ver ¿Quiénes son éstos? Ah, colhuaques, ¿no ven

343. ca o-qui-xipeuh-qu-e y no-chpoch-tzin. amo nican ye-z-que que PAS-0.3.sG-desollar-PAS-PL DET POS.1.sG-hija-HON no aquí estar-FUT-PL

yn tlahuelliloqu-e.

DET malo-PL

que han desollado a mi hija querida? No estarán aqui esos hombres tan malos,

344. ti-quin-micti-z-que ti-quin-po-pollo-z-que. nican tlami-z-que s.1.PL-o.3.PL-matar-FUT-PL s.1.PL-O.3.PL-RED-destruir-FUT-PL aquí acabar-FUT-PL

yn tlahueliloqu-e auh niman ye ic mo-yaotla. DET infeliz-PL PARTI luego ya por.eso REF.3.SG-pelear los mataremos, los destruiremos, aqui no quedará rastro de esos infelices." Entonces se pelea

345. niman ye quim-ilhuia yn i-ta-huan yn huitzilopochtli. luego ya o.3.PL-decir DET POs.3.sG-padre-PL DET Huitzilopochtli y después Huitzilopochtli dice a sus padres:

346. ca nehuatl ni-c-mati çan iviā çan iyollic x-on-quiça-can. PARTI yo s.1.SG-0.3.sG-saber sólo poco.a.poco sólo despacio IMP-DIR-salir-PL "Yo sé que poco a poco y despacio van a salir." 
$\$ 39[81]$

347. Auh niman ye te-toca yn culhuaque quin-toca yn Mexica. PARTI luego ya OINDA-expulsar DET colhuaques o.3.PL-perseguir DET mexicas Entonces expulsan a la gente, los colhuaques persiguen a los mexicas.

348. niman ye quim-on-quequetza yn a-tlah ${ }^{5}$ in Mexica. luego ya o.3.PL-DiR-empujar DET agua-LOC DET mexicas Luego empujan a los mexicas en el agua,

349. ynic quin-huall-ehuiti-q-' quin-tepehua-co. yn oncan PARTI O.3.PL-DIR-dispersar-PAS-PL O.3.PL-arrojar DET allí y-toca-yo-cā Acatzintitlan. POS.3.SG-nombre-ABSTR-LOC Acatzintitlan los vinieron a dispersar, los vinieron a arrojar en el lugar llamado Acatzintitlan.

350. yn mo-mat-qu-e culhuaque aço oncan o-yxpoliuh-qu-e yn a-tlan. DET REF.3.PL-pensar-PAs-PL colhuaques tal.vez allí PAS-perderse-PAS-PL DET agua-LOC Los colbuaques pensaron que tal vez se perderían en el agua.

351. niman toncan val-chimal-pano-qu-e. yc pano-q-' yn mi-tl. luego allí DIR-escudo-atravesar-PAs-PL con pasar-PAs-PL DET flecha-ABS Luego alli vinieron a atravesar con sus escudos, pasaron con las flechas,

352. yn chimal-li. auh yn mi-tl yn m-itohua yn tlacoch-tli. DET escudo-ABS PARTI DET flecha-ABS DET REF.3.SG-decir DET dardo-ABS yn mo-tocayotia tlatzontec-tli. DET REF.3.SG-nombrar jabalina-ABS con los escudos; con las flechas que se dicen dardos, que se nombran jabalinas

353. qui-cuitlalpi-qu-e. y-pā mo-tlalli-qu-e yn a-tlan ynic o.3.sG-hacer.un.atado-PAS-PL PRON.3.SG-LOC REF.3.PL-sentar-PAS-PL DET agua-LOC para hual-pano-qu-e. DIR-atravesar-PAS-PL hicieron unos atados y se sentaron sobre ellos para venir a pasar al otro lado del agua

5 Léase "atlan". 
354. yhuan yn chimal-li y-pan mo-tlalli-qu-e. yn a-tlan. y DET escudo-ABS PRON.3.SG-LOC REF.3.PL-sentar-PAS-PL DET agua-LOC

ynic hual-pano-qu-e. ynic quin-hual-toca-qu-e yn culhuaque. para DIR-pasar-PAS-PL mientras 0.3.PL-DIR-perseguir-PAS-PL DET colhuaques y se sentaron sobre los escudos para venir a pasar al otro lado del agua, mientras los venian persiguiendo los colhuaques.

$\$ 40[82]$

355. Auh niman yc oncā aci-co yn oncā toll-ihti-c. aca-yhti-c. PARTI luego poreso allí llegar-DIR DET allí junco-vientre-LOC caña-vientre-LoC

yn Mexicatzinco.

DET Mexicatzinco

Entonces vinieron a llegar entre los juncos y las cañas, en Mexicatzinco.

356. oncan qui-tzonicpillo-qu-e yn i-toca Acatzin. oncā allí 0.3.sG-poner.de.cabeza-PAs-PL DET Pos.3.sG-nombre Acatzin allí

qui-ti-lli-qu-e. yn i-tzin-co

0.3.SG-ver-APL-PAS-PL DET POS.3.SG-trasero-DIR

Alli pusieron de cabeza al llamado Acatzin, alli le vieron su trasero

357. qui-min-qu-e yc on ${ }^{\text {can }}$ tlatocayoti-qu-e. Mexicatzinco. 0.3.SG-flechar-PAs-PL poreso allí llamar-PAs-PL Mexicatzinco y lo flecharon, por eso llamaron al lugar Mexicatzinco.

358. niman. ye oncan qui-huahuātza yn opaltic yn in-yaotlatqui luego ya allí o.3.sG-ponera.secar DET mojado DET POs.3.PL-arma

yn in-tlahuitz. yn in-chimal yn ixquich. yn in-tlatqui. DET Pos.3.PL-divisa DET pos.3.PL-escudo DET todo DET Pos.3.PL-ropa Luego ponen a secar sus armas mojadas, sus divisas, sus escudos y todas sus ropas.

$\$ 41[83]$

359. auh in yehuātin yn in-cihua-huan. yn in-pil-huan niman ye PARTI DET ellos DET mujer-PL DET pos.3.PL-hijo-PL luego ya mo-choqui-llia. qu-itohua REF.3.PL-llorar-APL $\quad$ 0.3.SG-decir Sus mujeres y sus hijos entonces lloran, dicen: 
360. campan ti-hui ma çā nican ti-ye-cā. yn aca-yhti-c. dónde s.1.PL-ir OPT sólo aquí s.1.PL-estar-PL DET caña-vientre-LOC “Adónde vamos? Sólo estemos aquí, en medio de las cañas.”

361. niman oncan mo-tlalli-q-', niman ye oncan qui-quetza yn luego allí REF.3.PL-asentar-PAS-PL luego ya allí o.3.SG-levantar DET temazcal-li: baño.de.vapor-ABS Luego se asentaron alli y después levantan un baño de vapor:

362. oncan callac-qu-e yn ihtic yn temazcal-li. niman yc mo-tema. allí entrar-PAs-PL DET adentro DET temazcal-ABS luego por.eso REF.3.PL-bañar entonces entraron adentro del temazcal, asi que se bañan.

$\$ 42[84]$

363. auh ynic tlaquallani-qu-e oncan tetzinco mayauh-qu-e yn temazcal-co. PARTI por enojarse-PAS-PL allí Tetzinco retirarse-PAS-PL DET temazcal-LOC Por haberse enojado en Tetzinco, se retiraron del temazcal.

364. niman ye yc quin-hual-toca atlan quin-tepehua-to. luego ya por.eso 0.3.PL-DIR-perseguir agua-LOC 0.3.PL-empujar-DIR Entonces los vienen a perseguir, los fueron a empujar en el agua,

365. çā no toll-ihti-c. aca-yhti-c. yn mo-tlalli-co. sólo también junco-vientre-LOC caña-vientre-LOC DET REF.3.PL-asentar-DIR vinieron a asentarse otra vez en medio de los juncos, de las cañas.

366. oncan ce tlaca-tl mo-miqui-lli y-toca huito. allí un hombre-ABS REF.3.SG-morir-APL POS.3.sG-nombre Huito Alli murió un hombre de nombre Huito

367. oncan qui-tlati-qu-e. yn i-naca-yo. mochi yn ama-pani-tl. allí 0.3.SG-quemar-PAS-PL DET POs.3.sG-carne-ABSTR todo DET papel-bandera-ABS y en ese lugar quemaron su cuerpo, todas las banderas de papel,

368. ynic m-itohua mo-tenehua mo-pan-tlati-lli-qu-e yn Mexica así.que REF.3.sG-decir REF.3.SG-declarar REF.3.PL-bandera-quemar-APL-PAS-PL DET mexicas 
huehue-tq- ynic nexticpac m-itohua antiguo-PL por.eso Nextícpac REF.3.sG-decir asi que se dice, se declara que los antiguos mexicas quemaron banderas, por eso se dice Nexticpac.

\section{$\$ 43[85]$}

369. Auh nimā ye yc huitz-e hual-miquani-qu-e çā no oncan PARTI luego ya por.eso venir-PL DIR-apartarse-PAS-PL sólo también allí

Aca-yhti-c. y toll-ihti-c. cańa-vientre-LOC DET junco-vientre-LOC

En seguida vienen, vienen a apartarse en medio de las mismas cañas, de los mismos juncos,

370. yn mo-tlalli-co y-toca-yo-can yztacalco yn Mexica. DET REF.3.PL-asentar-DIR POs.3.SG-nombre-ABSTR-LOC Iztcacalco DET mexicas vienen a asentarse en el lugar que llaman Iztacalco.

371. quin-hual-yacantia yn i-toca tenochtzin. o.3.PL-DIR-guiar DET Pos.3.sG-nombre Tenochtzin Viene guiando a los mexicas el llamado Tenochtzin.

372. niman oncan ye qui-chihua. qui-tlacati-llia y-toca amatepetl. luego allí ya o.3.sG-hacer o.3.sG-engendrar-APL POs.3.sG-nombre Amatépetl Entonces alli hacen, engendran al que se llama Amatépetl.

373. tzohual-li yn qui-chiuh-qu-e. qui-tzonteconti-qu-e. amaranto-ABS DET o.3.sG-hacer-PAS-PL O.3.sG-poner.cabeza-PAS-PL qui-tlacti-qu-e. qui-mah-mati-qu-e. qu-icxiti-qu-e. o.3.SG-poner.busto o.3.SG-RED-poner.brazos-PAS-PL o.3.sG-poner.pies-PAS-PL Lo hicieron de amaranto, le pusieron cabeza, busto, brazos y pies,

374. yn o-qui-tlaca-quetz-qu-e nimā ye yc qui-tlaquētia qui-panti-qu-e. DET PAS-O.3.SG-persona-levantar-PAS-PL luego ya por.eso 0.3.sG-vestir o.3.sG-arreglar-PAS-PL lo levantaron como una persona, luego lo visten, lo arreglaron. 
375. niman ye yc qui-cuica-tia cen-yohual yn qui-cuica-ti-qu-e yn luego ya por.eso o.3.sG-cantar-CAUS una-noche DET o.3.sG-cantar-CAUS-PAS-PL DET oncan yztacalco.

ahí Iztacalco

Entonces le cantaron una noche entera, le cantaron ahi en Iztacalco.

376. niman ye yc huitz-e yn a-yhti-c y-toca-yo-can

luego ya por.eso venir-PL DET agua-vientre-LOC POS.3.SG-nombre-ABSTR-LOC

pantitlan. ōcan mo-tlalli-qu-e

Pantitlán allí REF.3.PL-asentar-PAS-PL

Después vienen en medio del agua, en el lugar llamado Pantitlán. Alli se asentaron,

377. huecauh-qu-e yn oncan catca yn pantitlan.

permanecer-PAS-PL DET allí estuvo DET Pantitlán

se quedaron un tiempo alli, estuvieron en Pantitlán.

378. auh niman ye huitz-e oncan çan no toll-ihti-c.

PARTI luego ya venir-PL allí sólo también junco-vientre-Loc

aca-yhti-c yn oncan mo-tlalli-qu-e.

cańa-vientre-LOC DET donde REF.3.PL-asentar-PAS-PL

Luego vienen otra vez en medio de los juncos, de las cañas, donde se asentaron.

379. nimā oncan ce tlaca-tl mixiuh yn in-pil-tzin. entonces allí un persona-ABS parió DET POS.3.PL-joven-DIM Entonces alli una persona parió, una jovencita de ellos,

380. yn im-ichpoch in Mexica. y-toca quetzalmoyahuatzin. DET POS.3.PL-hija DET mexicas POs.3.sG-nombre Quetzalmoyahuatzin una hija de los mexicas llamada Quetzalmoyahuatzin.

381. auh yn i-cone-uh y-toca contzallan.

PARTI DET POS.3.sG-párvulo-pos POs.3.sG-nombre Contzalan.

El nombre del párvulo era Contzalan. 
$\$ 44[86]$

382. auh y-pan yn cem-ilhui-tonal-li chiuhcnahui heca-tl. PARTI PRON.3.SG-LOC uno-fiesta-día-ABS nueve veinto-ABS

yehuatl y-pampa yn axcan y-toca-yo-can mixiuhcan. aquello PRON.3.sG-por DEt hoy POS.3.sG-nombre-ABSTR-LOC Mixiuhcan Eso fue en el día de fiesta nueve viento, por esta razón hoy se llama Mixiuhcan.

383. nimā ye yc huitz-e oncan mo-tlalli-co yn oncan ihcac. luego ya por.eso venir-PL donde REF.3.PL-establecer-DIR DET donde está

y-cal-tzin Sant. Pablo. ytepotzco

pos.3.sG-casa-Hon San Pablo Itepotzco

En seguida vienen ahi, vinieron a establecerse donde está la iglesia de San Pablo Itepotzco,

384. yn oncan qui-chiuh-qu-e. qui-quetz-qu-e yn temazcal-li. DET donde o.3.sG-hacer-PAS-PL 0.3.sG-levantar-PAS-PL DET temazcal-ABS en donde hicieron, levantaron un baño de vapor.

385. oncā qui-tē-qu-e yn im-ichpoch. yn mexica. yn i-toca allí o.3.sG-bañar-PAS-PL DET POs.3.PL-hija DET mexicas DET POs.3.sG-nombre quetzalmoyahuatzin. Quetzalmoyahuatzin Alli bañaron a la hija de los mexicas llamada Quetzalmoyahuatzin,

386. oncan o-mo-te ${ }^{6}$ yn i-nan. yn contzallan ynic allí PAS-REF.3.sG-banó DET pos.3.sG-madre DET Contzalan por.eso

mo-tocayotia yn temazcaltitlan.

REF.3.SG-llamar DET Temazcaltitlan

allí se bañó la madre de Contzalan, por eso se llama Temazcaltitlan,

387. oncan mo-ten-qu-e mochi-ntin yn mexica. oncan mo-tlalli-qu-e. allí REF.3.PL-bańar-PAS-PL todo-PL DET mexicas allí REF.3.PL-asentar-PAS-PL

ye cat-e.

ya estar-PL

alli todos los mexicas se bañaron, allí se asentaron, ya están.

6 Léase "omoten". 
$\$ 45[87]$

388. auh niman oncan on-ehua-qu-e o-yah-qu-e yn toll-ihti-c. PARTI luego allí DIR-partir-PAS-PL PAS-irse-PAS-PL DET junco-vientre-LOC

yn aca-yhti-c

DET caña-vientre-LOC

Luego partieron de alli, se fueron en medio de los juncos y de las cañas

389. yn oncan yn axcan mo-tocayotia tol-tzallan. aca-tzallan. DET donde DET ahora REF.3.SG-nombrar espadaña-entre carrizo-entre donde ahora se nombra Toltzalan Acatzalan.

390. niman ynic o-yah-qu-e yn Mexica huehue-tque yn i-toca luego de.eso PAs-irse-PAs-PL DET mexicas anciano-PL DET pos.3.sG-nombre yn quauhtlequetzqui.

DET Cuauhtliquetzqui

Después se fueron los ancianos mexicas, el llamado Cuauhtliquetzqui

391. yhuan no yehuatl yn i-toca yn axollohua tlamacazqui. y también él DET pos.3.sG-nombre DET Axolohua sacerdote y también el sacerdote llamado Axolohua,

392. ym omextin yah-qu-e yn tla-temo-to yn canin mo-tlali-z-que. DET ambos ir-PAs-PL DET oINDI-buscar-DIR DET lugar.donde REF.3.PL-establecer-PUT-PL ambos fueron a buscar un lugar donde pudieran establecerse.

$\$ 46[88]$

393. auh yn oy-pan quiça-to. yn o-qu-itta-qu-e cenca miec PARTI DET PRON.3.SG-LOC salir-DIR DET PAs-0.3.sG-Ver-PAs-PL muy mucho tlaman-tli. yn tlamahuiçol-li. cosa-ABS DET maravilloso-ABS Cuando fueron a salir vieron muchisimas cosas maravillosas

394. yn oncan ca yn aca-yhti-c ca yehica ypampa y-nnahuatil DET allí PARTI DET caña-vientre-LOC PARTI poreso porque pos.3.sG-promesa yuh quim-ilhui yn huitzilopochtli. así 0.3.PL-dijo DET Huitzilopochtli en ese lugar que está en medio de las cañas, y eso conforme a la promesa de quien asi lo habia dicho de Huitzilopochtli, 
395. yn teo-mama-qu-e yn i-ta-huan yn quauhtlequetzqui yn DET dios-cargar-PART-PL DET POs.3.sG-padre-PL DET Cuauhtliquetzqui DET axollohua tlamacazqui.

Axolohua sacerdote los cargadores del dios, sus padres Cuaubtliquetzqui y el sacerdote Axolohua.

396. ca quin-nahuati. ca yuh quim-ilhui yn ixquich yn oncan PARTI O.3.PL-ordenó PARTI así o.3.PL-dijo DET todo DET donde

yn onoc yn toll-ihti-c

DET encontrarse DET junco-vientre-LOC

De hecho, les ordenó, asi les dijo a todos que donde se encuentra en medio de los juncos,

397. yn aca-yhti-c. yn oncā yhca-z. yn oncan tla-pie-z. in DET caña-vientre-LOC DET allí estar-FUT DET allí oINDI-guardar-FUT DET yehuatl yn huitzilopochtli.

él DET Huitzilopochtli en medio de las cañas, alli estaría, allí guardaría las cosas, él, Huitzilopochtli

398. ca y-tencopa quim-ilhui. ca yuh quin-nahuati. yn mexica PARTI POS.3.SG-por.mandato PARTI así 0.3.PL-ordenó DET mexicas Por su mandato les dijo, asi lo ordenó a los mexicas.

399. auh niman o-qu-itta-qu-e. yztac yn ahuehue-tl. yztac yn huexo-tl. PARTI entonces PAS-O.3.SG-ver-PAS-PL blanco DET sabina-ABS blanco DET sauce-ABS

yn oncan yhcac. yhuan yztac yn aca-tl DET allí está y blanco DET caña-ABS Entonces vieron una sabina blanca, un sauce blanco que alli estaba, y también las cañas eran blancas,

400. yztac yn tol-li. yhuan yztac yn cueya-tl. yztac yn mich-in. blanco DET espadańa-ABS y blanco DET rana-ABS blanco DET pescado-ABS

yztac yn cohua-tl yn oncan nemi a-tlan. blanco DET serpiente-ABS DET allí andar agua-LOC las espadañas eran blancas, las ranas blancas, el pescado blanco, las serpientes blancas que alli andaban por el agua. 
401. auh niman o-qu-itta-qu-e nepaniuh-ti-ca-c yn texcal-li yn ozto-tl. PARTI luego PAS-0.3.SG-ver-PAS-PL mezclarse-LIG-estar-PAS DET peña-ABS DET cueva-ABS Luego vieron unas peñas y cuevas (fuentes) que se estaban cruzando:

402. ynic ce yn texcal-li. yn ozto-tl. Tonatiuh. y-quiça-yan ytz-t-oc. ORD uno DET peńa-ABS DET cueva-ABS sol POs.3.SG-salir-LOC mirar-LIG-estar y-toca tle-a-tl. a-tlatla-yan. POS.3.SG-nombre fuego-agua-ABS agua-hervir-Loc

el primer manantial estaba mirando hacia la salida del sol y se llamaba agua de fuego, lugar del agua hirviendo,

403. Auh ynic ome $\bar{y}$ texcal-li yn ozto-tl. mictlampa ytz-t-oc PARTI ORD dos DET peña-ABS DET cueva-ABS hacia.el.norte mirar-LIG-estar mientras que la segunda fuente estaba mirando hacia el norte,

404. ynic nepaniuh-t-oc. y-toca matlall-a-tl. yhuan y-toca por.eso cruzarse-LIG-estar POS.3.SG-nombre azul-agua-ABS y POS.3.sG-nombre

toxpall-a-tl.

amarillo-agua-ABS

de manera que estaban cruzándose la que se llamaba agua azul con la que se llamaba agua amarilla.

$\$ 47[89]$

405. Auh yn o-qu-itta-qu-e niman ye choca yn huehue-tque qu-itohua PARTI DET PAS-0.3.SG-ver-PAS-PL luego ya llorar DET viejo-PL o.3.sG-decir Después de haber visto eso, los viejos lloran, dicen:

406. Anca ye nican ye-z ca o-ti-qu-itta-qu-e. yn tech-ilhui ynic entonces ya aquí ser-fut que PAS-s.1.PL-O.3.SG-ver-PAS-PL DET o.1.PL-dijo PARTI tech-nahuati yn tlamaca-z-qui yn huitzilopochtli. o.1.PL-prometer DET sustentar-FUT-PART Huitzilopochtli "Entonces será aqui, dado que hemos visto lo que nos dijo, lo que nos ha prometido el sustentador Huitzilopochtli. 
407. yn qu-ihto. yn iuhqui an-qu-itta-z-que yn toll-ihti-c yn DET o.3.sG-dijo DET como S.2.PL-o.3.sG-ver-FUT-PL DET espadaña-vientre-LOC DET aca-yhti-c. miec tlaman-tli. yn oncan ca. cańa-vientre-LOC mucho cosa-ABS DET allí está Él dijo que muchas cosas de esta suerte verian ustedes entre las espadañas y carrizales $y$ alli están.

408. auh yn axcan ca o-ti-qu-itta-qu-e. o-ti-c-mahuiço-qu-e. ca PARTI DET ahora PARTI PAS-S.1.PL-ver-PAS-PL PAS-s.1.PL-0.3.SG-admirar-PAS-PL porque

ye nel-li ca o-mo-chiuh.

ya verdad-ABS PARTI PAS-REF.3.SG-realizar

Ahora lo hemos visto, lo hemos admirado, porque en verdad se realizó,

409. ca o-nelti-c yn i-tlahtol ynic tech-nahuati. PARTI PAS-ser.verdad-PAS DET POS.3.sG-palabra PARTI o.1.PL-prometer han sido verdad las palabras que él nos prometió."

410. niman o-qu-ihto-qu-e. mexica-ye ma oc ti-hui-an ca entonces PAS-0.3.SG-decir-PAS-PL mexicas-VOC OPT aún s.1.PL-irse-PL porque o-ti-tlamahuiço-qu-e PAS-S.1.PL-maravillarse-PAS-PL

Entonces dijeron: "Mexicas, vámonos porque nos hemos maravillado,

411. ma oc ti-c-tlahtol-chiye-can yn tlamaca-z-qui yehuatl qui-mati OPT aún s.1.PL-0.3.SG-palabra-esperar-PL DET sustentar-FUT-PART él o.3.SG-saber quenin mo-chihua-z. como REF.3.SG-hacer-FUT aún esperemos el mandamiento del sustentador, él sabe lo hay que hacer."

412. niman o-hualla-qu-e. mo-tlalli-co yn oncan temazcaltitlan. luego PAS-venir-PAS-PL REF.3.PL-asentar-DIR DET en Temazcaltitlan Luego vinieron, vinieron a asentarse en Temazcaltitlan. 
$\$ 48[90]$

413. auh niman yohual-tica yn o-qu-itta-c. yn o-qui-mo-ttiti.

PARTI luego noche-INTRS DET PAS-O.3.SG-ver-PAS DET PAS-0.3.SG-REF.3.SG-mostrar

yn teo-mama yn i-toca quauhtlequetzqui

DET dios-cargar DET POs.3.sG-nombre Cuauhtliquetzqui

Luego de noche vio, se le apareció al cargador del dios llamado Cuaubtliquetzqui

414. in yehuatl yn huitzilopochtli. o-qu-ilhui

DET él DET Huitzilopochtli PAS-0.3.sG-decir

él, Huitzilopochtli, le dijo:

415. quauhtlequetzqui-he. ca ohu-an-qu-itta-qu-e yn ixquich yn

$\begin{array}{lll}\text { Cuauhtliquetzqui-voc PARTI PAS-S.2.PL-o.3.SG-ver-PAS-PL DET todo DET } & \end{array}$

oncan onoc yn aca-yhti-c ohu-an-tlamahuiço-qu-e.

en.donde encontrarse DET caña-vientre-LOC PAS-s.2.PL-meravillarse-PAS-PL

"Cuaubtliquetzqui, ustedes han visto todo, en el lugar que se encuentra en medio de las cañas se han maravillado.

416. Auh tla xi-c-caqui-ca oc cē-tlaman-tli yn ayemo an-qu-itta. PARTI OPT IMP-0.3.SG-escuchar-PL aún uno-cosa-ABS DET aún.no s.2.PL-o.3.sG-ver Escuchen, aun una cosa les falta por ver.

417. auh ynin xi-hui-an xi-qui-tta-ti. yn te-noch-tli yn oncan PARTI DET IMP-ir-PL IMP-o.3.SG-ver-DIR DET piedra-tuna-ABS DET ahí

an-qu-itta-z-q-

s.2.PL-0.3.SG-ver-FUT-PL

¡Vayan a ver al tunal de piedra! Ahi lo verán,

418. i-cpac ca y-cpac iyhcac. in yehuatl. yn quauh-tli. PRON.3.SG-sobre está PRON.3.SG-sobre estar.parado DET ella DET águila-ABS

oncan tla-qua. oncan mo-totonia.

allí oINDI-comer allí REF.3.SG-calentarse

encima de él se encuentra, encima de él está parada un águila. Allí come y se calienta al sol. 
419. auh ca ye pachihui yn amo-yollo. ca yehuatl. yn i-yollo PARTI PARTI ya estar.enterrado DET pOs.2.PL-corazón PARTI aquel DET pOs.3.sG-corazón in copil yn ti-q-ual-mayauh yn oncā ti-mo-quetz tlalcocomocco DET Cópil DET s.2.sG-0.3.sG-DIR-arrojar DET allí s.2.sG-REF.2.sG-parar Tlalcocomocco Ya está enterrado vuestro corazón, aquel corazón de Cópil que viniste a arrojar en ese lugar de Tlalcocomocco donde tú te paraste.

420. Auh niman oncan huetzi-co yn o-an-qu-itta-qu-e texcal-ten-pa. PARTI después allí caer-DIR DET PAS-S.2.PL-0.3.SG-ver-PAS-PL peña-orilla-LOC ozto-ten-pa. yn aca-tzallan. yn tol-tzallan. cueva-orilla-LOC DET cańa-entre DET junco-entre Después de que allí vino a caer, ustedes vieron la orilla de la peña, la entrada de la cueva entre las cañas y los juncos.

421. auh ca ōcā yxhua-c. yn i-yollo. yn copil. yn axcan PARTI PARTI allí brotar-PAS DET POS.3.SG-corazón DET Cópil DET ahora mo-tocayotia tenochtli. REF.3.sG-llamar Tenochtli Alli brotó el corazón de Cópil que ahora se llama Tenochtli.

422. auh ca oncan yn t-ie-z-que. yn ti-tla-pie-z-que. yn PARTI PARTI allí DET s.1.PL-estar-FUT-PL DET s.1.PL-OINDI-aguardar-FUT-PL DET ti-te-chie-z-que. yn ti-te-namiqui-z-que. s.1.PL-OINDA-esperar-FUT-PL DET s.1.PL-OINDA-encontrar-FUT-PL Alli estaremos, aguardaremos, esperaremos y encontraremos

423. yn nepahpan. tlaca. t-elchiqui-uh to-tzonteco. DET diferente gente Pos.1.PL-pecho-pos pos.1.PL-cabeza a diferentes pueblos, nuestro pecho, nuestra cabeza,

424. to-mi-uh to-chimal. ynic ti-quim-itta-z-que yn ixquich yn Pos.1.PL-flecha-Pos $\quad$ Pos.1.PL-escudo PARTI s.1.PL-o.3.PL-ver-fuT-PL DET todo DET tech-yahuallo-t-oc o.1.pL-rodear-LIG-estar nuestra flecha, nuestro escudo los veremos, todos nos están rodeando, 

425. yxquich ti-quin-pehua-z-que ti-quim-açi-z-que. todo s.1.PL-0.3.PL-sujetar-FUT-PL s.1.PL-O.3.PL-alcanzar-FUT-PL todos los sujetaremos, todos los haremos prisioneros.
426. yc mani-z yn t-altepe-uh mexico. tenochtitlan. por.eso extenderse-FUT DET POs.1.PL-ciudad-pos México Tenochtitlan Por eso estará extendida nuestra ciudad México Tenochtitlan,

$\begin{array}{clll}\text { 427. quauh-tli } & \text { y-pi-pitzca-yan } & \text { y-ne-toma-yan. } & \text { quauh-tli } \\ \text { águila-ABS } & \text { POS.3.SG-RED-chillar-LOC } & \text { POS.3.SG-REF-extender-LOC } & \text { águila-ABS }\end{array}$ y-tla-cua-yan. yhuan mich-in y-patlani-an. POS.3.SG-OINDI-Comer-LOC y pez-ABS POS.3.SG-nadar-LOC donde el águila chilla, donde extiende sus alas, donde el águila come, donde el pez nada

428. yhuan cohua-tl y-çomoca-yan. ${ }^{7}$ yn mexico yn tenochtitlan. y serpiente-ABS POS.3.SG-roncar-LOC DET México DET Tenochtitlan $y$ donde la serpiente ronca, en México Tenochtitlan.

429. auh ca miec tlaman-tli. yn mo-chihua-z. PARTI PARTI mucho cosa-ABS DET REF.3.SG-hacer-FUT Muchas cosas se cumplirán."

7 No he podido encontrar el verbo "zomoca" en ningún diccionario náhuatl, sin embargo, es posible traducirlo como "roncar" si tomamos en cuenta la traducción que realizó el mismo Chimalpáin en una de sus obras en espańol llamada Historia o crónica mexicana (Chimalpahin Quauhtlehuanitzin, 1997: I, 28, "ado[nde] rronca la cunlebra"). Por otra parte, León (Tezozómoc, 1998: 65) interpreta el verbo como "tzomoca", derivado del verbo "tzomoni" (romper, desgrarrar) y traduce "es desgarrada la serpiente", inspirándose en la célebre iconografía del escudo nacional mexicano: un águila sobre un tunal que tiene entre su pico y sus garras una serpiente. Conformes con la traducción de Chimalpáin son las versiones de Riese (2004: 149, "die Schlage zischt"), Anderson y Schroeder (Chimalpahin Quauhtlehuanitzin, 1997, I, 103, “the serpent hisses”) y Tena (Chimalpáhin, 2012: 73, "bufa la serpiente"). 
430. niman o-qu-ilhui yn quauhtliquetzqui ca ye qual-li. Luego PAS-0.3.SG-decir DET Cuauhtliquetzqui está ya bueno-ABS tlamaca-z-qu-e O-tlacauhqui y mo-yollo-tzin sustentar-FUT-PART-VOC PAS-complacerse DET POs.2.sG-corazón-HON Luego Cuauhtliquetzqui dijo: "Está bien, sustentador, se ha complacido tu venerado corazón.

431. ma qui-caqui-can y mo-tta-huan yn huehue-tque yn ixquich-tin. OPT 0.3.SG-escuchar-PL DET POs.2.sG-padre-PL DET anciano-PL DET todo-PL Que lo escuchen tus padres, todos los ancianos."

432. yc niman o-quin-centlalli yn Mexica quauhtliquetzqui por.eso luego PAS-O.3.PL-convocar DET mexicas Cuauhtliquetzqui Por eso luego Cuaubtliquetzqui convocó a los mexicas,

433. o-quin-caqui-lti yn i-tlahtol yn huitzilopochtli. yn PAS-0.3.PL-oir-CAUS DET POs.3.sG-palabra DET Huitzilopochtli DET

o-qui-cac-qu-e mexica.

PAS-0.3.SG-escuchar-PAS-PL mexicas

les reveló las palabras de Huitzilopochtli y los mexicas lo escucharon.

$\$ 49[91]$

434. Auh niman ono ceppa yah-qu-e yn tol-tzallan. yn aca-tzallan. PARTI luego también una.vez ir-PAS-PL DET espadańa-entre DET caña-entre

yn ozto-ten-pa.

DET cueva-orilla-LOC

Luego otra vez fueron entre las espadañas y los carrizales, a la orilla la cueva.

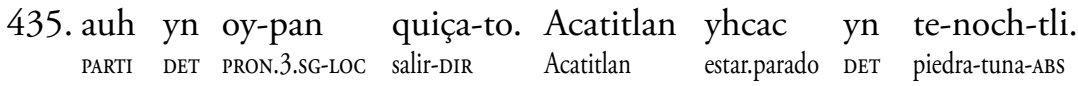

yn oncan ozto-ten-pa yn o-qu-itta-qu-e

DET allí cueva-orilla-LOC DET PAS-0.3.SG-ver-PAS-PL

Fueron a salir allá, a Acatitlan, donde está parado el tunal de piedra, alli a la orilla de la cueva lo vieron, 
436. y-срас ca y-cpac yhcac. mo-quetz-ti-ca.c PRON.3.SG-encima está PRON.3.SG-encima estar.parado REF.3.sG-levantar-LIG-estar-PAS

yn quauh-tli. in yehuatl yn te-noch-tli.

DET águila-ABS DET él DET piedra-tuna-ABS

encima de él se encuentra, encima de él está parada, se está levantando el águila, él, el tunal de piedra.

437. oncan tla-qua. oncan qui-qua qui-tzo-tzopitz-ti-ca-c. yn qui-qua. allí oINDI-comer allí o.3.sG-comer o.3.sG-RED-picotear-LIG-estar-PAS DET o.3.sG-comer Allí come algo, alli lo come, está picoteando lo que come.

438. auh in yehuatl yn quauh-tli. yn o-quim-itta-c. yn Mexica PARTI DET ella DET águila-ABS DET PAS-O.3.PL-ver-PAS DET mexicas El águila vio a los mexicas,

439. cenca o-mo-pechteca-c. yn quauh-tli. çan huecapa yn mucho PAS-REF.3.SG-bajar.la.cabeza-PAS DET águila-ABS sólo lejos DET c-on-itta-qu-e.

o.3.SG-DIR-ver-PAS-PL mucho bajó la cabeza el águila, sólo de lejos fueron a verla.

440. Auh in i-tapaçol yn i-pepech çan moch yehuatl yn ixquich PARTI DET pos.3.SG-nido DET pos.3.sG-cama sólo todo él DET todo

$\overline{\mathrm{y}}$ nepahpan tlaço-yhui-tl.

DET multitud.de precioso-pluma-ABS

Su nido, su cama es de todo eso, todo es de una multitud de plumas preciosas,

441. yn ixquich yn xiuhtoto-yhui-tl. yn tlauhquechol-yhui-tl. yn DET todo DET continga.azul-pluma-ABS DET espátula.rosa-pluma-ABS DET ixquich quetzal-li.

todo pluma.de.quetzal-ABS

todo es de plumas del cotinga azul, del espátula rosa, todo es de plumas de quetzal. 
$\$ 50[92]$

442. auh ca no oncan qu-itta-qu-e yn oncan tetepeuh-t-oc. PARTI PARTI también allí o.3.sG-ver-PAS-PL DET allí esparcir-LIG-estar

yn in-tzonteco $\bar{y}$ nepahpan toto-me yn tlaço-toto-me. DET POs.3.PL-cabeza DET multitud.de ave-PL DET precioso-ave-PL También en ese lugar vieron que alli estaban esparcidas las cabezas de una multitud de aves, de aves preciosas,

443. yn tzonteco oncan çoço-ti-cat-e. yhuan cequi toto-ycxi-tl. DET POS.3.PL-cabeza allí ensartar-LIG-estar-PL y algún ave-pata-ABS

cequi omi-tl.

algún hueso-ABS

sus cabezas alli estaban ensartadas, y algunas patas de las aves, algunos huesos.

444. auh oncan quin-notz in diablo quim-ilhui mexica-ye ye onca ye-c-in. PARTI allí 0.3.PL-llamó Detdiablo o.3.PL-dijo mexicas-voc ya allí ser-FUT-esto Entonces los llamó el diablo, les dijo: “'Mexicas, alli será esto!”

445. auh yece amo qu-itta yn mexica yn aquin quin-nozta. PARTI pero no 0.3.SG-ver DET mexicas DET quién o.3.PL-llamar

Pero no ven los mexicas quién los llama.

446. yc oncā tlahtocayoti-qu-e Tenochtitlan

PARTI allí llamar-PAS-PL Tenochtitlan

Asi fue que pusieron al lugar el nombre de Tenochtitlan.

447. Auh niman ye yc choca yn Mexica. qu-itohua o-to-cnopi-lti-c. PARTI luego ya por.eso llorar DET mexicas o.3.sG-decir PAS-s.2.sG-servir-CAUS-PAS

o-to-macehua-lti-c ${ }^{8}$

PAS-S.2.SG-merecer-CAUS-PAS

Entonces lloran los mexicas, dicen: “iHas hecho servicio, has hecho merecimiento,

8 Los verbos "otocnopiltic" y "otomacehualtic" están en la segunda persona del singular, sin embargo, todos los traductores de este pasaje los interpretan como verbos en la primera persona del plural: León (Tezozómoc, 1998: 66) traduce "fuimos dignos, merecimos", Anderson y Schroeder (Chimalpahin Quauhtlehuanitzin, 1997, I, 103) "We have won favor, we have received" y Riese (2004: 152) "Wir haben erlangt, wir haben erreicht." La traducción de Tena (Chimalpáhin, 2012: 75) "Dichosos de nosotros" no es apegada al náhuatl, pero mantiene el sentido de la primera persona del plural. 
448. ca o-ti-c-mahuiço-qu-e yn t-altepe-uh ye-z: ya.que PAS-s.1.PL-0.3.sG-asombrarse-PAS-PL DET POS.1.PL-ciudad-POS

ma oc ti-hui-an ma oc ti-to-cehui-ti. OPT aún s.1.PL-ir-PL OPT aún s.I.PL-REF.1.PL-descansar-DIR ya que nos asombramos de lo que será nuestra ciudad! ;Vámonos ya a descansar!”

449. niman ye yc huitz-e ōcan Temazcaltitlan. luego ya por.eso venir-PL en Temazcaltitlan En seguida vuelven a Temazcaltitlan.

$\$ 51[93]$

450. Auh ca niman ye yc quim-ilhuia in yehuat in PARTI PARTI luego ya por.eso o.3.PL-decir DET él DET quauhtlequetzqui. yn Mexica quim-ilhui Cuauhtliquetzqui DET mexicas o.3.PL-dijo En seguida Cuauhtliquetzqui habla a los mexicas, les dijo:

451. no-pil-huan-e ma ti-tlach-tequi-cā ma achitzin POS.I.SG-hijo-PL-VOC OPT S.I.PL-juego.de.pelota-edificar-PL оPT un.poco ti-c-tlalli-can tlachcuitec-tzin-tli. S.I.PL-O.3.SG-establecer-PL montículo-DIM-ABS “Hijos mios, edifiquemos el juego de pelota, establezcamos modestamente un pequeño montículo

452. yhuan to-tlal-momoz. yn oncā o-ti-qu-itta-to yn quauh-tli. y POs.1.PL-tierra-altar DET donde PAS-S.1.PL-0.3.SG-ver-DIR DET águila-ABS y nuestro altar de tierra a donde fuimos a ver el águila!

453. Aço quenmanian oncan mo-cehui-quiuh yn tlamacazqui yn quizá algún.día allí REF.3.sG-descansar-DIR DET tlamacazqui DET to-teo-uh yn huitzilopochtli. POS.1.PL-dios-pos DET Huitzilopochtli Quizá algún dia alli querrá venir a descansar el tlamacazqui, nuestro dios Huitzilopochtli." 
454. niman o-qu-ihto-qu-e in mexica. ca ye qual-li ma ti-c-chihua-can luego PAS-O.3.sG-hablar-PAS-PL DET mexicas está ya bueno-ABS OPT s.1.PL-0.3.SG-hacer-PL Luego hablaron los mexicas: "Está bien, jhagámoslo!"

455. niman o-qui-tlalli-qu-e yn tlachcuitetel-li yhuā yn in-tlal-momoz. entonces PAS-O.3.SG-asentar-PAS-PL DET montículo-ABS y DET POS.3.PL-tierra-altar

yn oncan ozto-ten-pa yn oncan yhcac yn te-noch-tli. DET allí cueva-orilla-LOC DET donde erguirse DET piedra-tuna-ABS

Entonces asentaron el montículo y el altar de tierra en la orilla de la cueva, donde se yergue el tunal de piedra.

456. auh ca ypampa. ca yuh qu-ilhui ca yuh qui-nahuati yn PARTI PARTI porque es así o.3.sG-dijo es así o.3.sG-mandó DET

huitzilopochtli. in yehuatl yn quauhtlequetzqui.

Huitzilopochtli DET él DET Cuauhtliquetzqui

La razón de esto es que Huitzilopochtli asi le dijo, asi se lo mandó a él, a Cuauhtliquetzqui

457. ca y-nahuatil yn qui-chihua-z-que yn Mexica. PARTI POs.3.sG-mandato DET o.3.sG-cumplir-FUT-PL DET mexicas y su mandato lo tienen que cumplir los mexicas.

\section{$\$ 52[94]$}

458. Auh ca cenca ycnoyo-tica netoliniliz-tica in ye qui-chihua in PARTI PARTI muy pobre-INSTR trabajo-INSTR DET ya o.3.sG-hacer DET

ye qui-tlallia yn i-cal yn huitzilopochtli.

ya 0.3.sG-asentar DET Pos.3.sG-casa DET Huitzilopochtli

Muy pobremente, con mucho trabajo hacen, asientan la casa de Huitzilopochtli,

459. ynic qui-quetz-qu-e ca çaçan oc tepiton y-toca Ayauhcalli. así.que 0.3.sG-levantar-PAS-PL es inutilmente aún pequeño POs.3.sG-nombre Ayauhcalli asi que levantaron aunque sea algo pequeño, llamado Ayauhcalli.

460. campa nel qui-cui-z-que yn t-etl. $\bar{y}$ quahui-tl dónde por.cierto 0.3.sG-tomar-FUT-PL DET piedra-ABS DET madera-ABS ¿De dónde por cierto tomarán las piedras, las maderas? 
461. auh ca nel te-tlal-pan yn cat-e yn mo-tlalli-co yn PARTI PARTI en.verdad OINDA-tierra-LOC DET estar-PL DET REF.3.SG-asentar-DIR DET

toll-iti-c yn aca-yhti-c.

tule-vientre-LOC DET carrizo-vientre-LOC

Porque en verdad están sobre la tierra de otra gente, vinieron a asentarse en medio de los tules y los carrizos,

462. ca yn in-tlal-pā yn tepaneca yn azcapotzalcatl. yhuan ca PARTI DET POS.3.PL-tierra-LOC DET tepanecas DET azcapotzalca-ABS y PARTI

yn-tlal-pan yn aculhuacatl.

POS.3.PL-tierra-LOC DET acolhuaca-ABS

sobre la tierra de los tepanecas, azcapotzalcas, sobre la tierra de los acolhuaques,

463. ca te-quaxoch-co yn cat-e yhuan ca yn-quaxoch-co yn culhuaque PARTI OINDA-término-LOC DET estar-PL y PARTI POS.3.PL-término-LOC DET colhuaques estaban en los términos de otra gente, en los términos de los colhuaques.

464. auh ca ypampa yn cenca mo-tollinia-ya. PARTI PARTI por.esta.causa DET mucho REF.3.PL-padecer-IMPE Por esta causa padecian mucho.

$\$ 53[95]$

465. Auh ca niman ye no ceppa mo-nahuatia yn Mexica. qu-ihtohua. PARTI PARTI luego ya también una.vez REF.3.PL-aconsejar DET mexicas 0.3.sG-decir Entonces una vez se aconsejan los mexicas, dicen:

466. tla xi-hual-hui-an mexica-ye ma ti-tlatlatlauhti-ti. yn $\begin{array}{llll}\text { OPT IMP-DIR-ir-PL mexicas-VOC OPT } & \text { s.1.pL-rogar-DIR DET }\end{array}$ tepanohuayan yhuā yn azcapotzalco. Tepanoayan y DET Azcapotzalco “Vamos, mexicas, vamos a rogar a Tepanoayan y a Azcapotzalco!"

467. Auh niman mochi-ntin. o-qu-ihto-qu-e ca amo huel PARTI luego todo-PL PAs-o.3.sG-decir-PAs-PL es no bien mo-chihua-z yn ompa ti-tlatlatlauhti-ti-hui REF.3.sG-hacer-FUT DET allá s.1.PL-rogar--IG-ir Pero todos dijeron: "No será bueno hacerlo, ir a rogar allá, 
468. ma çan ic ti-quin-quallani-ti yn tepanohuayan tlaca yhuan OPT sólo con.eso s.1.PL-0.3.PL-enojar-CAUS DET Tepanoayan gente y

yn azcapotzalca

DET azcapotzalcas

con eso sólo vamos a hacer enojar a la gente de Tepanoayan y a los azcapotzalcas."

$\$ 54[101]$

469. Auh niman ye no ceppa mo-nahuatia yn Mexica ye qu-itohua PARTI luego ya también una.vez REF.3.PL-aconsejar DET mexicas ya o.3.sG-decir Entonces otra vez los mexicas se aconsejan, ya dicen:

470. ma ti-c-cohua-can yn te-tl. yn quahui-tl. ma yehuatl y-ca. OPT s.1.PL-O.3.sG-comprar-PL DET piedra-ABS DET madera-ABS OPT eso PRON.3.SG-con

yn a-tlan chan-e-que yn a-tlan onoqu-e

DET agua-LOC CASA-POSE-PL DET agua-LOC estar-PL

“Compremos piedra y madera a cambio de eso, de los animales que viven en el agua, que están en el agua,

471. $\overline{\mathrm{y}}$ mich-in yn axollo-tl yhuan in cueya-tl. yn acocill-in. DET pescado-ABS DET ajolote-ABS y DET rana-ABS DET camarón.lacustre-ABS el pescado, el ajolote y la rana, el camarón lacustre,

472. yn anenez yn a-cohua-tl. yn axaxayaca-tl. DET larva.de.libélula DET agua-serpiente-ABS DET larva.de.mosco.acuático-ABS las larvas de libélulas, la serpiente de agua, las larvas de moscos acuáticos,

473. yn izcahui-tli. yhuan yn canauh-tli yn quachil-li yn DET gusano.de.la.laguna-ABS y DET pato-ABS DET focha-ABS DET acaçin-tli. yn ixquich yn toto-me yn a-tlan chan-e-que. focha-ABS DET todo DET ave-PL DET agua-LOC casa-POSE-PL el gusano de la laguna, el pato, las fochas cuachilli y yacacintli, todas las aves que viven en el agua!

474. ma yehuatl yc ti-c-cohua-ti. yn te-tzin-tli yn quauh-tzin-tli. OPT Eso PARTI s.1.PL-O.3.SG-comprar-DIR DET piedra-DIM-ABS DET madera-DIM-ABS ¡Vayamos a comprar estas cosas, piedritas y maderitas!” 
475. niman o-qu-ihto-qu-e ma yuhqui mo-chihua. niman ye yc luego PAS-0.3.SG-decir-PAS-PL OPT así REF.3.SG-hacer luego ya por.eso tla-tlama quim-ana quim-aci yn mich-in. oINDA-cazar 0.3.PL-capturar 0.3.PL-agarrar DET pescado-ABS Luego dijeron: “Asi se haga!” Entonces cazan, capturan, agarran los pescados,

476. yn axolo-tl. anenez-tli. acocill-in. in cueya-tl. DET ajolote-ABS larva.de.libélula-ABS camarón.lacustre-ABS DET rana-ABS yhuan yn ixquich-tin $\bar{y}$ toto-me yn a-tlan nemi. y DET todo-PL DET ave-PL DET agua-LOC vivir los ajolotes, las larvas de libélulas, los camarones lacustres, las ranas y todas las aves que viven en el agua.

$\$ 55[102]$

477. Auh niman o-yah-qu-e yn tla-namaca-to, yhuan tla-cohua-to PARTI luego PAS-ir-PAS-PL DET OINDI-vender-DIR y OINDI-comprar-DIR Luego se fueron a vender y a comprar.

478. niman o-hual-mo-cuep-qu-e o-hualla-qu-e o-qui-cui-to yn después PAS-DIR-REF.3.PL-volver-PAS-PL PAS-venir-PAS-PL PAS-0.3.SG-traer-DIR DET te-tl yn quahui-tl. atle hue-huei çan mochi tepitoton. piedra-ABS DET madera-ABS nada RED-grande sólo todo pequeńo Después volvieron, vinieron, fueron trayendo piedra y madera. No era para nada grande, todo era tan sólo pequeño,

479. auh yn quahui-tl çan no yuhqui. atle tomahuac PARTI DET madera-ABS sólo también así nada grueso

çan mochi pitzatoton yn quahui-tl. sólo todo menudo DET madera-ABS y la madera también es así, para nada gruesa, toda era tan sólo madera menuda.

480. niman ye yc quauh-tzotzona yn ozto-ten-pa luego ya por.eso madera-estacar DET cueva-orilla-LOC Luego estacan con madera la orilla de la cueva, 
481. ynic oncan qui-nelhuayoti-qu-e yn yehuatl altepe-tl. yn i-cal por.eso allí o.3.sG-echar.raíz-PAS-PL DET ella ciudad-ABS DET POs.3.sG-casa

yn i-teocal yn huitzilopoch-tli.

DET POs.3.sG-templo DET Huitzilopochtli

por eso alli echaron la raíz de la ciudad, de la casa, del templo de Huitzilopochtli.

482. Auh in yehuatl in. ca çan mochi tepitoton catca yn PARTI DET mismo esto PARTI sólo todo pequeño era DET

ayauhcal-li.

adoratorio-ABS

Esto mismo, el adoratorio era tan sólo todo pequeño.

483. auh yn o-nez te-tl. yn o-nez quahui-tl. niman ye PARTI DET PAS-aparecer piedra-ABS DET PAS-parecer madera-ABS luego ya

qui-pehua-ltia yn ayauhcal-li. o-qui-quechi-lli-qu-e. o.3.sG-empezar-APL DET adoratorio-ABS PAS-0.3.sG-levantar-APL-PAS-PL

Apareció la piedra, apareció la madera, entonces empiezan el adoratorio, lo levantaron.

$\$ 56[103]$

484. Auh niman ye no ceppa yohual-tica in ye qu-itohua ye PARTI luego ya también una.vez noche-INTR DET ya o.3.sG-hablar ya

no ceppa te-nahuatia in yehuatl. yn huitzilopochtli. también una.vez oINDA-mandar DET él DET Huitzilopochtli

Otra vez de noche habla, otra vez manda a la gente, Huitzilopochtli

485. niman qu-ilhui in ye qu-ihtoa. tla xi-c-caqui

luego o.3.sG-dijo DET ya o.3.sG-decir OPT IMP-0.3.sG-escuchar

Quauhtlequetztqui-he.

Cuauhtliquetzqui-voc

entonces dijo, ya dice: "Escucha, Cuaubtliqueztqui!

486. Nauhcampa xi-mo-tlalli-cā xi-mo-xello-cā. xi-tlahtocayoti-can. en.cuatro.partes IMP-REF.3.PL-asentar-PL IMP-REF.3.PL-dividirse-PL IMP-darse.gobierno-PL ¿En cuatro partes asiéntense, dividanse, dense gobierno!” 
487. auh niman o-qui-tlacamat-qu-e. nauhcampa o-mo-tlalli-qu-e PARTI luego PAS-O.3.SG-obedecer-PAS-PL en.cuatro.parcialidades PAS-REF.3.SG-asentar-PAS-PL

yn mexica.

DET mexicas

Entonces le obedecieron, en cuatro parcialidades se asentaron los mexicas,

488. auh yn o-yah ye nauh-can o-mo-tlalli-qu-e o-qu-ilhui

PARTI DET PAS-irse ya cuatro-LOC PAS-REF.3.SG-asentar-PAS-PL PAS-0.3.SG-decir

yn quauhtlequetzqui

DET Cuauhtliquetzqui

se fue cada uno en uno de los cuatro lugares, se asentaron. Dijo Cuaubtliquetzqui:

489. ca o-mo-chiuh tlamaca-z-qu-e. ynic o-ti-nech-nahuati.

PARTI PAS-REF.3.SG-hacer sustentar-FUT-PART-VOC PARTI PAS-s.2.SG-O.1.SG-mandar

o-mo-xello-qu-e yn mo-ta-huan.

PAS-REF.3.PL-dividir-PAS-PL DET POs.2.SG-padre-PL

"Se hizo, sustentador, como me mandaste, se han dividido tus padres."

490. niman o-qu-ihto yn huitzilopochtli. ca ye qual-li. luego PAS-0.3.SG-decir DET Huitzilopochtli está ya bueno-ABS Luego habló Huitzilopochtli: "Está bien.

491. Auh xi-quin-mo-mamaca-can yn ixquich-tin yn PARTI IMP-o.3.PL-REF.3.PL-repartir-PL DET todo-PL DET

ti-quin-hual-huica-qu-e yn amo-calpol-teo-vā yn tlacochcalca. s.1.PL-O.3.PL-DIR-traer-PAS-PL DET POS.2.PL-barrio-dios-PL DET tlacochcalcas ¡Repartan todos sus dioses de los barrios que trajimos acá entre los de Tlacochcalco, 
492. yn cihuatecpan. yn huitznahuac yn tlacatecpan. in yopico. DET Cihuatecpan DET Huitznáhuac DET Tlacatecpan DET Yopico

yn tezcacohuac. tlamatzinco in molloco itlillan: yn chalmeca. DET Tezcacóac Tlamatzinco DET Molloco Itlillan DET chalmecas

yn tzomolco. yn cohuatlan. yn chillilico. yn izquitla.

DET Tzonmolco DET Coatlan DET Chillilico DET Izquitlan

yn milnahuac. yn cohuatlxoxouhca.

DET Milnáhuac DET Coatlxoxouhcan

Cihuatecpan, Huitznáhuac, Tlacatecpan, Yopico, Tezcacóac, Tlamatzinco, Moloco Itlillan, Chalman, Tzonmolco, Coatlan, Chillilico, Izquitlan, Milnábuac y Coatlxoxouhcan!

493. ma yxneci-can nauhcampa xi-quin-quixti-can yn moyotlan

OPT manifestarse-PL por.cuatro.partes IMP-0.3.PL-enviar-PL DET Moyotlan

yn axcan ye m-itoa San Juan. yn teopan yn axcan

DET hoy ya REF.3.sG-decir San Juan DET Teopan DET ahora

ye m-itoa San Pablo.

ya REF.3.sG-nombrar San Pablo

Que se manifiesten, envienlos por las cuatro parcialidades en Moyotlan (que hoy en dia se dice San Juan), en Teopan (que ahora se nombra San Pablo),

494. yn atzaqualco yn axcan ye m-itoa San Sebastian. yhuan

DET Atzacualco DET hoy ya REF.3.sG-llamar San Sebastián y

cuepopan yn axcan ye m-itoa Sancta maria Redonda.

Cuepopan DET actualmente ya REF.3.SG-denominar Santa María Redonda en Atzacualco (que hoy se llama San Sebastián) y en Cuepopan (que actualmente se denomina Santa María la Redonda)."

$\$ 57[104]$

495. auh niman o-qu-ihto-qu-e yn Mexica. ca ye qual-li. PARTI entonces PAS-O.3.SG-decir-PAS-PL DET mexicas está ya bueno-ABS

tlamaca-z-qu-e ma yuh mo-chihua. sustentar-FUT-PART-VOC OPT así REF.3.SG-hacer Entonces los mexicas dijeron: "Está bien, sustentador, así se haga." 
496. nimā o-quin-mo-mamaca-q-' yn in-capol-teo-huan yn Mexica. luego PAS-0.3.PL-REF.3.PL-repartir-PAS-PL DET POS.3.PL-barrio-dios-PL DET mexicas Luego los mexicas se repartieron a sus dioses de los barrios.

497. auh yn iquac in ye huecauh in ye cat-e yn toll-ihti-c. in PARTI DET cuando DET ya mucho.tiempo DET ya estar-PL DET junco-vientre-LOC DET aca-yhti-c.

caña-vientre-LOC

Cuando ya hace mucho tiempo que están en medio de los juncos y de las cañas,

498. in yehuantin. yn Mexica. yn huehue-tque yn oncan yhcac yn DET ellos DET mexicas DET antiguo-PL DET donde erguirse DET te-noch-tli. niman ye yc mo-xellohua. yn Mexica. piedra-tuna-ABs luego ya por.eso REF.3.PL-devidir DET mexicas los antiguos mexicas en el lugar en el que se yergue el tunal de piedra, entonces los mexicas se dividen.

499. yn oyuh qu-itta-to. yn toll-ihti-c. yn aca-yhti-c. yn oncan ca DET así.que 0.3.sG-ver-DIR DET junco-vientre-LOC DET caña-vientre-LOC DET donde está yn tlatil-li. y-toca xaltilol-li. DET montículo POS.3.sG-nombre Xaltilolli Asi que fueron a ver en medio de los juncos y de las cañas, donde está un monticulo que se llamaba Xaltilolli.

500. niman o-mo-xello-qu-e. yn ompa o-ya-qu-e $\bar{y}$ Mexica entonces PAS-REF.3.PL-dividir-PAS-PL DET allá PAS-irse-PAS-PL DET mexicas huehue-tque.

viejo-PL

Entonces se dividieron, los viejos mexicas se fueron allá.

501. auh yn axcan ti-qu-itohua ti-c-tocayotia. tlatilolco Santiago. PARTI DET ahora s.1.PL-0.3.sG-decir s.1.PL-0.3.sG-llamar Tlatelolco Santiago Ahora a ese lugar le decimos, lo llamamos Santiago Tlatelolco. 
$\$ 58[105]$

502. Auh in yehuantin yn ompa qui-tzitzqui-to yn altepe-tl. PARTI DET aquéllos DET allá o.3.SG-tomar.posesión-DIR DET ciudad-ABS

yzca yn in-toca

he.aquí DET POS.3.PL-nombre

De aquéllos quienes fueron allá a tomar posesión de la ciudad he aqui sus nombres:

503. ynic ce Atlanquahuitl. ynic ome y-toca huicton. yniqu-ey ORD uno Atlancuáhuitl ORD dos POS.3.SG-nombre Huicton ORD-tres

y-toca opochtli. ynic nahui y-toca Atlahçol.

POS.3.SG-nombre Opochtli ORD cuatro pos.3.sG-nombre Atlazol

el primero se llamaba Atlancuáhuitl, el segundo Huicton, el tercero Opochtli, el cuarto Atlázol.

504. yn ompa yah-qu-e xaltilolco. yn ompa mo-tlalli-to DET allá ir-PAs-PL Xaltilolco DET allá REF.3.PL-asentar-DIR

cenca tlahuelliloqu-e catca

muy malo-pL eran

Fueron allá a Xaltilolco, fueron allá a asentarse esos quienes eran muy malos.

505. niman yuh mo-tlalli-to. in amo tlaca cat-e tlatilolca entonces así REF.3.SG-asentar-DIR DET no hombres ser-PL tlatelolcas

cenca moxicohuani.

muy envidioso

Entonces asi se fueron a asentar los tlatelolcas, quienes no son hombres, son muy envidiosos

506. yn axcan ca ye yuhqui yn im-ixhui-huan yn iuhqui yn DET ahora estar ya como DET POS.3.PL-nieto-PL DET asimismo DET

iuhqui ${ }^{9}$ amo tlaca nemi

asimismo no gente vivir

y los que ahora están como sus nietos, asimismo no viven como gente de bien.

9 Repetición de “yn iuhqui” en el manuscrito. 
$\$ 59[97]$

507. Auh in yehuantin yn Mexica huehue-tque $\bar{y}$ nican yn PARTI DET aquellos DET mexicas viejo-PL DET aquí DET qui-tzitzqui-qu-e yn altepetl. o.3.SG-tomar.posesión-PAS-PL DET ciudad-ABS De aquellos viejos mexicas quienes aqui tomaron posesión de la ciudad

508. ynic m-itohua ynic mo-tenehua yn toltzallan yn acatzallan yn PARTI REF.3.SG-decir PARTI REF.3.sG-nombrar DEt Toltzalan DET Acatzalan DET

Mexico yn tenochtitlan. yzca yn in-toca México DET Tenochtitlan he.aquí DET pos.3.PL-nombre que se dice, que se nombra Toltzalan Acatzalan, México Tenochtitlan, he aqui sus nombres:

509. ynic ce y-toca atl tenoch ynic ome y-toca quauhtli ORD uno pos.3.sG-nombre Atl Ténoch ORD dos Pos.3.sG-nombre Cuáuhtli yolqui yniqu-ey y-toca Acacitli. Yolqui ORD-tres Pos.3.sG-nombre Acacitli el primero de nombre Atl Ténoch, el segundo de nombre Cuáuhtli Yolqui, el tercero de nombre Acacitli,

510. ynic nahui y-toca tençacatetl. ynic macuil-li y-toca ORD cuatro POS.3.SG-nombre Tenzacátetl ORD cinco-ABS POS.3.sG-nombres

Ahuexotl. Ynic chiquacen y-toca Ocelopan Ahuéxotl ORD seis POS.3.sG-nombres Ocelopan el cuarto de nombre Tenzacátetl, el quinto de nombre Abuéxotl, el sexto de nombre Ocelopan,

$\begin{array}{clllll}\begin{array}{c}\text { 511. ynic } \\ \text { ORD }\end{array} & \text { shicome } & \text { y-toca } & \text { quauhtliquetzqui } & \text { ynic } & \text { chicuey } \\ \text { Pos.3.sG-nombre } & \text { Cuauhtliquetzqui } & \text { ORD } & \text { ocho }\end{array}$ y-toca tzompantzin. POS.3.SG-nombre Tzompantzin el séptimo de nombre Cuaubtliquetzqui, el octavo de nombre Tzompantzin,

$\begin{array}{llll}\begin{array}{l}\text { 512. ynic chiuhcnahui } \\ \text { ORD nueve }\end{array} & \text { pos.3.sG-nombre İzhuac } & \text { tlaxquitl. } \\ & \text { Tláxquitl }\end{array}$ el noveno de nombre İzhuac Tláxquitl, 
513. ynic matlac-tli y-toca Ocomecatzin. ynic matlactlohce ORD diez-ABS POS.3.SG-nombre Ocomecatzin ORD once

y-toca chicopach mani.

pos.3.SG-nombre Chicópach Mani

el décimo de nombre Ocomecátzin, el décimo primero de nombre Chicópach Mani,

514. ynic matlactlomome y-toca Ahatzin. ynic matlactlome ORD doce POS.3.SG-nombre Ahátzin ORD trece

y-toca copil

POS.3.SG-nombre Cópil

el décimo segundo de nombre Ahátzin y el décimo tercero de nombre Cópil.

$\$ 60[98]$

515. auh yn teo-mama-qu-e yn qui-tlaca-ytta-ya yn iuhqui yn

PARTI DET dios-cargar-PART-PL DET O.3.sG-persona-ver-IMPE DET así DET

qui-tlaca-notza-ya. yn huitzilopochtli.

o.3.sG-persona-hablar-IMPE DET Huitzilopochtli

Los cargadores de los dioses los cuales veian en persona y asi le hablaban personalmente a Huitzilopochtli eran:

516. ce tlaca-tl y-toca quauhtlequetzqui. ynic ome y-toca uno persona-ABS POs.3.sG-nombre Cuauhtliquetzqui ORD dos POs.3.sG-nombre

ococal. ynic yey y-toca chachallayotl.

Ocócal ORD tres pos.3.sG-nombre Chachaláyot

primero el que se llamaba Cuaubtliquetzqui, el segundo de nombre Ocócal, el tercero de nombre Chachaláyotl

517. auh in yehuatl ynic nahui yn i-toca yn tlamacazqui

PARTI DET él ORD cuatro DET POS.3.sG-nombre DET tlamacazqui

yn axollohua.

DET Axolohua

y el cuarto de nombre tlamacazqui Axolohua. 
$\$ 61[110]$

518. Auh yn ihquac in ye huecahua in ye cat-e yn Mexica yn PARTI DET cuando DET ya permanecer DET ya estar-PL DET mexicas DET

tenochca. yn oyuh on-mic yn tenochtzin.

tenochcas DET después.de DIR-murió DET Tenochtzin

Cuando los mexicas tenochcas ya permanecen, ya están después de que murió Tenochtzin

519. yhuan in ye huecauh cate yn tlatilolca yn ocececni

y DET ya por.mucho.tiempo DET thatelolcas DET por.separado

mo-tlalli-qu-e.

REF.3.PL-asentar-PAS-PL

y también los tlatelolcas ya por mucho tiempo están por separado,

520. niman ye mo-nonotza yn mexica tenochca huehue-tque.

luego ya REF.3.sG-hacer.consejo DET mexicas tenochcas anciano-PL

ye qui-mo-lhuia

ya 0.3. SG-REF.3.sG-decir

entonces los ancianos mexicas tenochcas hacen consejo, se dicen:

521. tla xi-hual-hui-an in yehuātin in yn tlahueliloqu-e yn OPT IMP-DIR-Ir-PL DET ellos DET estos malvado-PL DET

o-tech-cauh-ti-quiz-qu-e yn o-mo-tlalli-to. yn xaltilolco. PAS-0.1.PL-dejar-LIG-salir-PAs-PL DET PAS-REF.3.PL-establecer-DIR DET Xaltilolco "Vengan, esos malvados han salido dejándonos, se fueron a establecer a Xaltilolco.

522. ma quenmanian ytla qui-mo-yolloti-tin

OPT algunas.veces algo 0.3.SG-REF.3.PL-delatar-VET.PL

Que no vayan algunas veces a delatar algo,

523. ca tlahuelliloqu-e ca amo tlaca yn atlanquahuitl. yn huictō porque malo-PL porque no gente DET Atlancuáhuitl DET Huicton

yn opochtli, yn atlaçol. ma ytla to-ca qui-tlalli-tin DET Opochtli DET Atlázol OPT algo PRON.1.PL-contra o.3.sG-poner-VET.PL porque son malos, no son gente de bien Atlancuáhuitl, Huicton, Opochtli y Atlázol, que no vayan a poner algo en contra de nosotros. 
524. auh ynin ma xi-c-cemito-can campan t-ia-z-que PARTI éstos OPT IMP-o.3.SG-tomar.una.decisión-PL dónde s.1.PL-ir-FUT-PL

Que éstos tomen una decisión acerca de dónde iremos,

525. ca te-tlal-pā in ti-cat-e ca te-quaxoch-co. ca te-tepā-co porque OINDA-tierra-LOC DET s.1.PL-estar-PL PARTI OINDA-término-LOC PARTI OINDA-frontera-LOC porque estamos en tierra ajena, en términos ajenos, en fronteras ajenas,

526. yn iyhyo-tl. ti-c-mati ca yn-tlal-pan yn tepaneca-tl DET aflicción-ABS s.1.PL-O.3.SG-conocer porque POS.3.PL-tierra-LOC DET tepaneca-ABS

yn azcapotzalca-tl. yn aculhuaca-tl.

DET azcapotzalca-ABS DET acolhuaca-ABS

conocemos la aflicción porque ésta es la tierra de los tepanecas azcapotzalcas y de los acolhuaques.

527. auh yn culhuacan tlaca ca yn-quaxcho-co yn ti-cat-e PARTI DET Colhuacan gente PARTI POs.3.PL-término-LOC DET s.1.PL-estar-PL Estamos en los términos de la gente de Colhuacan,

528. $\bar{y}$ tlah to-tlahtoca-uh ti-c-tlalli-z-que. campa yehuatl yn si Pos.1.PL-gobierno-pos s.1.PL-0.3.sG-poner-FuT-PL dónde eso DET

t-ia-z-que mexica-ye. tenochca-ye. Ma xi-tla-hto-can s.1.PL-ir-FUT-PL mexicas-VOC tenochcas-voc OPT IMP-OINDI-hablar-PL si hemos de poner nuestro gobernante, ¿adónde iremos, mexicas tenochcas? Hablen."

\section{$\$ 62[111]$}

529. Auh niman o-qu-ihto-qu-e in yehuantin yn yzca yn in-toca PARTI luego PAS-0.3.SG-hablar-PAS-PL DET ellos DET he.aquí DET POS.3.PL-nombre

yn acacihtli. yn tençacatetl. in ahuexotl. yn ahatl. DET Acacitli DET Tenzacatetl DET Ahuéxotl DET Áhatl Entonces hablaron ellos, cuyos nombres aparecen aqui, Acacitli, Tenzacátetl, Ahuéxotl y Áhatl,

530. O-qu-ihto-qu-e.mexica-ye. intla ye ompa ti-hui-an yn azcapotzalco PAS-0.3.sG-decir-PAS-PL mexicas-Voc si ya allá s.1.PL-ir-PL DET Azcapotzalco dijeron: "Mexicas, si vamos a Azcapotzalco 
531. ca amo huel mo-chihua-z. auh ìtla noce ompa ti-hui-an yn PARTI no bien REF.3.sG-hacer-FUT PARTI si tampoco allá s.1.PL-ir-PL DET acalhuacā anoço Aculhuacan

Acalhuacan $0 \quad$ Acolhuacan

no saldrán bien las cosas y tampoco si vamos a Acalhuacan o Acolhuacan

532. yn cohuatlychan ca amo huel mo-chihua-z DET Coatlichan PARTI no bien REF.3.sG-hacer-FUT y Coatlichan tampoco saldrán bien las cosas.”

$\$ 63[112]$

533. qu-ihto-qu-e yn oc cequi-ntin mexica. o.3.SG-decir-PAS-PL DET otro alguno-PL mexicas Respondieron algunos mexicas:

534. auh campa yn am-on-tla-tohua campan t-ia-z-que PARTI dónde DET s.2.PL-DIR-OINDI-hablar dónde s.1.PL-ir-PUT-PL “Adónde irán a hablar ustedes, adónde iremos?

535. Auh ynin maçompa ma ye ompa ti-hui-an yn culhuacan. PARTI este tal.vez OPT ya allá s.1.pL-ir-pL DET Colhuacan yn ompa ti-q-ual-cauh-qu-e yn opochtli yn yztahuatzin DET allá s.1.PL-0.3.sG-DIR-dejar-PAs-PL DET Opochtli DET Iztahuatzin Tal vez vayamos a Colhuacan, allá venimos a dejar a Opochtli Iztahuatzin

536. yhuan yn ixquich-tin yn to-telpoch-huan yn to-chpoch-huā y DET todo-PL DET pos.1.PL-hijo-PL DET Pos.1.PL-hija-PL y a todos nuestros hijos e hijas.

537. quen cat-e. quen nemi. yn in-cah. ${ }^{10}$ yn culhuaque Aço quin-tollinia. cómo estar-PL cómo vivir DET POS.3.PL-casa DET colhuaques acaso 0.3.PL-maltratar ¿Cómo están, cómo viven en la casa de los colhuaques? ¿Acaso los maltratan?

10 Léase "incal”. 
538. auh ca yuh ti-c-mati yn to-pampa y nauhxiuhti-qu-e yn PARTI PARTI como s.1.PL-0.3.SG-saber DET PRON.1.PL-por DET estar.cuatro.años-PAS-PL DET

cocontitlan. yn quin-teca-q-' yn quin-tlalli-qu-e

Cocontitlan DET o.3.PL-juntar-PAS-PL DET O.3.PL-establecer-PAS-PL

Como sabemos por nuestra culpa estuvieron cuatro años en Cocontitlan, donde los juntaron, los establecieron,

539. ynic quin-tlahti-qu-e. yn in-montta-huan yn in-monnan-huan. PARTI o.3.PL-esconder-PAS-PL DET POS.3.PL-suegro-PL DET POs.3.PL-suegra-PL

in yehuātin in culhuaque

DET ellos DET colhuaques

los escondieron sus suegros, sus suegras de ellos, los colhuaques.

540. açoc cem-e on-nemi. auh ca o-ti-c-mat-qu-e yn o-mic Tal.vez uno-PL DIR-vivir PARTI PARTI PAS-S.1.PL-0.3.SG-saber-PAS-PL DET PAS-morir

in yehuatl yn opochtli yn iztahuatzin.

DET él DET Opochtli DET Iztahuatzin

Tal vez algunos de ellos sobreviven. Supimos que murió Opochtli Iztahuatzin,

541. yehuatl ti-qu-itz-ti-hui yn i-techcopa o-quiz. yn i-pil-tzin

él s.1.PL-0.3.sG-ver-LIG-ir DET PRON.3.SG-de PAS-salir DET POS.3.sG-hijo-HON

yn opochtli tequihua

DET Opochtli capitán

pero vamos a ver a aquél que de él desciende, el hijo querido del capitán Opochtli.

542. auh ca to-mexica-pil-tzin. ca to-chichichimeca-pil-tzin. ca PARTI PARTI POs.1.PL-mexica-hijo-HON PARTI POS.1.PL-chichimeca-hijo-HON PARTI

yehuatl tech-nequi-z.

él o.1.PL-querer-Fut

Nuestro venerado hijo mexica, nuestro venerado hijo chichimeca nos querrá,

543. yn qui-pie-z. yn mexica-yotl. yn tenochca-yotl. Auh ca DET 0.3.sG-cuidar-FUT DET mexica-ABSTR DET tenochca-ABSTR PARTI porque

necoc o-yol.

de.ambas.partes PAs-vivir

cuidará de lo mexica, de lo tenochca, porque vino a la vida, 
544. o-tlacat tlacamecayo-tica. yn culhuaq ca yn i-xhui-uh yn PAs-nacer linaje-INSTR DET colhuaques es DET POS.3.sG-nieto-POS DET te-teuhc-tin yn tla-hto-qu-e RED-señor-PL DET OINDI-gobernar-PART-PL nació del linaje de ambas partes, es nieto de los señores y gobernantes colhuaques

545. auh in tehuantin yn ti-mexica ti-chichimeca auh ynin ma PARTI DET nosotros DET s.1.PL-mexicas s.1.pL-chichimecas PARTI DET OPT ti-hui-an Mexica-ye. s.1.PL-ir-pL mexicas-voc $y$ de nosotros que somos mexicas chichimecas. Asi que vayamos, mexicas."

$\$ 64[113]$

546. auh niman o-yah-qu-e yn ompa culhuacan yn Mexica. yn PARTI luego PAS-ir-PAs-PL DET allá Colhuacan DET mexicas DET on-aci-qu-e niman ye qu-ilhuia DIR-llegar-PAs-PL luego ya o.3.sG-decir Luego los mexicas fueron a Colhuacan y llegados en seguida dicen,

547. ye qui-tlatlauhtia yn i-toca teuhc-tlamacazqui. nauhyotl ya 0.3.sG-pedir DET Pos.3.sG-nombre señor-sacerdote Náuhyotl tla-htohua-ni culhuacan. yn Mexica. qu-ilhui-qu-e oINDI-gobernar-AG Colhuacan DET mexicas o.3.sG-decir-PAs-PL piden al sacerdote señor que se llamaba Náuhyotl, gobernante de Colbuacan, los mexicas le dijeron:

548. co $^{11}$ ti-hualla-qu-e tlaca-tl-e no-xhui-uh-tzin-e tla-htohua-ni-e PARTI s.1.PL-Venir-PAS-PL señor-ABS-VOC POS.1.sG-nieto-POS-HON-VOC OINDI-gobernar-AG-VOC "Hemos venido, señor, mi nieto querido, gobernante,

549. ti-mitz-to-tlalcahualti-li-z-que. ti-mitz-to-tlapololti-li-z-que. s.1.PL-O.2.SG-REF.1.PL-molestar-APL-PUT-PL $\quad$ s.1.PL-O.2.SG-perturbar-APL-FUT-PL te molestaremos, te perturbaremos 
550. yn ti-mo-col-huan yn ti-mo-ta-huan yn ti-mexica ti-chichimeca DET s.1.PL-Pos.2.sG-abuelo-PL DET s.1.PL-POs.2.sG-padre-PL DET s.1.PL-mexicas s.1.PL-chichimecas nosotros quienes somos tus abuelos, quienes somos tus padres, los mexicas chichimecas.

551. ca ti-qu-icno-yto-co yn m-a-tzin y mo-tepe-tzin yn PARTI s.1.PL-0.3.sG-humilde-decir-DIR DET POs.2.sG-agua-HON DET POs.2.sG-cerro-HON DET tenochtitlan

Tenochtitlan

Venimos a pedirte humildemente tu agua y tu cerro, Tenochtitlan.

552. ca ti-c-ana-co y mo-macehual-tzin catca yn opochtli yn PARTI s.1.PL-0.3.sG-tomar-DIR DET POs.2.sG-súbdito-HON era DET Opochtli DET

iztahuatzin. yn i-necauhca

Iztahuatzin DET POs.3.sG-descendencia

Venimos a tomar a la descendencia del que era tu venerado súbdito Opochtli Iztahuatzin,

553. yehuatl yn pil-tzin-tli y cone-tzin-tli. yn to-cozqui yn aquel DET hijo-HON-ABS DET niño-DIM-ABS DET POs.1.pL-joya DET

to-quetzal.

pos.1.PL-pluma.de.quetzal

a aquel hijo y niño querido, nuestra joya y pluma de quetzal,

554. yn i-toca yn iteheca yn itzpapalotl. yn acamapich. DET POs.3.sG-nombre DET tercero DET Itzpapálotl DET Acamápich cuyo nombre es Itzpapálotl tercero, Acamápich.

555. auh ca ti-c-mo-macahui-li-z. ca nel to-mexica-pil-tzin. PARTI PARTI s.2.SG-0.3.SG-REF.2.sG-dar-APL-FUT porque en.verdad POs.1.PL-mexica-hijo-HON Nos lo darás porque en verdad es nuestro querido hijo mexica.

556. auh ca to-yollo qui-mati. ca culhuaca yxhuiuh-tli. ca PARTI PARTI POs.1.PL-corazón o.3.sG-saber que colhuaca nieto-ABS es yn-tzon yn-izti. yn te-teuhc-tin. yn tla-hto-qu-e. yn culhuaque. POS.3.PL-cabello POS.3.PL-uña DET RED-señor-PL DET OINDI-gobernar-PART-PL DET colhuaques Nuestro corazón sabe que es nieto colhuaca, es cabello y uña de los señores y gobernantes colhuaques. 
557. auh ynin ca ti-qu-itohua ma c-on-mo-pie-lli-qui yn PARTI éste PARTI s.1.PL-0.3.SG-decir OPT o.3.SG-DIR-REF.3.sG-custodiar-APL-DIR DE

m-a-tzin yn mo-tepe-tzin. yn tol-tzallan. Pos.2.sG-agua-HON DET POs.2.sG-cerro-HON DET espadaña-entre

Decimos que éste venga a custodiar tu agua, tu cerro entre las espadañas,

558. yn aca-tzallan yn mexico yn tenochtitlan. auh ynin ma DET carrizo-entre DET México DET Tenochtitlan PARTI esta OPT

c-on-mo-chihui-li-tiuh

o.3.SG-DIR-REF.3.SG-hacer-APL-DIR

entre los carrizales, en México Tenochtitlan. Y que ésta venga a hacerse

559. yn t-ochpo-tzin. yn cihua-pil-li. yn illancueytl. DET POs.1.PL-hija-HON DET mujer-noble-ABS DET Ilancuéitl nuestra hija querida, la señora Ilancuéitl."

$\$ 65[114]$

560. Auh niman quim-ilhui in yehuatl yn tla-htohua-ni yn PARTI luego o.3.PL-habló DET él DET OINDI-gobernar-AG DET

teuhc-tlamacazqui nauhyotl. o-qu-ihto. señor-sacerdote Náuhyotl PAs-0.3.SG-decir

Luego habló él, el gobernante y sacerdote señor Náuhyotl, respondió:

561. ma yhui ca ye qual-li oc xi-c-chiye-can tenochca-ye. yn tlahtol-li. OPT así está ya bueno-ABS aún IMP-O.3.SG-esperar-PL tenochcas-voc DET palabra-ABS "Así sea, está bien, pero aún esperen la palabra, tenochcas,

562. ma oc ti-to-nonotza-can ma oc ne-nonotza-llo. OPT aún s.1.PL-REF.1.PL-consultar-PL OPT aún REF-consultar-PASI aún tenemos que consultarnos, aún va haber consejo."

563. auh yn on-mo-nonotz-qu-e-qu-e ${ }^{12}$ yn culhuaque. nimā ye PARTI DET DIR-REF.3.PL-consultar-PAS-PL-PAS-PL DET colhuaques luego ya qu-itohua yn teuhc-tlamacazqui nauhyotl. o.3.SG-hablar DET seńor-sacerdote Náuhyotl Fueron a consultarse los colhuaques y después habla el sacerdote señor Náuhyotl:

12 Léase "mononotzque". 
564. ca ye qual-li mexica-ye. tle ni-qu-ilhui-z $\bar{y}$ nicā yn culhuacan. está ya bueno-ABS mexicas-Voc qué s.1.SG-0.3.sG-decir-FUT DET aquí DET Colhuacan "De acuerdo, mexicas, ¿qué tengo que decir aqui en Colbuacan?

565. auh ca nel amo-pil-tzin amo-xhui-uh ma c-on-yauh PARTI PARTI cierto POS.2.PL-hijo-HON POs.2.PL-nieto-POS OPT OPTO.3.SG-DIR-ir

xi-c-huica-can ca nel oquich-tli.

IMP-0.3.SG-llevar-PL es cierto hombre-ABS

Es cierto que es vuestro hijo querido, es vuestro nieto, que se vaya, llévenselo ya que es hombre.

566. yntla cihua-tl. amo huel mo-chihua-z. yn an-qui-huica-z-que. si mujer-ABS no vaUX REF.3.sG-hacer-FUT DET S.2.PL-o.3.sG-llevar-FUT-PL

Si fuera mujer, no sería posible que ustedes se lo llevaran.

567. auh ynin ma qui-pacho. yn cuitlapil-li yn atlapal-li.

PARTI éste OPT 0.3.SG-gobernar DET cola-ABS DET ala-ABS

Que éste gobierne la cola, las alas,

568. yn i-macehual yn tloqu-e yn nahuaque.

DET POs.3.sG-servidor DET junto-POSE DET cerca-POSE

yn yohual-li yn eheca-tl. yn aotzin ${ }^{13}$ yn tezcatlipoca.

DET noche-ABS DET viento-ABS DET Yaotzin DET Tezcatlipoca

que sea el servidor del dueño de lo que está junto y de lo que está cerca, de la noche y del viento, de Yaotzin Tezcatlipoca.

569. auh ma c-on-tla-pie-lli. yn tlamaca-z-qui yn huitzilopochtli. PARTI OPT 0.3.SG-DIR-OINDI-guardar-APL DET dar.vida-FUT-PART DET Huitzilopochtli Que vaya a ser guardián del dador de la vida Huitzilopochtli.

570. auh cuix oc qui-hualmati y n-ochpoch-tzin. yn cihua-pil-li. PARTI INT aún 0.3.sG-visitar DET POs.1.sG-hija-HON DET mujer-noble-ABS

yn atotoztli.

DET Atotoztli

¿Aún vendrá a visitar a mi querida hija, a la noble mujer Atotoztli?

13 Léase “yaotzin”. 
571. yntla oc y-xpan acaço qui-cahualiztlamati-zquia. ca nel si aún PRON.3.SG-frente tal.vez.no 0.3.SG-conceder-IRRE porque por.cierto $\mathrm{y}$-cone-tzin. POS.3.sG-hijo-HON

Si aún estuviera frente a él, tal vez no hubiera querido concederlo, porque por cierto es su hijo querido.

572. auh ynin cuix nell oc qui-hualmati. xi-c-mo-huiqui-lli-ti-hui-an PARTI éste INT sí todavía 0.3. sG-visitar IMP-0.3.SG-REF.2.PL-llevar-APL-LIG-ir-PL

ca nel i-chan

porque en.verdad pos.3.sG-casa

¿Si vendrá éste todavía a visitarla? ¡Vayan a llevárselo!, porque en verdad es su casa."

$\$ 66[115]$

573. niman qu-ito-q- ${ }^{-}$yn mexica. ca ye qual-li. entonces o.3.SG-decir-PAS-PL DET mexicas está ya bueno-ABS

o-ti-c-mo-cnelli-li yn m-a-tzī yn mo-tepe-tzin. PAS-s.2.SG-0.3.SG-REF.2.SG-hacer-merced-APL DET POS.2.sG-agua-HON DET POS.2.SG-cerro-HON Entonces los mexicas dijeron: "Muy bien, nos hiciste merced de tu agua, de tu cerro.

574. ma ti-c-uica-ti-hui-an, niman qu-ihto-qu-e yn culhuaque OPT s.1.PL-0.3.sG-llevar-LIG-ir-PL luego o.3.sG-decir-PAS-PL DET colhuaques ¡Vayamos a llevárnoslo!" Luego dijeron los colhuaques:

575. camo nican nemi. ma ompa xi-c-m-ani-lli-ti. yn ompa no aquí vivir OPT allá IMP-O.3.SG-REF.2.PL-tomar-APL-DIR DET allá cohuatl ichan yn i-toca acamapich. Coatl ichan DET POs.1.sG-nombre Acamápich "No vive aqui. ¡Vayan a tomar allá en Coatlichan al que se llama Acamápich!"

576. auh yc niman ompa yah-qu-e in mexica yn cohuatl ichan PARTI por.eso luego allá ir-PAs-PL DET mexicas DET Coatl ichan Asi que los mexicas fueron allá a Coatlichan. 
$\$ 67[116]$

577. Auh yn on-aci-to. niman ye qui-nonotza. yn aculmiztli. ye PARTI DET DIR-llegar-DIR luego ya o.3.sG-hablar.con DET Acolmiztli ya

qu-ilhuia ca ti-c-ana-co. yn acamapich. o.3.sG-decir PARTI s.1.PL-0.3.sG-tomar-DIR DET Acamápich

Llegados allá, hablan con Acolmiztli, le dicen: "Venimos a tomar a Acamápich."

578. niman quim-ilhui. ac amehuantin campa ohu-a-hualla-qu-e ${ }^{14}$ entonces 0.3.PL-decir quién ustedes dónde PAS-S.2.PL-venir-PAS-PL Entonces les preguntó: “Quiénes son ustedes? ¿De dónde han venido?”

579. c-on-ilhui-qu-e ca ompa tenochtitlan qu-ihto o.3.SG-DIR-decir-PAS-PL PARTI allá Tenochtitlan 0.3.sG-dijo Le contestaron: "De Tenochtitlan." Él dijo:

580. ca ye qual-li ma oc xi-c-mo-huiqui-lli-ti-hui-an ma qui-huica está ya bueno-ABS OPT aún IMP-REF.2.PL-llevar-APL-LIG-ir-PL OPT O.3.sG-llevar

yn i-nan-tzin illancueytl.

DET POS.3.SG-madre-HON Ilancuéitl

"Está bien, también váyanse llevando, llévense a su madre Ilancuéitl."

581. yc nimā ye qui-huica-tz-e yn mexica yn acamapich. por.eso luego ya o.3.SG-traer-HON-PL DET mexicas DET Acamápich Asi que los mexicas trajeron a Acamápich

582. y-cihua-uh val-mo-chiuh-tia yn illancueytl. pos.3.sG-mujer-pos DIR-REF.3.sG-hacer-Caus DET Ilancuéitl y a la que viene haciéndose su mujer, Ilancuéitl.

\section{$\$ 68[117]$}

583. Auh niman qui-hual-huica-qu-e. c-axiti-co yn Mexico yn PARTI entonces 0.3.SG-DIR-traer-PAS-PL 0.3.SG-llevar-DIR DET México DET

tenochtitlan. yc mo-tlalli-co yn-petla-pan. Tenochtitlan para REF.3.sG-sentar-DIR DET-petate-LOC Entonces lo trajeron, lo vinieron a llevar a México Tenochtitlan para que viniera a sentarse en el petate,

14 Léase "ohuanhuallaque" o "oanhuallaque". 
584. yn i-cpal-pan ynehuan yn i-cihua-uh yn i-toca illancueytl. DET pos.3.sG-asiento-Loc junto.con DET POS.3.sG-mujer-POS DET POS.3.sG-nombre Ilancuéitl en el asiento junto con su mujer llamada Ilancuéitl.

585. auh yn o-c-on-axiti-co yn tenochtitlan. yn tla-htohua-ni. PARTI DET PAs-o.3.sG-DIR-llevar-DIR DET Tenochtitlan DET oINDI-gobernar-AG

yn o-te-ana-to mexica.

DET PAS-OINDA-recibir-DIR mexicas

Fueron a llevar a Tenochtitlan al gobernante, fueron a recibir a la gente los mexicas

586. niman ye quim-on-ilhuia yn oc cequī-tin Mexica tenochca luego ya o.3.PL-DIR-decir DET otro alguno-PL mexicas tenochcas

quim-ilhui-qu-e

o.3.PL-decir-PAS-PL

y luego algunos otros mexicas tenochcas les van diciendo, les dijeron:

587. to-cni-huan-e. ca o-to-c-on-axiti-co yn tla-htohua-ni e-z. ${ }^{15}$ POS.1.PL-amigo-PL-VOC PARTI PA-S-1.PL-0.3.SG-DIR-Ilevar-DIR DET OINDI-gobernar-AG ser-FUT "Amigos nuestros, nosotros hemos venido a traer al que será gobernante."

588. quim-on-nanquilli-qu-e quim-ilhui-qu-e ca ye qual-li. o.3.PL-DIR-responder-PAS-PL O.3.PL-decir-PAS-PL está ya bueno-ABS

o-quim-ihiyohui-lti. auh tle $y$-toca PAS-0.3.PL-cansar-APL PARTI cuál POS.3.sG-nombre

Les respondieron, les dijeron: "Muy bien, los ha cansado. ¿Cuál es su nombre?"

589. quin-hual-ilhui-qu-e quil mach acamapich. auh qu-ih ${ }^{\text {to }}$-qu-e o.3.PL-DIR-decir-PAs-PL dizque parece.que Acamápich PARTI 0.3.SG-decir-PAS-PL

Les contestaron: "Le dicen Acamápich." Dijeron:

590. ca ye qualli Auh yn o-c-on-tlalli-qu-e tla-htohua-ni está ya bueno-ABS PARTI DET PAs-0.3.sG-DIR-sentar-PAS-PL OINDI-gobernar-AG "Está bien" y fueron a sentar al gobernante.

15 Léase "yez". 
$\$ 69[118]$

591. Auh yn Mexica, nima ye qui-tlatlauhtia yn tlaca-tl. qu-ilhuia PARTI DET mexicas luego ya o.3.sG-rogar DET hombre-ABS 0.3.sG-decir Los mexicas entonces ruegan al hombre, le dicen:

592. no-xhuiuh-tzin-e tla-htohua-ni-e o-ti-c-m-ihiyohui-lti POS.1.SG-nieto-HON-VOC OINDI-gobernar-AG-VOC PAS-S.2.SG-O.3.SG-REF.2.SG-cansar-APL o-ti-c-mo-ciyahui-lti. PAS-S.2.SG-0.3.SG-REF.2.sG-fatigar-APL

"Nieto mio, gobernante, te has cansado, te has fatigado

593. o-ti-m-axi-ti-co yn mo-chan-tzin-co. yn tol-tzallan. yn PAS-s.2.SG-REF.2.SG-llegar-APL-DIR DET POs.2.SG-casa-HON-LOC DET espadańa-entre DET aca-tzallan. carrizo-entre y has llegado a tu casa honrada, entre las espadañas y los carrizos.

594. auh mo-tollinia yn mo-col-huan yn mo-tla-huan yn mexica PARTI REF.3.PL-ser.pobre DET $\quad$ POs.2.SG-abuelo-PL DET $\quad$ POs.2.SG-tío-PL DET mexicas

yn chichimeca.

DET chichimecas

Tus abuelos, tus tios, los mexicas chichimecas son pobres.

595. Auh ca to-c-on-tla-pie-lli-z. yn tlamaca-z-qui yn tetzahui-tl PARTI PARTI s.2.SG-0.3.SG-OINDI-custodiar-APL-FUT DET dar.vida-FUT-PART DET prodigio-ABS

yn huitzilopochtli.

DET Huitzilopochtli

Vas a tener que custodiar al que nos da la vida, al prodigio Huitzilopochtli.

596. auh yhuan ca yuh qui-mati yn mo-yollo-tzin. yn te-quaxoch-co. PARTI y PARTI así O.3.SG-saber DET POs.2.sG-corazón-HON DET OINDA-término-LOC

yn te-pepan-co yn amo to-tlal-pan yn ti-cat-e. DET OINDA-frontera-LOC DET no POs.1.PL-tierra-LOC DET s.1.PL-estar-PL Asi que sabe tu venerable corazón que estamos en términos ajenos, en fronteras ajenas, no estamos en nuestra tierra. 
597. auh ca ti-c-iahui-z. ca ti-qui-hiyohui-z. ca ti-tequiti-z.

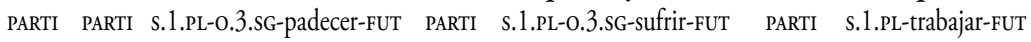

ca ti-tlacoti-z. ca yci. yn tlalhuac-pā yn azcapotzalco. PARTI s.1.PL-ser.esclavo-FUT porque este.lugar DET isla-LOC DET Azcapotzalco Padecerás, sufrirás, trabajarás, serás esclavo, porque este lugar es una isla de Azcapotzalco."

\section{Abreviaturas}

$\begin{array}{llll}\text { APL } & \text { Aplicativo } & \text { O } & \text { objeto } \\ 1 & \text { primera persona } & \text { OINDA } & \text { objeto indefinido animado }(t e-) \\ 2 & \text { segunda persona } & \text { OINDI } & \text { objeto indefinido inanimado }(t l a-) \\ 3 & \text { tercera persona } & \text { OPT } & \text { optativo }(\text { ma }, \text { tla }) \\ \text { ABS } & \text { absolutivo } & \text { ORD } & \text { ordinal }(\text { inic }) \\ \text { ABSTR } & \text { abstracto } & \text { PL } & \text { plural } \\ \text { AG } & \text { agentivo } & \text { PART } & \text { participio } \\ \text { APL } & \text { aplicativo } & \text { PARTI } & \text { partícula }(a u h, c a, i c, \ldots) \\ \text { CAUS } & \text { causativo } & \text { PAS } & \text { pasado } \\ \text { DET } & \text { determinante }(\text { in }) & \text { PASI } & \text { pasivo } \\ \text { DIM } & \text { diminutivo } & \text { POS } & \text { posesivo } \\ \text { DIR } & \text { direccional } & \text { POSE } & \text { poseedor }(-e,-h u a) \\ \text { FUT } & \text { futuro } & \text { PRON } & \text { uso pronominal del posesivo } \\ \text { HON } & \text { honorífico } & \text { RED } & \text { reduplicación } \\ \text { IMP } & \text { imperativo } & \text { REF } & \text { reflexivo } \\ \text { IMPE } & \text { imperfecto } & \text { S } & \text { sujeto } \\ \text { INSTR } & \text { instrumental } & \text { SG } & \text { singular } \\ \text { INT } & \text { interrogativo }(\text { cuix }) & \text { VAUX } & \text { verbo auxiliar } \\ \text { IRRE } & \text { irreal } & \text { VET } & \text { vetativo } \\ \text { LIG } & \text { ligadura }(-t i-) & \text { VOC } & \text { vocativo } \\ \text { LOC } & \text { locativo (suf. }- \text { co, }- \text { pan },- \text { tlan, } & & \\ & \text {-can,... }) & & \end{array}$

\section{Fuentes}

$\mathrm{CC}=$ Codex Chimalpahin, vol. I, véase Chimalpahin Quauhtlehuanitzin, 1997.

$\mathrm{CM}=$ Crónica mexicana, véase Tezozómoc, 1997.

$\mathrm{HI}=$ Historia de las Indias de Nueva España e islas de la tierra firme, Vol. I, véase Durán, 1995. 
Referencias

BARlow, Robert H.

1945 "La Crónica X: versiones coloniales de la historia de los mexica tenochca", Revista Mexicana de Estudios Antropológicos 7: 65-87.

1990 "La Crónica X: versiones coloniales de la historia de los mexica tenochca”, en Obras de Robert Barlow, H. Paillés, editor, pp. 13-32, Volumen III. México: Instituto Nacional de Arqueología e Historia / Universidad de las Américas.

Bernal, Ignacio

1947 "Los calendarios de Durán. Más confusiones alrededor de la Crónica X”, Revista Mexicana de Estudios Antropológicos 9: 125-134.

Castañeda de la Paz, María

2005 "El Códice X o los anales del 'Grupo de la Tira de la Pererginación'. Evolución pictográfica y problemas en su análisis intepretativo", Journal de las Société des Américanistes 91 (1): 7-40.

2008a "El Códice X o los anales del 'Grupo de la Tira de la Peregrinación'. Copias, duplicaciones y uso por parte de los cronistas", Tlalocan XV: 183-214.

2008b "Codex Azcatitlan and the work of Torquemada: a historiographical puzzle in Aztec-Mexica sources", Latin American Indian Literatures Journal 24 (2): 1-43.

Castañeda de la Paz, María y Michel Oudijk

2009 "El uso de fuentes históricas en pleitos de tierras: la Crónica X y la Ordenanza de Cuauhtémoc", Tlalocan XVI: 255-278.

Camelo, Rosa y José Rubén Romero

1995 "Estudio preliminar", en Diego Durán, Historia de las Indias de Nueva España e islas de la tierra firme, Rosa Camelo y José Rubén Romero Galván, editores, pp. 15-47, vol. 1. México: Consejo Nacional para las Cultura y las Artes, Dirección General de Publicaciones. 
Chavero, Alfredo,

1878 "Códice Ramírez - Durán - Acosta - Tezozómoc", en Hernando Alvarado Tezozómoc, Crónica mexicana. Anotada por Manuel Orozco y Berra y precedida del Códice Ramírez, manuscrito del siglo XVI intitulado "Relación del origen de los mexicanos que habitan esta Nueva España según sus historias", José María Vigil, editor, pp. 162-167. México: Imprenta y Litografía de Ireneo Paz.

Chimalpahin Quauhtlehuanitzin, Domingo de San Antón Muñón

1997 Codex Chimalpahin. Society and politics in Mexico Tenochtitlan, Tlatelolco, Texcoco, Culhuacan, and other Nahuas altepetl in central Mexico. The Nahuatl and Spanish annals and accounts collected and recorded by don Domingo de San Antón Muñón Chimalpahin Quauhtlehuanitzin, 2 vols., Arthur J. O. Anderson y Susan Schroeder, editores. Norman: University of Oklahoma Press.

Chimalpáhin, Domingo

2012 Tres crónicas mexicanas. Textos recopilados por Domingo Chimalpáhin, Rafael Tena, editor. México: Consejo Nacional para la Cultura y las Artes, Dirección General de Publicaciones.

Colston, Stephen A.

1973a “Fray Diego Durán’s 'Historia de las Indias de Nueva España e islas de tierra firme': a Historiographical Analysis.” Tesis Doctoral, University of California, Los Angeles.

1973 b “The 'Historia Mexicana' and Durán's Historia”, Journal de la Société des Américanistes 62: 35-42.

1974 "Tlacaelel's descendants and the authorship of the 'Historia Mexicana”, Indiana 2: 69-72.

1977 “A comment on dating the 'Crónica X", Tlalocan VII: 371377.

Cortés, Rocío

2003 "El misterio de los capítulos perdidos de la Crónica mexicana de Hernando de Alvarado Tezozómoc", Colonial Latin American Review 12 (2): 149-167. 
Couch, N. C. Christopher

1987 "Style and Ideology in the Durán Illustrations: an Interpretative Study of Three Early Colonial Mexican Manuscripts". Tesis Doctoral, Columbia University, New York.

DuRÁn, Diego

1995 Historia de las Indias de Nueva España e islas de la tierra firme, Rosa Camelo y José Rubén Romero, editores, 2 vols. México: Consejo Nacional para la Cultura y las Artes, Dirección General de Publicaciones.

Fuente del Pilar, José Javier

2001 "Prólogo", en Juan de Tovar, Historia y creencias de los indios, José Javier Fuente del Pilar, editor, pp. 5-54. Madrid: Miraguano.

Graham, Ann Marie

1998 "Dos interpretaciones de la historia de los mexicas: un análisis comparativo de la Crónica Mexicana de Hernando Alvarado Tezozómoc y la Historia de las Indias de Nueva España e islas de Tierra Firme de Fray Diego Durán.” Tesis doctoral, Universidad Nacional Autónoma de México, México.

Kirchoff, Paul

1951 "El autor de la segunda parte de la Crónica Mexicáyotl", en Homenaje al doctor Alfonso Caso, Gonzalo Aguirre et al., editores, pp. 225-227. México: Imprenta Nuevo Mundo.

Kruell, Gabriel Kenrick

2011 "La Crónica X: nuevas perspectivas a partir del problema historiográfico de la Crónica mexicáyotl y su cotejo con la Crónica mexicana." Tesis de maestría, Universidad Nacional Autónoma de México, México.

2013 "La Crónica mexicáyotl: versiones coloniales de una tradición histórica mexica tenochca”, Estudios de Cultura Náhuatl 45 (1): 197-232.

Kubler, George y Charles Gibson

1951 The Tovar Calendar. New Haven: Yale University Press. LAFAYE, Jacques

1972 "In limine", en Juan de Tovar, Manuscrit Tovar. Origines et croyances des indiens du mexique. Relación del origen de los Yndios 
/ que havitan en esta / Nueva España / segun sus / Historias. Tratado de los ritos y ceremonias / y Dioses que en su Gentilidad / usavan los Indios en esta Nueva España, Jacques Lafaye, editor, pp. 11-47. Graz: Akademische Druck- und Verlagsanstalt.

Manuscrito 117

"Chronica Mexicana de Tezozomoc", Colección H.P. Kraus de la Biblioteca del Congreso de Washington, Washington D.C., $158 \mathrm{f}$.

Manuscrito 374, vol. III,

"Fragmentos de historia mexicana", copia de Domingo de San Antón Muñón Chimalpahin, Biblioteca de la Sociedad Bíblica, Cambridge (Inglaterra), 202 f.

Manuscrito Durán

"Historia de las Indias de N[ueva España] y yslas y tierra firme", Biblioteca Nacional de España, Madrid, $344 \mathrm{f}$.

http://www.bne.es

O'Gorman, Edmundo

1940 “Apéndice tercero. Fr. Diego Durán, el P. Juan de Tovar y la Historia natural y moral de las Indias del P. José de Acosta (Textos y opiniones)", en José de Acosta, Historia natural y moral de las Indias, en que se tratan de las cosas notables del cielo / elementos / metales / plantas y animales dellas / y los ritos / y ceremonias / leyes y gobiernos de los indios, Edmundo O'Gorman, editor, pp. xxv-xcv. México: Fondo de Cultura Económica.

Orozco y Berra, Manuel

1878 “Ojeada sobre cronología mexicana”, en Hernando Alvarado Tezozómoc, Crónica mexicana. Anotada por Manuel Orozco y Berra y precedida del Códice Ramírez, manuscrito del siglo XVI intitulado "Relación del origen de los mexicanos que habitan esta Nueva España según sus historias", José María Vigil, editor, pp. 151-222. México: Imprenta y Litografía de Ireneo Paz.

Peperstraete, Sylvie

2007 La "Chronique X": reconstitution et analyse d'une source perdue fondamentale sur la civilisation Aztèque, d'après l'Historia de las Indias de Nueva España de D. Durán (1581) et la Cróni- 
ca Mexicana de F.A. Tezozomoc (ca. 1598). Oxford : Archaeopress.

2010 "Nouvelles hypothèses sur la Crónica mexicáyotl", Journal de la Société des Américanistes 96 (1): 1-31.

Ramírez, José Fernando

1867 "Introducción”, en Diego Durán, Historia de las Indias de Nueva España e islas de la tierra firme, José Fernando Ramírez, editor, pp. iii-xvi. México: Imprenta de J. M. Andrade y F. Escalante.

1878 "Advertencia", en Hernando Alvarado Tezozómoc, Crónica mexicana. Anotada por Manuel Orozco y Berra y precedida del Códice Ramírez, manuscrito del siglo XVI intitulado "Relación del origen de los mexicanos que habitan esta Nueva España según sus historias, José María Vigil, editor, pp. 9-15. México: Imprenta y Litografía de Ireneo Paz.

RIESE, Berthold

1998 "Handschriften und Editionen des Crónica mexicáyotl", Journal de la Société des Américanistes 84 (2): 209-226.

2004 "Einleitung", en Crónica mexicáyotl. Die Chronik der Mexikanertums des Alonso Franco, des Hernando Alvarado Tezozómoc und des Domingo Francisco de San Antón Muñón Chimalpahin Cuauhtlehuanitzin. Aztekischer Text ins Deutsche übersetzt und erläutert, Berthold Riese, editor, pp. 13-31. Sankt Agustin: Academia Verlag.

Romero Galván, José Rubén

2003a Los privilegios perdidos. Hernando Alvarado Tezozómoc, su tiempo, su nobleza y su Crónica mexicana. México: Universidad Nacional Autónoma de México, Instituto de Investigaciones Históricas.

2003b "La Crónica X", en Historiografía mexicana. Volumen I. Historiografía novohispana de tradición indígena, José Rubén Romero Galván, coordinador, pp. 185-195. México: Universidad Nacional Autónoma de México, Instituto de Investigaciones Históricas.

Ruwet, Wayne

1994 "Los manuscritos de la Bible Society: su historia, redescubrimiento y contenido", en Suma y epiloga de toda la descripción 
de Tlaxcala, Andrea Martínez Baracs y Carlos Sempat Assadourian, editores, pp. 27-57. Tlaxcala: Universidad Autónoma de Tlaxcala / Centro de Investigaciones y Estudios Superiores en Antropología Social.

Schroeder, Susan

1997 "Introduction", en Domingo de San Antón Muñón Chimalpahin Quaubtlehuanitzin, Codex Chimalpahin. Society and politics in Mexico Tenochtitlan, Tlatelolco, Texcoco, Culbuacan, and other Nahuas altepetl in central Mexico. The Nahuatl and Spanish annals and accounts collected and recorded by don Domingo de San Antón Muñón Chimalpahin Quaubtlehuanitzin, 2 vols., Arthur J. O. Anderson y Susan Schroeder, editores, vol. 1, pp. 3-13. Norman: University of Oklahoma Press.

2011 "The Truth about the Crónica Mexicayotl", Colonial Latin American Review 20 (2): 233-247.

Tena, Rafael

1997 "Revisión de la hipótesis sobre la Crónica X”, en Códices y documentos sobre México. Segundo Simposio, Costanza Vega Sosa, Salvador Rueda Smithers y Rodrigo Martínez Baracs, editores, pp. 163-178. México: Instituto Nacional de Arqueología e Historia / Consejo Nacional para la Cultura y las Artes.

Tezozómoc, Hernando de Alvarado

1997 Crónica mexicana, Gonzalo Díaz Migoyo y Germán Vázquez Chamorro, editores. Madrid: Historia 16.

1998 Crónica mexicáyotl, $3^{a}$ ed., Adrián León, traductor. México: Universidad Nacional Autónoma de México, Instituto de Investigaciones Históricas.

VÁzQuez Chamorro, Germán

1997 "Alvarado Tezozómoc, el hombre y la obra", en Hernando de Alvarado Tezozómoc, Crónica mexicana, Gonzalo Díaz Migoyo y Germán Vázquez Chamorro, editores, pp. 33-59. Madrid: Historia 16. 
